\author{
UNIVERSIDADE DE SÃO PAULO \\ ESCOLA DE ENGENHARIA DE SÃO CARLOS \\ DEPARTAMENTO DE ENGENHARIA DE ESTRUTURAS
}

IZADORA PIVOTTO ABE

SIMULAÇÃO NUMÉRICA DE REFORÇO E REABILITAÇÃO DE VIGAS DE CONCRETO ARMADO

São Carlos

2019 



\section{SIMULAÇÃO NUMÉRICA DE REFORÇO E REABILITAÇÃO DE VIGAS DE CONCRETO ARMADO}

\section{VERSÃO CORRIGIDA}

A versão original encontra-se na Escola de Engenharia de São Carlos

Dissertação apresentada ao Departamento de Engenharia de Estruturas da Escola de Engenharia de São Carlos, Universidade de São Paulo, como parte dos requisitos para obtenção do título de Mestre em Engenharia Civil (Estruturas).

Orientador: Prof. Dr. Rodrigo Ribeiro Paccola 
AUTORIZO A REPRODUČ̃O TOTAL OU PARCIAL DESTE TRABALHO, POR QUALQUER MEIO CONVENCIONAL OU ELETROONICO, PARA FINS DE ESTUDO E PESQUISA, DESDE QUE CITADA A FONTE.

Ficha catalográfica elaborada pela Biblioteca Prof. Dr. Sérgio Rodrigues Fontes da EESC/USP com os dados inseridos pelo(a) autor(a).

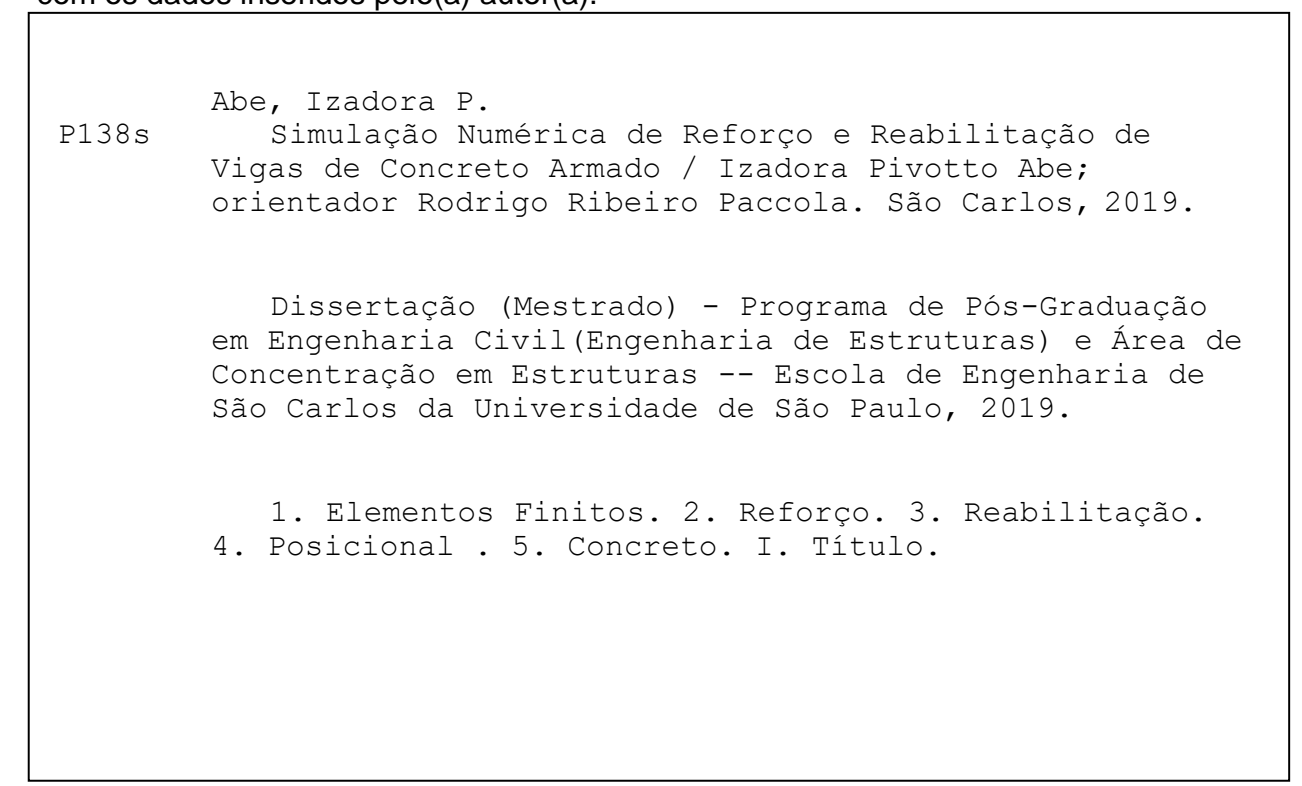

Eduardo Graziosi Silva - CRB - 8/8907 


\section{FOLHA DE JULGAMENTO}

Candidata: Engenheira IZADORA PIVOTTO ABE.

Título da dissertação: "Simulação numérica de reforço e reabilitação de vigas de concreto armado".

Data da defesa: $07 / 11 / 2019$

Comissão Julgadora:

Prof. Associado Rodrigo Ribeiro Paccola

(Orientador)

(Escola de Engenharia de São Carlos/EESC)

Prof. Dr. Gustavo Henrique Siqueira

(Universidade Estadual de Campinas/UNICAMP)

Prof. Dr. Vladimir José Ferrari

p/(Universidade Estadual de Maringá/UEM)
Resultado:

ADROVADA

APROVABA

Coordenador do Programa de Pós-Graduação em Engenharia Civil (Engenharia de Estruturas):

Prof. Associado Vladimir Guilherme Haach

Presidente da Comissão de Pós-Graduação:

Prof. Titular Murilo Araujo Romero 

Primo, você tinha razão

A gente saiu mais forte! 



\section{AGRADECIMENTOS}

Primeiramente, gostaria de agradecer à Deus, sem Ele nada seria possível.

Ao meu orientador, professor Rodrigo Ribeiro Paccola, pelo apoio, dedicação, paciência, preocupação e ensinamentos durante o cuidadoso trabalho de orientação.

Aos meus amigos do Departamento de Engenharia de Estruturas Alex, Antônio, Murilo, Péricles e Túlio pela disposição e ajuda durante todo o processo desta jornada, sem vocês isto não seria possível.

A todos os professores e funcionários do departamento que fizeram parte dessa jornada.

Aos meus pais, Edson e Vera, e aos meus irmãos, Izabella e Ihan, pelo apoio incondicional e necessário para a concretização desta pesquisa.

Aos meus parentes e familiares que sempre apoiaram e torceram pelo meu triunfo.

Ao meu amigo e companheiro Arthur, pelos cuidados, amor, incentivos, lealdade e crença, até mesmo quando eu não acreditava.

Aos meus amigos Ana, Diego, Isabella, Jonatas, Kleber, Luís Otávio, Marcelo, Mariane, Marina e a todos os que me acompanharam e continuam presentes, pelo carinho e companheirismo durante todos os momentos e dificuldades.

Ao Conselho Nacional de Desenvolvimento Científico e Tecnológico (CNPq), pela bolsa de estudos de Mestrado. 

"O caminho do progresso não é rápido nem fácil." 



\section{RESUMO}

ABE, I. P. Simulação Numérica de Reforço e Reabilitação de Vigas em Concreto Armado. 2019. 113 p. Dissertação (Mestrado em Engenharia de Estruturas) - Escola de Engenharia de São Carlos, Universidade de São Paulo, São Carlos, 2019.

Apesar do concreto ser um dos materiais mais utilizados na construção civil, muitos estudos sobre o comportamento desse material ainda vêm sendo desenvolvidos devido à complexidade de sua estrutura interna, podendo ser caracterizado como isotrópico ou até anisotrópico, a depender da escala de análise utilizada. Um problema recorrente em elementos estruturais compostos por esse material é o aparecimento de fissuras provocadas principalmente devido à sua baixa resistência à tração. Dessa forma, técnicas para o reforço de estruturas em concreto armado vêm sendo estudadas e aplicadas pelos profissionais da área. Modelos numéricos representativos dos procedimentos para recuperação de estruturas têm sido desenvolvidos, resultando em ferramentas computacionais para simulação dessas estratégias. Nesse contexto, o objetivo principal deste trabalho é a elaboração de um código computacional para simulação numérica de uma viga em concreto armado com reforço (por meio de uma manta polimérica) e recuperação (através da substituição do concreto). Para a consideração da não linearidade física do material, utilizou-se o modelo de dano de Mazars. A modelagem ocorreu desde a geração da situação em que foi verificada a necessidade de intervenção na estrutura até a aplicação do reforço e análise posterior à execução do processo. Foram combinados diferentes elementos finitos na representação do conjunto, descrevendo separadamente a armadura e a matriz cimentícia. A análise foi realizada através da implementação do método dos elementos finitos com formulação posicional, ou seja, considerando as posições nodais ao invés dos deslocamentos como variáveis e considerando a não linearidade geométrica. A formulação utilizada permitiu a representação da armadura e da matriz cimentícia sem a necessidade de coincidência das malhas. O sistema de referência para a formulação posicional é o Lagrangiano total e a formulação foi feita a partir da minimização do funcional de energia potencial total do sistema. Para a solução do problema não linear foi utilizado o método incremental iterativo de Newton-Raphson. As implementações foram realizadas na linguagem computacional FORTRAN.

Palavras-chave: Elementos finitos. Reforço. Reabilitação. Posicional. Concreto. 



\begin{abstract}
ABE, I. P. Numerical Simulation of Reinforcement and Rehabilitation of Beams in Reinforced Concrete. 2019. 113 p. Dissertation (Master in Structural Engineering) - School of Engineering of São Carlos, University of São Paulo, São Carlos, 2019.
\end{abstract}

Although concrete is one of the materials most used in construction, many studies on the behavior of this material have been conducted due to the complexity of its internal structure, which can be characterized as isotropic or even anisotropic depending on the scale of analysis used. A recurring problem in structural elements composed of this material is the appearance of cracks caused mainly due to its low tensile strength. Thus, techniques for reinforcement of concrete structures have been studied and used by the professionals of the field. Numerical models representative of these procedures for the recovery of structures have been developed, resulting in computational tools to simulate these strategies. In this context, the main objective of this project is the development of a computational code for the numerical simulation of a reinforced concrete beam (by polymeric blanket) and its recovery (by substitution of the concrete). For the physical non-linearity of the material, the Mazars damage model was used. The modeling occurred from the generation of the situation in which the need for intervention in the structure was verified until the application of the reinforcement and analysis after the execution of the process. Different finite elements were combined in the representation of the set, separately describing the reinforcement and the cementitious matrix. The analysis was performed through the implementation of the finite element method with positional formulation, that is, considering nodal positions instead of displacements as variables and considering geometric non-linearity. The formulation used allowed the representation of the reinforcement and cementitious matrix without the need to match the meshes. The reference system for the positional formulation is the total Lagrangian and the formulation is made from the minimization of the total potential energy functional of the system. Newton-Raphson's iterative incremental method was used to solve the non-linear problem. The implementations were performed in FORTRAN computational language.

Key words: Finite elements. Reinforcement. Rehabilitation. Positional. Concrete. 



\section{LISTA DE ILUSTRAÇÕES}

Figura 1.1- Hipóteses para reconversão de estruturas com desempenho insatisfatório.

Figura 2.1 - Região de reparo

Figura 2.2- Ruptura - Delaminação

Figura 2.3 - Características da solução de um problema não linear geométrico 34

Figura 3.1 - Mudança de configuração. 37

Figura 3.2 - Mudança de volume 39

Figura 3.3 - Componentes de tensão 40

Figura 3.4 - Equilíbrio de momentos 41

Figura 3.5 - Mudança de configuração. 42

Figura 4.1- Elemento finito de treliça 50

Figura 4.2 - Coordenadas adimensionais para elemento triangular com aproximação cúbica 53

Figura 4.3 - Solução de Newton-Raphson para sólidos bidimensionais 57

Figura 4.4- Geometria e condições de contorno 58

Figura 4.5- Validação exemplo 4.1. - Deslocamento vertical 59

Figura 4.6- Resultados exemplo 4.1 59

Figura 4.7- Geometria e condições de contorno. 60

Figura 4.8 - Deslocamento lateral (m) x carregamento (N) 61

Figura 4.9- Configuração deslocada e mapa de cores (m) 62

Figura 4.10 - Arranjo das fibras no domínio bidimensional 64

Figura 4.11- Geometria e condições de contorno. 68

Figura 4.12- Deslocamento vertical (m). 69

Figura 4.13- Comparação do exemplo: com e sem armadura 69

Figura 4.14- Célula periódica: fração volumétrica $45 \%$ 70

Figura 4.15- Curva força $\mathrm{x}$ deslocamento para a extremidade da célula 71

Figura 4.16- Geometria e condições de contorno 
Figura 4.17- Primeira situação: (a) Deslocamento em x (m); (b) Deslocamento em y (m). ................. 73

Figura 4.18- Segunda situação: (a) Deslocamento em x (m); (b) Deslocamento em y (m). ................. 73

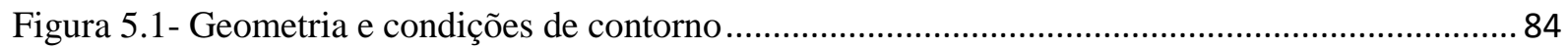

Figura 5.2- Curva tensão x deformação para ensaio de compressão …………………………........... 84

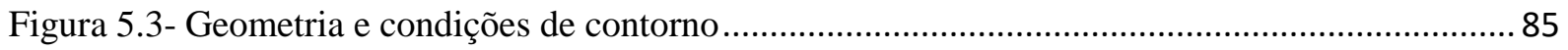

Figura 5.4- Curva tensão x deformação para ensaio de tração .............................................................. 86

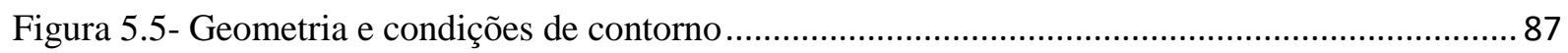

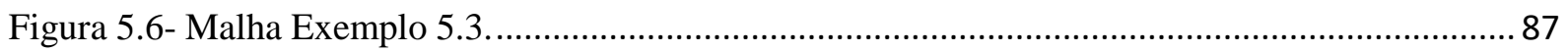

Figura 5.7- Diagrama Força aplicada x Deslocamento vertical.......................................................... 88

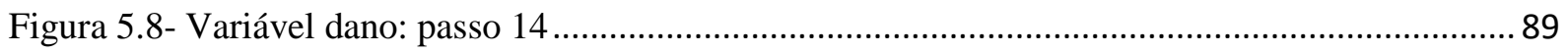

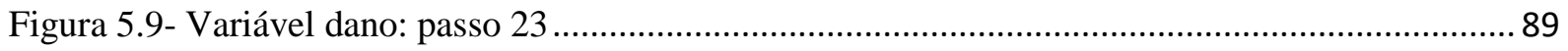

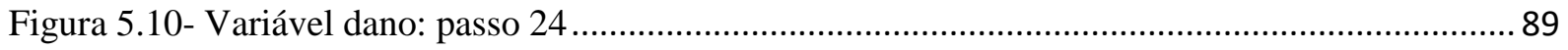

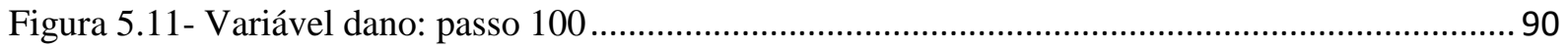

Figura 6.1- Variável dano: passo 47 (deslocamento aumentado 50x) ................................................ 93

Figura 6.2- Deslocamento: passo (a) 47 (b) 52 (deslocamento aumentado 50x) ................................ 93

Figura 6.3- Força aplicada x Deslocamento vertical nó 93 (meio do vão) ........................................... 95

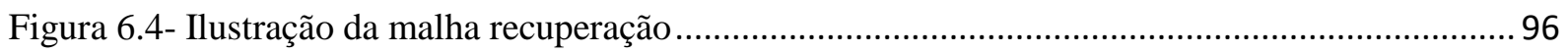

Figura 6.5- Força aplicada x Deslocamento vertical nó 93, situação (a).............................................. 97

Figura 6.6- Força aplicada x Deslocamento vertical nó 93, situação (b).............................................. 98

Figura 6.7- Força aplicada x Deslocamento vertical nó 93 ................................................................. 99 


\section{SUMÁRIO}

1 INTRODUÇÃO............................................................................................................... 19

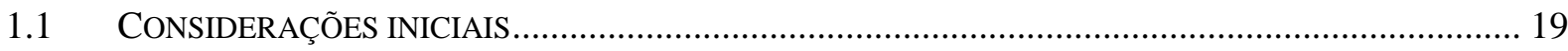

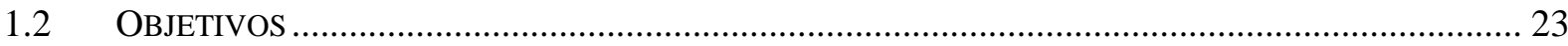

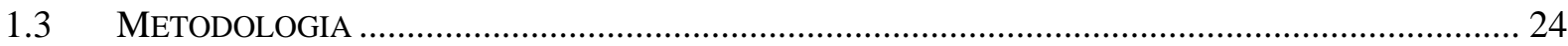

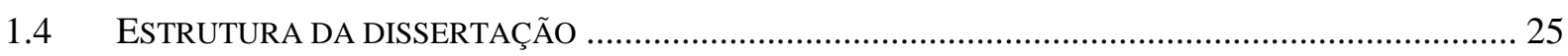

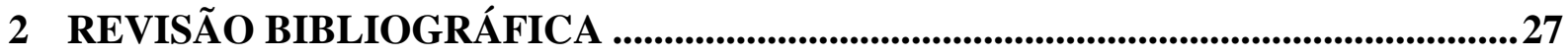

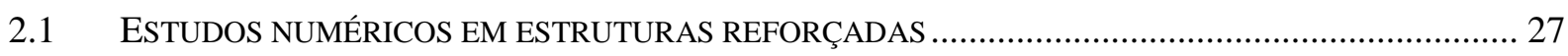

2.2 MÉTOdo dos ELEMENTOS Finitos PosicionAL ........................................................................ 30

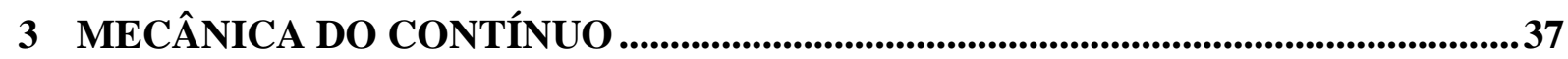

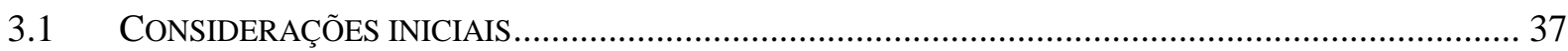

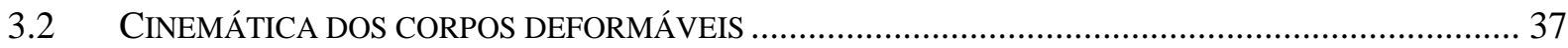

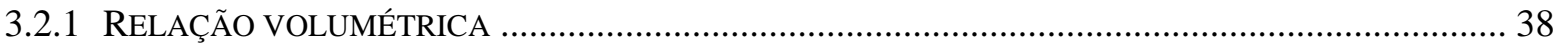

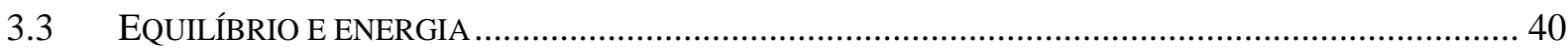

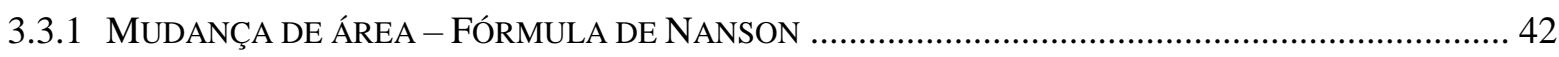

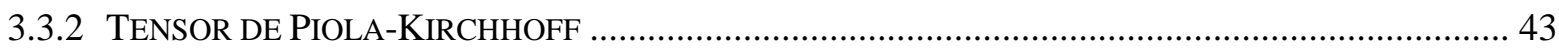

3.3.3 Modelo ConSTITUTIVO DE SAINT - VENANT - KIRCHHOFF ………........................................ 44

3.3.4 PRINCÍPIO DA ESTACIONARIEDADE DA ENERGIA MECÂNICA.................................................. 46

4 FORMUlaÇão NÃo linear geOMÉtrica APLICAdA A PROBLemas

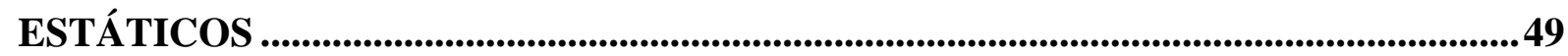

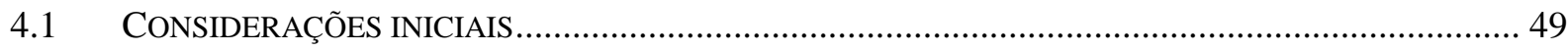

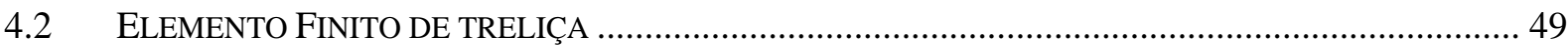

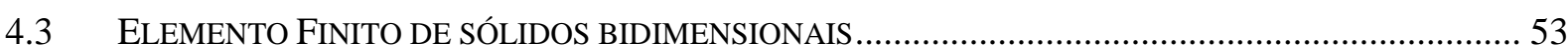




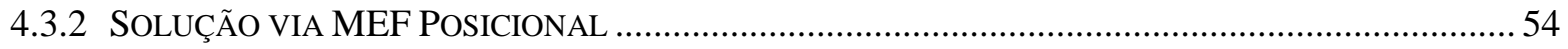

4.4 EXEMPLOS: VALIDAÇÃO DA FORMULAÇÃO DO ELEMENTO FINITO DE CHAPA ………................ 57

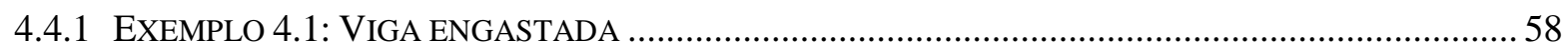

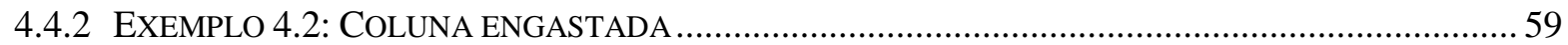

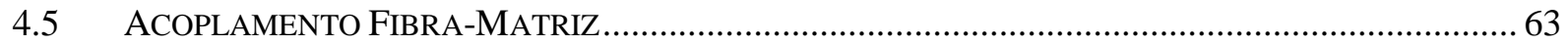

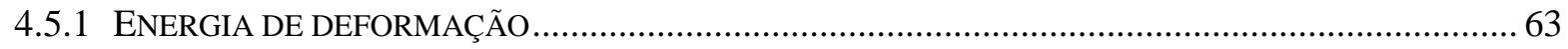

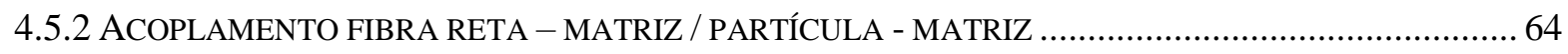

4.6 EXEMPLO 4.3: VALIDAÇÃO ACOPLAMENTO FIBRA-MATRIZ ...................................................... 68

4.7 EXEMPLO 4.4: VALIDAÇÃO ACOPLAMENTO PARTÍCULA-MATRIZ …......................................... 70

4.8 EXEMPLO 4.5: ACOPLAMENTO PARTÍCULA-MATRIZ ……..................................................... 72

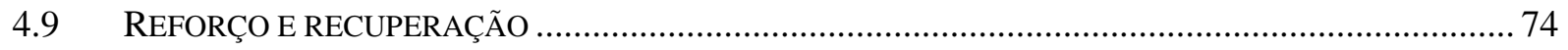

4.10 FASES DE CARGA: ESTRATÉGIA NUMÉRICA PARA REFORÇO/RECUPERAÇÃO DA VIGA................ 75

5 MECÂNICA DO DANO........................................................................................ 77

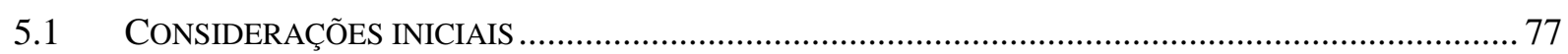

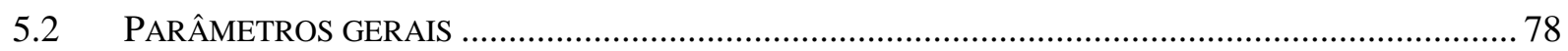

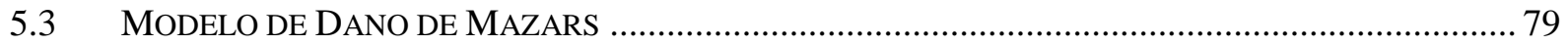

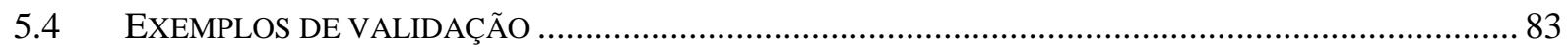

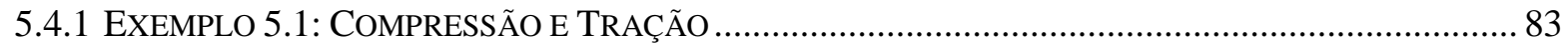

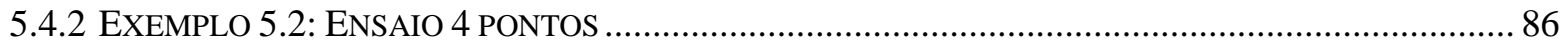

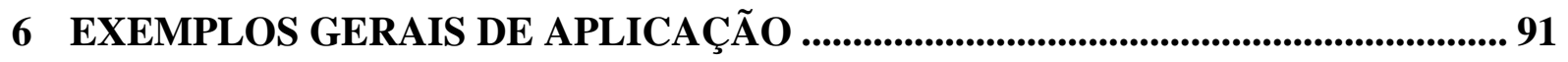

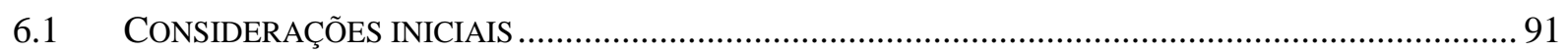

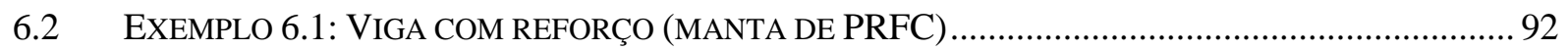

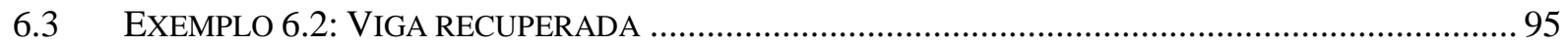

6.4 EXEMPLO 6.3: VIGA REABILITADA (RECUPERAÇÃO + REFORÇO) ………................................. 98 
7 CONSIDERAÇÕES FINAIS.

101

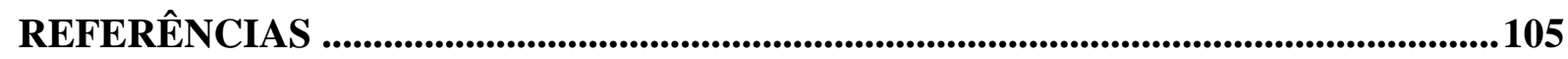

APÊNDICE A - PONTOS E PESOS DE HAMMER .......................................................113 



\section{INTRODUÇÃO}

\subsection{Considerações iniciais}

O concreto é um dos materiais mais utilizados na construção civil, motivando estudos relacionados ao seu complexo comportamento. A patologia das estruturas é um campo da engenharia que se ocupa do estudo das origens, formas de manifestação, consequências e mecanismos de ocorrência das falhas e dos sistemas de degradação das estruturas (SOUZA; RIPPER, 1998).

A degradação de materiais estruturais é um problema que afeta a construção civil desde os primórdios das civilizações. Segundo Souza e Ripper (1998), as principais causas das manifestações patológicas no concreto podem ser divididas em duas categorias. As causas intrínsecas são inerentes as estruturas: falhas humanas durante a construção (deficiência na armadura, deficiência na concretagem) e durante a utilização (porosidade do concreto, causas químicas e físicas); as causas extrínsecas são externas ao corpo estrutural: falha na concepção do projeto, ações mecânicas (choque de veículos, recalque da fundação, acidentes), ações físicas (variação da temperatura, atuação da água) ações químicas e biológicas. As manifestações patológicas podem ainda serem geradas durante a concepção da estrutura (projeto), execução (construção) ou utilização (manutenção).

Em relação ao comportamento mecânico do concreto, sabe-se que sua resistência à compressão é da ordem de dez vezes maior do que a resistência à tração, sendo comum fissuras na região tracionada das estruturas.

Caso o desempenho de uma estrutura torne-se insatisfatório devido as manifestações patológicas apresentadas, é necessário avaliar como proceder. Nesse sentido, para assegurar integridade estrutural, cresce a importância da manutenção e da análise de regiões sujeitas à ruptura e ainda se verifica a necessidade do desenvolvimento de técnicas para reforço e recuperação estrutural. A Figura 1.1. contém um quadro que relaciona as possíveis procedências para estruturas com desempenho não-satisfatório. 
Figura 1.1- Hipóteses para reconversão de estruturas com desempenho insatisfatório.

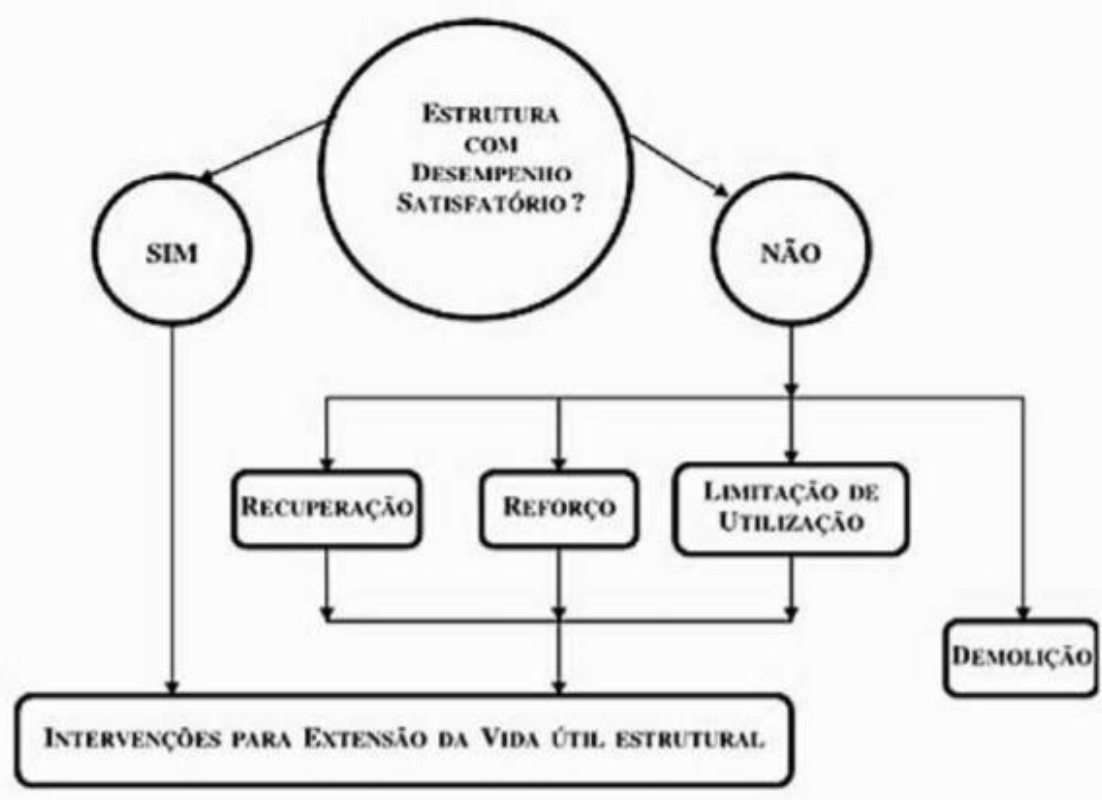

Fonte: SOUZA e RIPPER (1998)

Nesse contexto, é válido destacar a diferença entre reforço e recuperação. Enquanto o reforço resulta em um aumento de resistência, a recuperação retorna o desempenho (parcial ou total) inicial da estrutura. Em uma estrutura, a reabilitação consiste na sua adequação para as novas demandas, ou seja, na adaptação para que a estrutura trabalhe sob novas condições. Em geral, para a reabilitação, é necessário a execução de um reforço (MACHADO; MACHADO, 2016). A recuperação e o reforço geram um aumento na vida útil da estrutura e ainda garante segurança, resultando em um desempenho superior a antiga ou pelo menos equivalente à estrutura nova.

Citam-se a utilização de perfis laminados, a adição de cabos externos de protensão e colagem de chapas de aço com resina epóxi como os processos de reforço mais comuns (BEBER; CAMPOS FILHO; CAMPAGNOLO, 2000). Dentre essas técnicas, o uso das chapas de aço chama a atenção pela sua simplicidade de execução, baixo custo e facilidade de acesso. Entretanto, é comum a corrosão da chapa de aço em sua interface com a resina. Em substituição ao uso de chapas de aço, as fibras sintéticas têm se destacado. As fibras sintéticas, comparativamente ao aço, são mais leves e possuem alta resistência (LEAL, 2000).

No que se refere à utilização de compósitos com fibras para realização de reforço em estruturas, dentre todas as fibras sintéticas disponíveis, as de carbono representam uma boa alternativa para utilização em estruturas de concreto armado, uma vez que apresentam alta 
resistência a tração, elevado módulo de elasticidade, leveza, durabilidade, resistência a fadiga e à corrosão. O uso de polímeros reforçados com fibra de carbono (PRFC) em elementos estruturais de concreto tem se destacado e sido aplicado com sucesso no reforço de estruturas de concreto.

Para a recuperação, é necessário inicialmente realizar uma avaliação para o diagnóstico do problema para buscar a melhor alternativa. Uma alternativa usual que assegura estabilidade e bom desempenho para o concreto armado consiste na retirada do material degradado seguido da limpeza e substituição dos elementos estruturais de concreto.

Apesar do aumento no interesse sobre reforço e recuperação de estruturas, no Brasil não existem normas para recuperação estrutural. Alternativamente, tem-se algumas normas estrangeiras, como o ACI 440.2R-17, que indica critérios e procedimentos para o projeto e execução de reforços com o uso de PRF.

No âmbito nacional, a ausência de um padrão normativo afeta não só os projetistas, mas também os fabricantes, que sofrem com a dificuldade em padronizar seus produtos. Dessa forma, o estudo do comportamento de estruturas restauradas é necessário para prever e estimar o novo desempenho estrutural. Preocupações com manutenção e adequação de construções tem instigado pesquisas a fim de buscar novas soluções. Entretanto, apesar do desenvolvimento de tecnologias, cada situação particular gera problemas com características distintas, impossibilitando o uso de uma única ferramenta para o redimensionamento.

Para a resolução de problemas com geometria, carregamento e propriedades simplificadas, existem soluções analíticas, que relacionam as grandezas mecânicas com as dimensões, carregamento externo e constantes da lei constitutiva por meio de expressões matemáticas fechadas. Entretanto, as soluções analíticas são específicas para cada problema estrutural, sendo estes, em geral, bem simplificados.

Dessa forma, os métodos numéricos surgem como alternativa, uma vez que os ensaios experimentais possuem elevado custo e dependem do caso específico a ser analisado. Em sua maioria, esses modelos baseiam seus desenvolvimentos em métodos de energia (LI e LIU, 2002; TOULEMOND; MASSON; GHARIB, 2008; WANG; KWAN; CHAN, 1999).

Assim, a fim de modelar estruturas complexas e casos mais gerais de carregamentos, geometria e condições de contorno, os métodos numéricos têm sido usualmente adotados como alternativa para a obtenção de soluções aproximadas através de simulações computacionais. Para representar o comportamento mecânico das estruturas, diversos modelos numéricos vêm 
sendo propostos ao longo dos anos (ZIENKIEWICZ; TAYLOR; ZHU, 2013). Dentre os métodos numéricos, o Método dos Elementos Finitos (MEF) possui destaque pela grande quantidade de estudos existentes, metodologia de implementação em códigos computacionais simples e confiabilidade dos resultados

A utilização e o desenvolvimento de modelos numéricos estão atrelados, principalmente, à busca de boas aproximações, estimando de forma precisa o comportamento das estruturas. Ressalta-se que a origem do MEF não está associada a um único autor ou época específica, mas é possível afirmar que a rápida evolução da ciência da computação difundiu o método e o aplicou em diversas áreas (ASSAN, 2003; ZIENKIEWICZ; TAYLOR; ZHU, 2013).

Para assegurar o máximo aproveitamento das propriedades dos materiais, utilizam-se teorias mais complexas, como as formulações não lineares. Existem três tipos de não linearidade: a física, a geométrica e a de contato. Enquanto a não linearidade física está associada à deformação, levando em consideração o comportamento não linear da lei constitutiva adotada, a não linearidade geométrica refere-se ao deslocamento, considerando a importância que a mudança da geometria tem na configuração equilibrada deslocada da estrutura ou corpo (BONET e WOOD, 1997). Os problemas de contato representam uma classe de problemas para a qual a não linearidade é introduzida pela alteração das condições de contorno envolvidas nas análises (PIEDADE NETO, 2009).

Em geral, códigos baseados no MEF para modelagem de estruturas com grandes deslocamentos e deformações utilizam as referidas não linearidades em suas formulações (SORIANO, 2003).

Cabem aos projetistas avaliar as alternativas disponíveis e buscar soluções que equilibrem um bom desempenho estrutural com um baixo custo. Com a finalidade de atingir esse objetivo, o uso de materiais com alto desempenho tem se intensificado nas últimas décadas, resultando em estruturas mais delgadas e deslocáveis (YASIN; KAPURIA, 2013). Nota-se, assim, a importância das análises não lineares não apenas na modelagem computacional do comportamento dessas estruturas para avaliação da eficiência das diferentes técnicas de reforço e/ou recuperação existentes para um determinado problema em análise, mas também para análises de instabilidade e dinâmica.

Nesse contexto, o presente projeto objetiva avaliar o comportamento de uma viga antes e após o reforço. Para isso, a simulação da viga de concreto armado foi realizada através da 
formulação baseada no MEF posicional. O estudo do comportamento não linear geométrico foi realizado com a formulação baseada em posições nodais dos elementos finitos, desenvolvida em Coda (2003) e Coda e Greco (2003) para problemas estáticos e lineares, sendo que a não linearidade geométrica é naturalmente atendida por meio do processo iterativo da solução. A não linearidade física foi considerada por meio do modelo de dano de Mazars, apresentado no Capítulo 5.

A utilização de elementos finitos diferentes para a matriz cimentícia e barras de aço permite levar em consideração as diferentes fases do compósito. Conforme já justificado, a análise contempla a não linearidade física, por meio do modelo de dano, e não linear geométrica, através da formulação posicional. Destaca-se que o presente projeto não prevê o estudo e a implementação de modelos de fissuração para o concreto e, portanto, o comportamento não elástico gerado pela fissuração na região tracionada do concreto foi simplificadamente considerado por meio da penalização do material tracionado pelo modelo de dano de Mazars.

As manifestações patológicas de interesse nesse trabalho são as fissuras na região tracionada geradas durante a utilização da estrutura. As implementações computacionais das formulações foram escritas na linguagem de programação FORTRAN. Vale destacar que as propriedades do reforço podem ser alteradas no programa desenvolvido de forma a adequar as necessidades do usuário.

\subsection{Objetivos}

O objetivo geral desta pesquisa é avaliar o comportamento de estruturas recuperadas com reforço através da implementação de um modelo numérico. Objetiva-se representar as fases de carga de uma viga reforçada por meio de simulações bidimensionais, obtidas pela elaboração de um código computacional não linear geométrico e físico.

Dessa forma, são estabelecidos os seguintes objetivos específicos:

- Desenvolver um código computacional em FORTRAN utilizando a formulação posicional do Método dos Elementos Finitos para simulação de chapas;

- Implementar o modelo de dano de Mazars para a consideração da não linearidade física; 
- Implementar o modelo que represente a viga de concreto armado utilizando elementos de chapa para consideração da matriz de concreto e elementos de barra para a representação da armadura de aço;

- Validar o programa desenvolvido;

- Obter um diagrama de deslocamento x passo.

\subsection{Metodologia}

Com a finalidade de desenvolver uma ferramenta computacional para a simulação numérica bidimensional do comportamento de uma viga de concreto armado reforçada, o projeto pode ser dividido nas seguintes etapas:

- Revisão bibliográfica: estudos teóricos e levantamento de bibliografias relevantes para aprofundamento dos conhecimentos sobre o tema;

- Implementação da malha: a viga e as armaduras foram divididas em elementos de chapa e barra, respectivamente, para a sua análise;

- Acoplamento: a formulação posicional desenvolvida possibilita a consideração da interação entre partículas, fibras e matriz sem a necessidade de coincidência entre as malhas. Destaca-se que foi considerada aderência perfeita entre a armadura e concreto;

- Carregamento: a viga foi solicitada por um carregamento crescente até que fosse atingido o critério de parada. Para uma consideração simplificada das fissuras geradas pela baixa resistência do concreto à tração, foi implementado o modelo de dano de Mazars. Dessa forma, foi escolhido um critério de parada baseado na variável dano. Após a deformação devido ao carregamento, foi imposto que a estrutura retorne à sua posição inicial (com auxílio de macacos hidráulicos, por exemplo) sem retirar o carregamento;

- Reabilitação estrutural: com a estrutura em sua posição inicial, o material tracionado degradado foi substituído para a recuperação da estrutura e foram adicionados elementos lineares na região inferior da viga para a consideração do reforço. Após a reabilitação, a peça teve o seu deslocamento livre para a análise. Ressalta-se que 
apesar de não serem previstos grandes deslocamentos a análise será elástica e não linear geométrica, pois essa não linearidade é naturalmente atendida pela formulação posicional;

- Validação: simulação de exemplos com o objetivo de verificar e analisar os resultados obtidos.

\subsection{Estrutura da dissertação}

O presente texto encontra-se dividido em 7 capítulos, sendo que neste primeiro capítulo introdutório são também apresentados os objetivos, justificativas e metodologias do trabalho desenvolvido.

O Capítulo 2 tem por objetivo apresentar definições e embasamentos teóricos necessários para a pesquisa desenvolvida. São apresentadas ainda algumas referências da literatura relacionadas aos temas abordados.

O Capítulo 3 trata dos conceitos cinemáticos e formulações essenciais para corpos contínuos com base na descrição Lagrangiana total, que considera como referencial a posição inicial da estrutura.

O Capítulo 4 apresenta a formulação utilizada para o desenvolvimento da presente pesquisa. Nesse capítulo, o método dos elementos finitos posicionais é tratado com maiores detalhes e são mostrados os algoritmos usados no código desenvolvido nesse trabalho. Alguns exemplos são apresentados para a validação do código implementado.

No Capítulo 5 apresenta-se, de forma simples, os conceitos relacionados à mecânica do dano, sendo esta a não linearidade física considerada na formulação desenvolvida. São apresentados, em particular, os conceitos e formulações do dano de Mazars. São mostrados ainda exemplos com a finalidade de validar as formulações apresentadas.

No Capítulo 6 expõe-se os exemplos numéricos. Esses exemplos visam demonstrar a eficiência e a utilização prática do código desenvolvido, com todas as fases de cargas propostas.

Por fim, o Capítulo 7 apresenta as conclusões e as discussões finais da pesquisa, bem como as propostas para desenvolvimentos futuros relacionados ao presente tema. 
26 | Introdução 


\section{REVISÃO BIBLIOGRÁFICA}

\subsection{Estudos numéricos em estruturas reforçadas}

Antes de escolher o produto de reparo é preciso estudar a compatibilidade entre os materiais. Sendo o concreto um material de estrutura interna e propriedades complexas, a previsão de seu comportamento ao longo do tempo e a avaliação da confiabilidade da estrutura são dificultadas. No caso particular de reabilitação de estruturas de concreto, a correção da manifestação patológica torna-se ainda mais complexa, pois além de partir de uma origem problemática, outros materiais serão adicionados. Assim, todas as propriedades do concreto devem ser criteriosamente analisadas e estimadas (REIS, 2003).

O processo de reparo deve ser cuidadosamente estudado, pois uma avaliação errônea pode considerar regiões íntegras quando não são. De acordo com o Manual de Reabilitação de Estruturas de Concreto: reparo, reforço e proteção (2003) é importante que a região de reparo não coincida exatamente com a região danificada porque é necessário um substrato de concreto mecanicamente compatível com as características do material de reparo. A Figura 2.1 ilustra a ideia discutida nesse parágrafo.

Figura 2.1 - Região de reparo
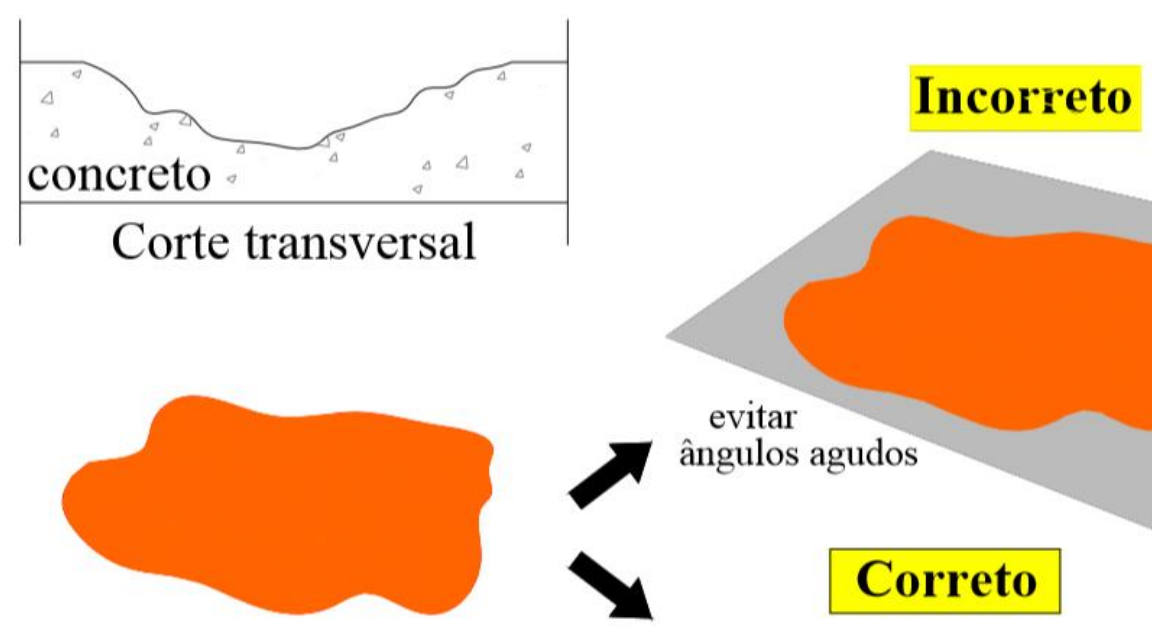

evitar

ângulos agudos

Vista em planta

região danificada

região de reparo

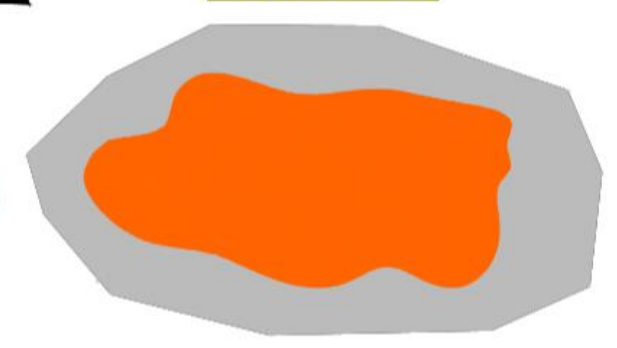

Fonte: Adaptado do Manual de Reabilitação de Estruturas de Concreto: reparo, reforço e proteção (2003) 
Desde 1940, os compósitos a base de fibras têm sido aplicados para o desempenho de funções importantes no campo da engenharia militar, aeroespacial, naval, ferroviária e automobilística (JUVANDES; MARQUES; FIGUEIRAS, 1996). Devido ao seu desempenho, passaram a ser utilizados também na construção civil como alternativas de reforço pela combinação de polímeros com fibras sintéticas.

De acordo com FIB (2010), as principais vantagens da utilização dos polímeros reforçados com fibras (PRF) para o reforço de estruturas de concreto são: imunidade à corrosão, pequeno peso próprio, facilidade de aplicação em lugares de difícil acesso, redução dos custos de mão de obra, resistência à tração consideravelmente alta, rigidez adaptável às necessidades de projeto, grande capacidade de deformação e grande disponibilidade em tamanhos e geometrias.

Como aspecto negativo ressalta-se que o uso de manta de PRF impossibilita o total aproveitamento das propriedades à tração do polímero pois resulta em uma suscetibilidade a ruptura frágil. A ruína na ligação reforço-concreto antecipa o colapso da viga por falha na transferência de esforços. O peeling-off (delaminação), Figura 2.2, é um desses mecanismos de transferências que destaca o reforço a partir de sua zona de ancoragem ou de concentração de fissuras. Assim, a ruína prematura deve ser evitada para alcançar o aumento de resistência desejado (FIB, 2000).

Figura 2.2- Ruptura - Delaminação
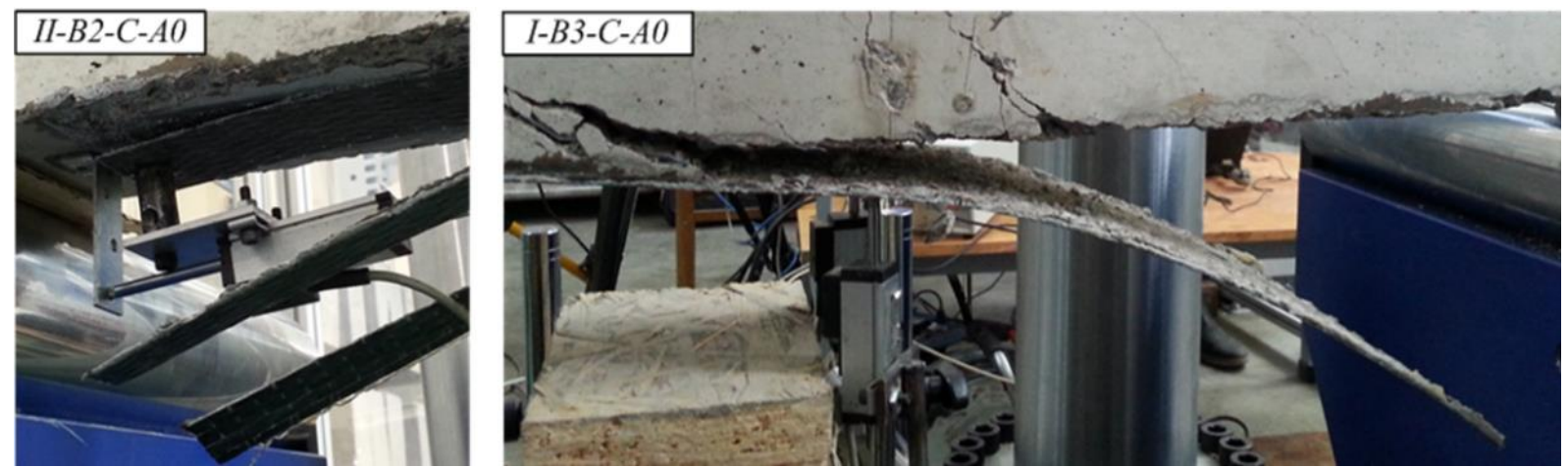

Fonte: Adaptado de Gribniak et al. (2017)

Dentre as fibras empregadas nos PRF's na construção civil, as mais utilizadas são as de carbono, vidro e aramida. Na Tabela 2.1 são apresentadas as propriedades mecânicas típicas desses tipos de fibras. 
Tabela 2.1 - Propriedades das fibras

\begin{tabular}{lccc}
\hline \multicolumn{1}{c}{ Material } & $\begin{array}{c}\text { Módulo de } \\
\text { elasticidade (GPa) }\end{array}$ & $\begin{array}{c}\text { Resistência à } \\
\text { tração (MPa) }\end{array}$ & $\begin{array}{c}\text { Deformação última } \\
\text { de tração (\%) }\end{array}$ \\
\hline Carbono & & & \\
$\quad$ Alta resistência & $215-235$ & $3500-4800$ & $1.4-2.0$ \\
$\quad$ Ultra-alta resistência & $215-235$ & $3500-6000$ & $1.5-2.3$ \\
$\quad$ Alto módulo & $350-500$ & $2500-3100$ & $0.5-0.9$ \\
$\quad$ Ultra-alto módulo & $500-700$ & $2100-2400$ & $0.2-0.4$ \\
\hline Vidro & & & \\
$\quad$ E & 70 & $1900-3000$ & $3.0-4.5$ \\
S & $85-90$ & $3500-4800$ & $4.5-5.5$ \\
\hline Aramida & & & \\
$\quad$ Baixo módulo & $70-80$ & $3500-4100$ & $4.3-5.0$ \\
$\quad$ Alto módulo & $115-130$ & $3500-4000$ & $2.5-3.5$ \\
\hline
\end{tabular}

Fonte: Adaptado de FIB (2001).

Em relação à recuperação estrutural, o uso dessa ferramenta é necessário em regiões que sofreram danos mais intensos. As situações mais comuns em que são necessárias recuperações são: a perda do concreto de cobrimento; danificação e fissuração excessiva do concreto tracionado; exposição das armaduras de concreto pelas manifestações patológicas, entre outros.

Lemos de Faria e Ribeiro (2016) citam a utilização de concreto projetado como um método de recuperação estrutural para proteger as armaduras expostas e evitar a sua corrosão. Dessa forma, inicialmente é necessário remover toda a região do concreto comprometido e fragilizado. Depois, a superfície deve ser limpa e os elementos não estruturais devem ser removidos. Por fim, uma nova camada de concreto deve ser executada de maneira a reestabelecer o cobrimento. Ressalta-se que a camada superficial do concreto velho precisa ser escarificada para permitir a sua adesão com o material novo.

Por fim, em relação ao estudo numérico, o primeiro estudo realizado sobre o acoplamento entre o Método dos Elementos Finitos e o Método dos Elementos de Contorno (MEC) que pode ser utilizado para soluções de estruturas reforçadas foi realizado em Zienkiewicz, Kelly, Bettes (1977). Ainda sobre o acoplamento MEC/MEF, Mesquita (2002) propôs novas formulações para o tratamento de problemas inelásticos considerando o acoplamento progressivo com considerações de hipóteses especiais para o reforço.

Castro (2005) apresenta uma avaliação comparativa entre o reforço de vigas pela colagem externa de mantas de PRFC e o reforço pela colagem de diversos tipos de barras, como laminados de PRFC e barras de aço com seção circular, polímero reforçado com fibras de 
carbono e de vidro. Um estudo sobre reforço de vigas à flexão com a utilização de modelos numéricos baseado no Método dos Elementos Finitos foi realizado por Kang et al. (2005), no qual foi avaliada a eficiência da técnica NSM (Near Surface Mounted) no reforço à flexão de vigas por meio de um estudo paramétrico, tendo como variáveis a profundidade do entalhe e a disposição dos laminados de PRFC.

No que se refere aos trabalhos desenvolvidos no Departamento de Engenharia de Estruturas da Escola de Engenharia de São Carlos da Universidade de São Paulo (SET/EESC/USP), Ferrari (2007) estudou reforço com manta de PRFC aderido a substrato de transição constituído por compósito cimentício de alto desempenho em vigas de concreto armado. Fonseca (2007) estudou o incremento de rigidez à flexão de ligações de concreto prémoldado com PRFC. A aplicação de PRFC inserido em substrato de microconcreto com fibras de aço para reforço à flexão de vigas de concreto armado foi realizada por Arquez (2010).

\subsection{Método dos Elementos Finitos Posicional}

O comportamento associado a grandes mudanças de geometria é complexo e de interesse em vários campos de engenharia. De acordo com Cook, Malkus, Plesha (2002), o Método dos Elementos Finitos (MEF), em sua forma clássica em deslocamentos, teve origem com o trabalho de Courant (1943) que determinou a rigidez à torção de um eixo vazado dividindo a seção transversal em elementos triangulares dentro dos quais empregou funções lineares para interpolar o campo de tensão. Uma das soluções mais antigas para problemas com geometria simples é apresentada em Bisshopp e Drucker (1945). Para soluções analíticas, o artigo de Mattiasson (1981) apresenta respostas para problemas de viga engastada e quadros (articulado e rígido).

O MEF consiste, de maneira simples, em discretizar o domínio em uma quantidade finita de pequenas regiões, os elementos finitos. Além disso, as variáveis mecânicas (deslocamentos, deformações e tensões) são descritas por funções aproximativas no domínio de cada elemento (ASSAN, 2003). As funções aproximativas são compostas, em geral, pela combinação linear entre os valores nodais e as funções de forma. Os valores nodais desconhecidos são os valores da variável mecânica aproximada nos nós. As funções de forma são funções interpoladoras conhecidas, usualmente polinomiais e definidas no domínio de cada elemento. O grau de aproximação do elemento finito é definido pelo grau das funções de forma e o equilíbrio de 
forças interdependentes entre os elementos finitos resulta no equilíbrio global da estrutura (ZIENKIEWICZ; TAYLOR; ZHU, 2013).

O nome "elementos finitos" foi empregado pela primeira vez em Clough (1960), que criou em Berkeley o primeiro grupo de pesquisa formal no assunto. De acordo com Crisfield (2000), o artigo mais antigo sobre MEF para análise não linear é de Turner et al. (1960). Assim, o MEF adquiriu aceitação no meio acadêmico e foi reconhecido como uma variante do método de Rayleigh-Ritz, tornando-se uma ferramenta extremamente útil para resolver equações diferenciais associadas a problemas físicos com geometrias complexas.

Na literatura, existem várias formulações baseadas no método dos elementos finitos para resolver problemas com não linearidade geométrica. Essas formulações podem descrever coordenadas de duas formas: Lagrangiana ou Euleriana. Enquanto a descrição Lagrangiana utiliza como referencial um ponto fixo no espaço, a descrição Euleriana aborda mudança de configuração a partir de um referencial móvel.

A descrição Lagrangiana pode ser total, atualizada ou parcial, sendo todas as operações feitas a partir de uma posição conhecida. Se a configuração de referência é atualizada durante os incrementos (de carga ou tempo), a formulação é chamada atualizada; se a configuração de referência é atualizada apenas no início, é parcialmente atualizada; se a configuração de referência é tomada fixa, como a configuração inicial, é chamada de total (WONG; TINLOI, 1990).

A formulação posicional não linear geométrica foi utilizada por Coda (2003) para o tratamento de sólidos bidimensionais. Um procedimento semelhante foi utilizado por Bonet et al. (2000) para análise de membranas. O termo posicional vem do fato de considerar as posições nodais como variáveis no equacionamento ao invés dos tradicionais deslocamentos. Para a formulação posicional baseada no MEF desenvolvida em Coda (2003), é utilizada a descrição Lagrangiana total.

Dessa forma, alguns trabalhos merecem destaque sobre esse sistema de referência. $\mathrm{O}$ artigo de Gadala, Dokainish e Oravas (1984) apresenta as diferenças entre as formulações Lagrangiana total e atualizada. Formulações com descrição Lagrangiana total são encontradas nos artigos de Mondkar e Powell (1977), Surana (1983), Schulz e Filippou (1990), dentre outros.

A eficiência da abordagem posicional para a formulação e implementação computacional foi demonstrada em diferentes trabalhos desenvolvidos no SET/EESC/USP. 
Coda e Greco (2006) realizaram análise dinâmica de estruturas formadas por barras; a análise não linear geométrica com impacto de domínios elástico bidimensionais pode ser encontrada em Marques (2006); Coda e Paccola (2007) realizaram análise não linear geométrica de estruturas formadas por casca e também considerando a variação linear da deformação ao longo da espessura do elemento (CODA; PACCOLA, 2008), além da análise dinâmica (CODA; PACCOLA, 2009); em Pascon (2008) tem-se a análise não linear geométrica de chapas com modelos constitutivos elastométricos; a análise de impacto entre estruturas com comportamento termo elástico e termo-plástico é encontrada no trabalho de Carrazedo (2009); Rigobello (2011) emprega elemento de barra no estudo de estruturas de aço expostas a incêndios, considerando o critério tridimensional de plasticidade e relata caráter mais realista dos resultados utilizando a formulação posicional.

Em estudos mais aprofundados, tem-se a análise dinâmica não linear geométrica de estruturas laminadas modeladas com elementos tridimensionais de barra considerando o efeito do empenamento da seção transversal estática e dinâmica (CODA; PACCOLA, 2010, 2011), análise estática e dinâmica não linear de risers (SANCHEZ, 2013); destaca-se ainda o trabalho de Coda, Paccola e Sampaio (2013) em que foi utilizado a cinemática de Reissner-Mindlin para formular um elemento finito de casca laminada anisotrópica; em Coda e Paccola (2014) e Reis e Coda (2014) a formulação posicional de pórticos planos foi utilizada para simulação de efeitos elastoplásticos na estrutura; Sampaio (2014) apresenta o acoplamento entre elementos finitos curvilíneos tridimensional e elemento de casca, fibra e matriz, para simular o comportamento de materiais compósitos.

Em relação a técnica de acoplamento de fibras na matriz, Vanalli (2004) propôs formulação para a análise estática de meios contínuos anisotrópicos viscoplásticos reforçados ou não por fibras. Essa formulação foi realizada através do MEF e do MEC, com aplicações que englobam ambos os métodos. Posteriormente, Vanalli, Paccola e Coda (2008) propuseram o modelo para a inserção de fibras em elementos finitos bidimensionais sem o aumento no número de graus de liberdade. A análise não linear geométrica de sólidos elásticos bidimensionais reforçados com fibras, via MEF posicional, foi apresentada por Sampaio, Coda e Paccola (2011).

Os trabalhos desenvolvidos por Sampaio, Paccola e Coda (2013), Baiocco, Coda e Paccola (2013), Sampaio (2014), Moura (2015), Pereira (2015), Fernandes (2016), seguem a formulação posicional e complementam a metodologia inicialmente proposta por Vanalli 
(2004). Os autores apresentam uma técnica na qual as fibras são introduzidas por meio de relações cinemáticas simples que garantem a sua aderência à matriz sem a introdução de novos graus de liberdade e sem a necessidade de que os nós na discretização das fibras e matriz coincidam, sendo a interface entre a matriz e as partículas é desconsiderada (assumida a aderência perfeita entre as duas fases). As fibras, nessa nova formulação, podem ser formadas por elementos de barras retos ou curvos e a matriz pode ser constituída por elementos finitos de chapa ou casca.

A formulação de acoplamento utilizando o MEF posicional trata da interação entre matriz e partículas. As vantagens para a abordagem numérica de compósitos reforçados são devidas a análise não precisar que as malhas da matriz e das partículas coincidam, e ainda, os compósitos reforçados são analisados sem o aumento do número de graus de liberdade dos problemas (MOURA, 2015).

A não linearidade geométrica, naturalmente atendida por meio da formulação posicional, considera a condição de equilíbrio levando em conta os deslocamentos durante o processo de mudança de configuração. Essa análise busca descrever trajetórias de equilíbrio da estrutura, ou seja, representar as configurações equilibradas correspondentes aos sucessivos níveis de força ou deslocamento, identificar pontos críticos em que ocorrem mudança da condição de equilíbrio e analisar a condição de estabilidade do equilíbrio associada a cada configuração (CRISFIELD, 1991).

Assim, um método para a resolução de problemas não lineares geométricos deve se adaptar às mudanças de carregamento nos pontos limites, manter a estabilidade numérica para as iterações em todas as regiões e deve ajustar automaticamente o tamanho dos passos de carga para representar os comportamentos de amolecimento e enrijecimento (softening e stiffening) da estrutura (YANG; SHIEH, 1990), conforme ilustra a Figura 2.3. 
Figura 2.3 - Características da solução de um problema não linear geométrico

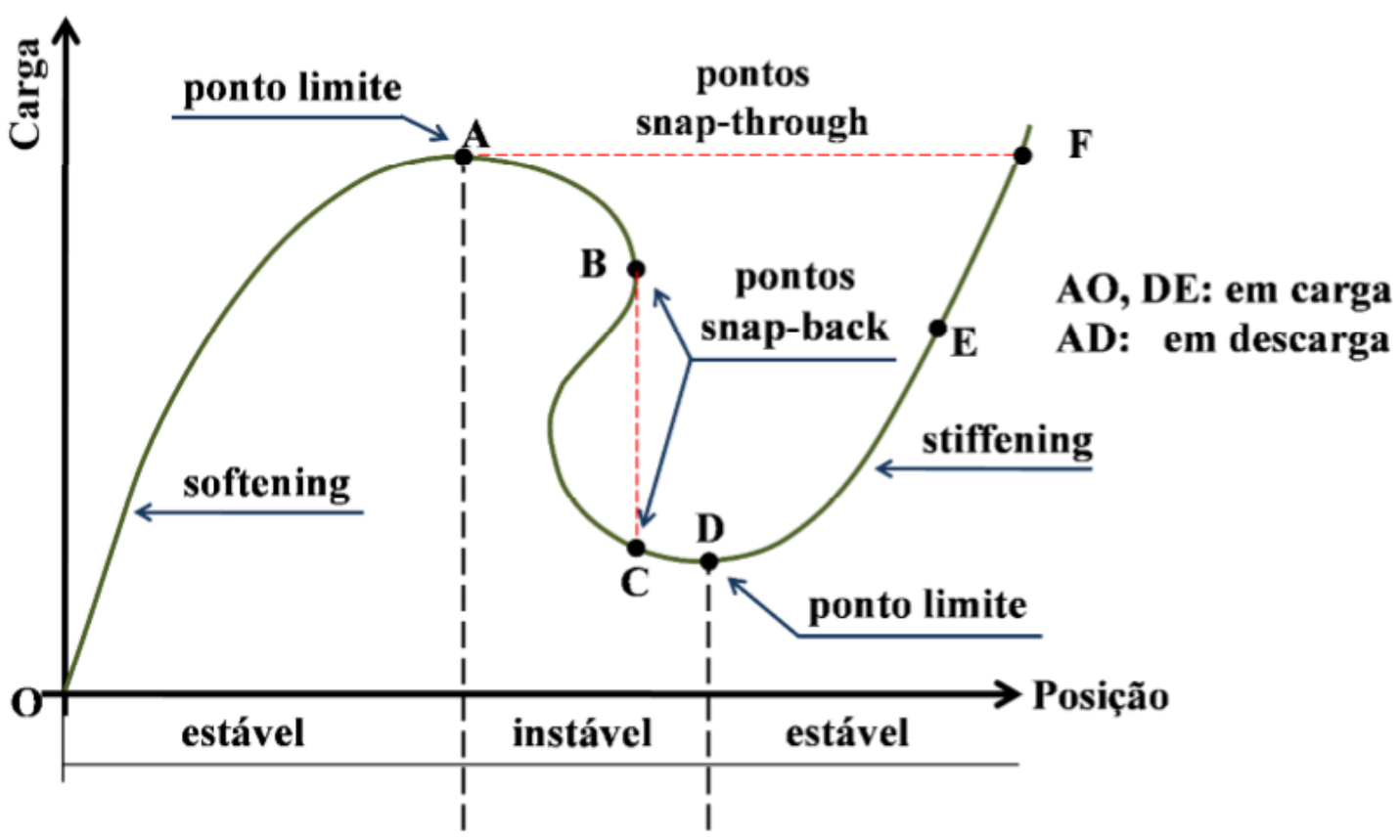

Fonte: Yang e Shieh (1990)

Dessa forma, inicialmente é necessário descrever a função mudança de configuração e o seu gradiente. Assim, é possível chegar na equação de equilíbrio para problemas estáticos em função da energia de deformação acumulada no corpo e do gradiente da função mudança de configuração a partir da equação da energia potencial total seguido da aplicação do teorema da mínima energia potencial total. Por fim, é necessário aplicar uma estratégia numérica para solução de problemas não lineares, visto que o sistema de equações de equilíbrio resultante de tal procedimento é naturalmente não linear.

As principais estratégias podem ser encontradas em Ricks (1972) e Luenberg (1989) que apresenta o método de Newton-Raphson; em Haisler e Stricklin (1977), Batoz e Dhatt (1979) e Samartin (1993), encontra-se o método do Controle de Deslocamento; em Yang e McGuire (1985) o método do Controle do Trabalho; em Riks (1979) o método do Controle do Comprimento de Arco; em Crisfield (1981), a estratégia do comprimento de arco na versão modificada é desenvolvida. A estratégia do comprimento de arco pode ser encontrada ainda no artigo de Souza Neto e Feng (1999), enquanto que a estratégia do controle de deslocamento variável em Fujii, Choong e Gong (1992).

Outro artigo que merece destaque é o de Yang e Shieh (1990), que apresenta uma estratégia unificada para facilitar a incorporação de diversos métodos numéricos presentes na 
literatura e testadas em problemas estruturais em que se encontram pontos críticos da análise não linear geométrica, sendo capaz de representar as características apresentadas na Figura 2.3. Apresentam-se ainda as estratégias de Newton-Raphson, controle de deslocamento e método do comprimento de arco desenvolvidos segundo o esquema unificado.

Para a solução de sistemas não lineares no presente trabalho, foi utilizado o método clássico de Newton-Raphson, que assegura, no mínimo, ordem dois de convergência (LUENBERG, 1989), além de ser simples de implementar computacionalmente. 
36 | Revisão Bibliográfica 


\section{MECÂNICA DO CONTÍNUO}

\subsection{Considerações iniciais}

Quando se pretende analisar o comportamento de um corpo a nível macroscópio, assume-se a hipótese de meio contínuo, onde a infinidade de partículas é substituída por apenas algumas de interesse. Essa abordagem é uma alternativa eficaz para resolver problemas de engenharia sem a necessidade de abranger as microestruturas de cada elemento.

Nesse capítulo, são apresentados conceitos cinemáticos para corpos deformáveis (contínuos), utilizando a decomposição aditiva, não se limitando a pequenas deformações e pequenos deslocamentos. A abordagem é feita considerando deformações moderadas e a elasticidade não linear com descrição Lagrangiana total.

\subsection{Cinemática dos corpos deformáveis}

Todo sólido deformável em equilíbrio (estático ou não) muda de forma quando sujeito a ações externas. Na Figura 3.1, para um corpo genérico, a função $\vec{f}$ descreve a mudança da configuração inicial $\mathrm{B}_{0}$ para a configuração atual $\mathrm{B}$. Essa função é considerada contínua e diferenciável até a segunda derivada, sendo chamada de função mudança de configuração. $\mathrm{O}$ uso da função $\vec{f}$ para descrever o comportamento geral do sólido resulta em uma análise Lagrangiana, enquanto a utilização de sua inversa $\vec{g}$ em uma análise Euleriana.

Figura 3.1 - Mudança de configuração

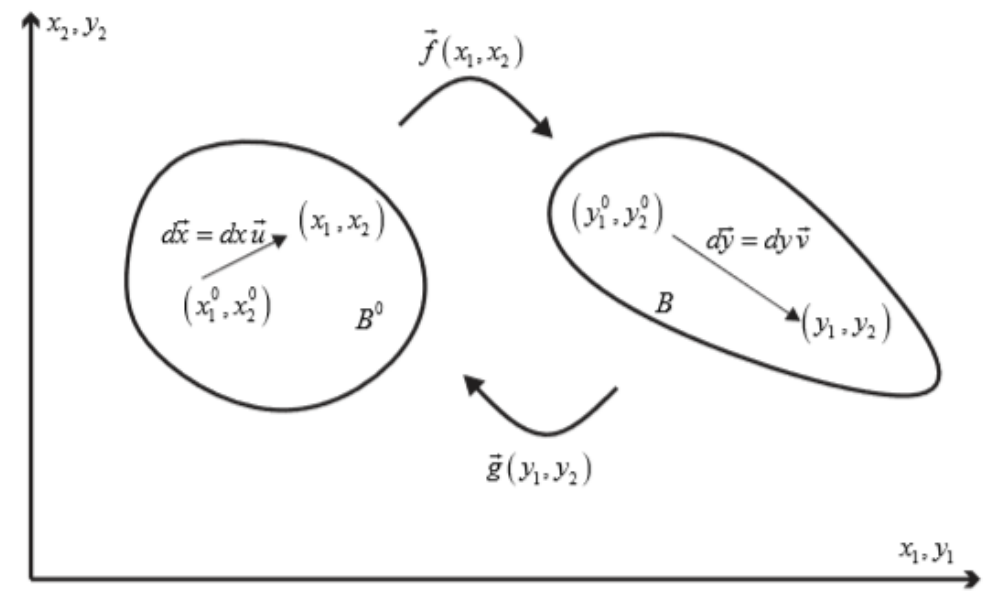


Em um corpo contínuo, ao sofrer uma mudança de configuração, pode ocorrer translação, rotação ou mudança de forma (HOLZAPFEL, 2000). Quando é possível apenas observar movimentos de translação e rotação, o sólido passou por um movimento de corpo rígido. Os materiais deformáveis são os que permitem que uma mudança de forma e de tamanho ocorra.

$\mathrm{Na}$ mecânica do contínuo existem algumas formas matemáticas de se medir a deformação de um corpo, como a deformação de Green-Lagrange, Euler-Almansi e a de engenharia, que está relacionada a pequenos deslocamentos e deformações. Neste trabalho foi utilizada a medida de deformação de Green-Lagrange por ser uma medida objetiva que permite separar os movimentos de corpo rígido das deformações e também por possuir argumentos Lagrangianos.

\subsubsection{Relação volumétrica}

Considere o elemento infinitesimal genérico, conforme a Figura 3.2 com dimensões iniciais $\mathrm{dx}^{1}, \mathrm{dx}^{2}, \mathrm{dx}^{3}$. Assim, o volume na configuração inicial pode ser calculado conforme a Equação 3.1. Supondo que o corpo sofra uma mudança de configuração e as suas dimensões passem a ser dy ${ }^{1}, \mathrm{dy}^{2}$ e dy ${ }^{3}$, o volume na configuração atual fica expresso na Equação 3.2.

$$
\begin{aligned}
& d V_{0}=d x^{1} \cdot\left(d x^{2} \times d x^{3}\right)=\operatorname{det}\left(d x^{1}, d x^{2}, d x^{3}\right) \\
& d V=d y^{1} \cdot\left(d y^{2} \times d y^{3}\right)=\operatorname{det}\left(d y^{1}, d y^{2}, d y^{3}\right)
\end{aligned}
$$


Figura 3.2 - Mudança de volume

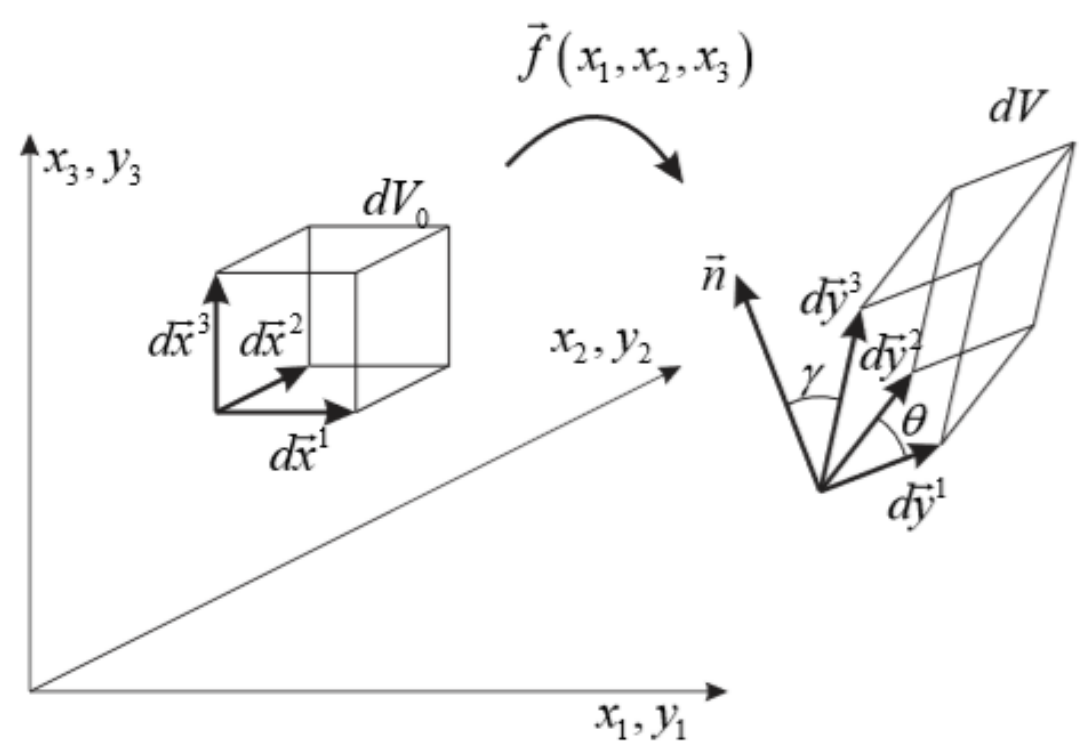

Fonte: Coda, 2017

Sendo A o gradiente da função mudança de configuração em relação à configuração inicial do contínuo, conforme a Equação 3.3, escreve-se a Equação 3.4. O determinante da função mudança de configuração recebe o nome de Jacobiano (Equação 3.5).

$$
\boldsymbol{A}(x, t)=\operatorname{Grad}(y(x, t))
$$

$$
d y=\boldsymbol{A} \cdot d x
$$

$$
J=\operatorname{det}(\boldsymbol{A})
$$

Utilizando a Equação 3.4, reescreve-se a Equação 3.2.

$$
\begin{gathered}
d V=\operatorname{det}(\boldsymbol{A}) \cdot \operatorname{det}\left(d x^{1}, d x^{2}, d x^{3}\right) \\
d V=J \cdot d V_{0}
\end{gathered}
$$




\subsection{Equilíbrio e energia}

A tensão quantifica a interação entre as partículas que constituem um sólido sujeito às ações externas. A resistência ao afastamento ou aproximação de superfícies paralelas é quantificada pela componente de tensão normal, enquanto a resistência ao deslizamento relativo entre os planos é quantificada pela tensão de cisalhamento. $\mathrm{O}$ estado de tensão refere-se à representação de todas as componentes de tensão em um ponto. A tensão de Cauchy é referida à configuração atual do corpo.

Na Figura 3.3 observa-se as faces do volume elementar com as tensões atuantes. As componentes de tensão possuem dois índices, o primeiro referente ao plano onde atua e o segundo indicando a sua direção. As componentes ortogonais são chamadas de tensões normais e sua convenção de sinal é positiva quando indicam tração e negativa na compressão. As componentes que seguem direção tangencial são chamadas de tensões de cisalhamento e sua convenção de sinal coincide com a de força cortante para barras gerais.

Figura 3.3 - Componentes de tensão

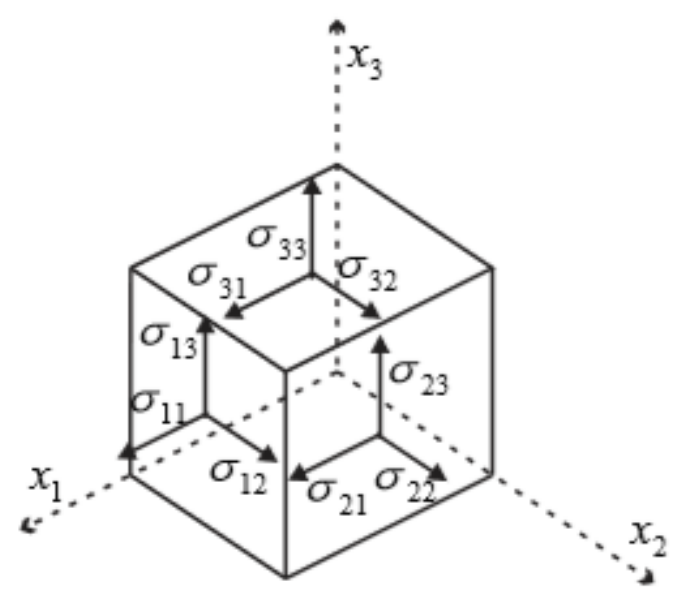

Fonte: Coda, 2017

Dessa forma, organiza-se as componentes de tensão de forma tensorial, sendo o tensor das tensões indicados pela Equação 3.8.

$$
\sigma=\left[\begin{array}{lll}
\sigma_{11} & \sigma_{12} & \sigma_{13} \\
\sigma_{21} & \sigma_{22} & \sigma_{23} \\
\sigma_{31} & \sigma_{32} & \sigma_{33}
\end{array}\right]
$$


Estando o volume da Figura 3.3 em equilíbrio, pode-se calcular o equilíbrio de momentos em torno do eixo $\mathrm{x}_{3}$. A face $\mathrm{x}_{1} \mathrm{x}_{2}$ é mostrado na Figura 3.4. Os infinitésimos de força são resultados do produto entre a componente de tensão e sua área de atuação.

Figura 3.4 - Equilíbrio de momentos

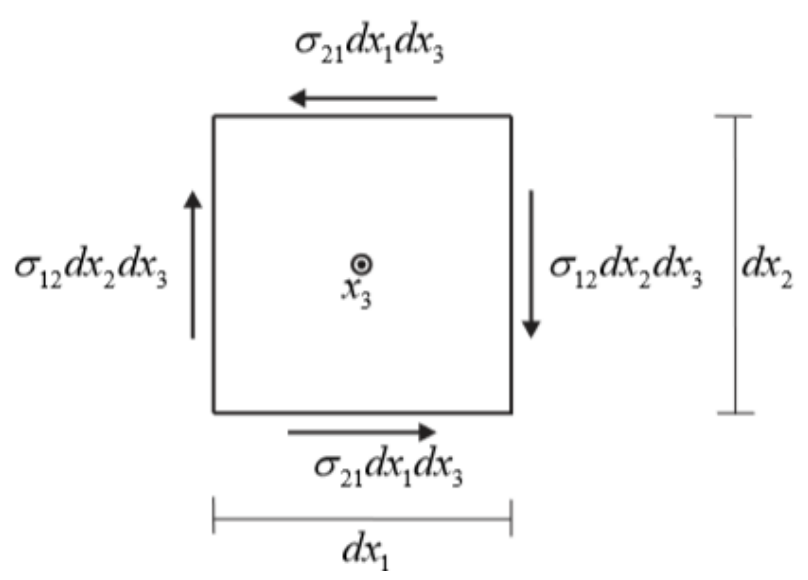

Fonte: Coda, 2017

$$
\begin{gathered}
\left(\sigma_{12} \cdot d x_{2} \cdot d x_{3}\right) \cdot d x_{1}=\left(\sigma_{21} \cdot d x_{1} \cdot d x_{3}\right) \cdot d x_{2} \\
\sigma_{12}=\sigma_{21}
\end{gathered}
$$

O cálculo pode ser repetido para as demais faces, resultando na expressão conhecida por Teorema de Cauchy, mostrado na Equação 3.10. Dessa forma, o tensor das tensões é simétrico e possui apenas 6 componentes de tensão independentes.

$$
\sigma_{i j}=\sigma_{j i} \text { ou } \quad \sigma=\sigma^{t}
$$

Sendo $\boldsymbol{A}$ (tensor de ordem 2) o gradiente da função mudança de configuração, o alongamento à direita de Cauchy-Green $\mathrm{C}$ é calculado conforme a Equação 3.11.

$$
C=\boldsymbol{A}^{t} \cdot \boldsymbol{A}
$$

Sendo I a matriz identidade, o tensor de deformação de Green-Lagrange é definido conforme a Equação 3.12 . 


$$
E=\frac{1}{2}(C-I)
$$

\subsubsection{Mudança de área - Fórmula de Nanson}

A relação entre áreas da configuração inicial e atual é essencial para estabelecer a relação entre a tensão na configuração atual (tensão de Cauchy) e as medidas de tensão relacionadas à configuração inicial, as tensões de Piola-Kirchhoff de primeira e segunda espécie. A Figura 3.5 mostra um cilindro que sofreu uma mudança de configuração. Os volumes são gerados pelas áreas infinitesimais e pelos vetores $\vec{u} e \vec{v}$. Assim, o vetor de área inicial é expresso pela Equação 3.13 e o vetor de área atual pela Equação 3.14, onde $\vec{n} e \vec{N}$ são versores unitários ortogonais à área.

Figura 3.5 - Mudança de configuração

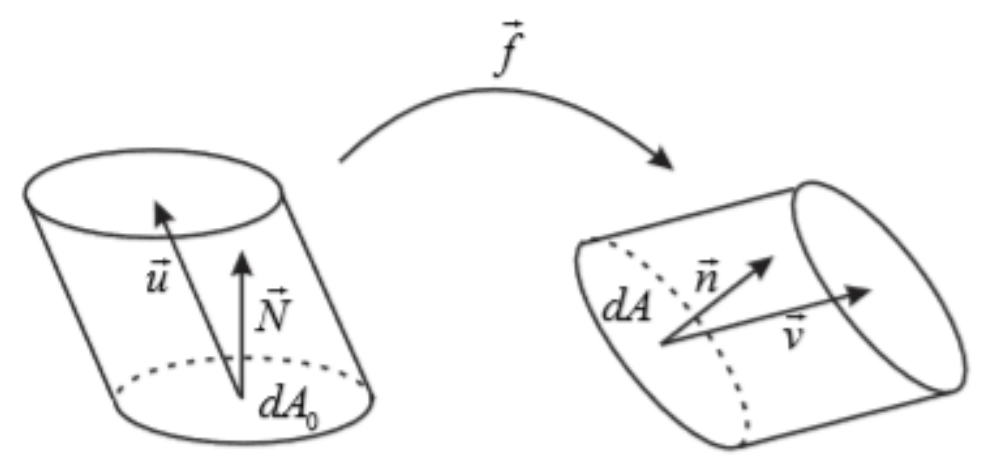

Fonte: Coda, 2017

$$
\begin{gathered}
d \overrightarrow{A_{0}}=\vec{N} d A_{0} \\
d \vec{A}=\vec{n} d A
\end{gathered}
$$

Os volumes são calculados conforme a Equação 3.15.

$$
d V_{0}=\vec{u}^{t} \cdot d \vec{A}_{0} \quad e \quad d V=\vec{v}^{t} \cdot d \vec{A}
$$


Substituindo a Equações 3.15 na Equação 3.7, tem-se:

$$
\vec{v}^{t} \cdot \vec{n} d A=J \cdot \vec{u}^{t} \cdot \vec{N} d A_{0}
$$

A partir da Equação 3.4 pode-se reescrever a Equação 3.16. A Equação 3.18 é conhecida como Fórmula de Nanson.

$$
\begin{gathered}
\vec{u}^{t} \cdot \boldsymbol{A}^{t} \cdot \vec{n} d A=J \cdot \vec{u}^{t} \cdot \vec{N} d A_{0} \\
\vec{n} d A=J \cdot \boldsymbol{B} \cdot \vec{N} d A_{0} \\
\boldsymbol{B}=\left(\boldsymbol{A}^{t}\right)^{-1}
\end{gathered}
$$

\subsubsection{Tensor de Piola-Kirchhoff}

Como a configuração atual é desconhecida, é conveniente utilizar tensores de tensão com referência Lagrangiana. Dessa forma, será apresentado o tensor de tensões de PiolaKirchhoff de primeira espécie e, posteriormente, o de segunda espécie.

Considere um corpo genérico e deformável em que atuam forças arbitrárias. Ao seccionar o corpo, são observadas forças internas na seção responsáveis pelo equilíbrio. Holzapfel (2000) mostra que a força resultante na superfície df pode ser calculada por:

$$
d \boldsymbol{f}=T d S=\boldsymbol{t} d s
$$

Onde $\mathrm{T}=\mathrm{T}(\mathrm{x}, \mathrm{t}, \mathrm{N})$ é conhecido como vetor de forças de superfície de Piola-Kirchhoff, calculado em relação à configuração inicial de acordo com a Equação 3.21 e t é o vetor tensão de Cauchy.

$$
T=T(x, t, N)=P(x, t) N
$$

Em que $\mathrm{P}(\mathrm{x}, \mathrm{t})$ é o tensor de tensões de Piola-Kirchhoff de primeira espécie, enquanto $\mathbf{t}=\mathbf{t}(\mathrm{y}, \mathrm{t}, \mathrm{n})$ é o vetor de forças de superfície de Cauchy. 


$$
\boldsymbol{t}=\boldsymbol{t}(y, t, n)=\sigma(y, t) n
$$

Substituindo as Equações 3.21 e 3.22 na 3.20 e aplicando a fórmula de Nanson, tem-se:

$$
P=J \cdot \boldsymbol{A}^{-1} \cdot \sigma=J \cdot \boldsymbol{B}^{t} \cdot \sigma
$$

O primeiro tensor de Piola-Kirchhoff possui a desvantagem por não ser simétrico. Assim, o tensor de Piola-Kirchhoff de segunda espécie (S) é obtido substituindo a Equação 3.24 na Equação 3.23.

$$
\begin{gathered}
P=S^{t} \cdot A^{t} \\
S^{t}=J \cdot \boldsymbol{A}^{-1} \cdot \sigma \cdot \boldsymbol{B}
\end{gathered}
$$

\subsubsection{Modelo constitutivo de Saint - Venant - Kirchhoff}

As leis constitutivas referem-se a um modelo matemático que relaciona as tensões com as deformações de um corpo qualquer. A relação constitutiva usada no presente trabalho é a de Saint-Venant-Kirchhoff.

Esse modelo constitutivo é uma extensão Lagrangiana direta da Lei de Hooke, ou seja, uma relação linear entre o tensor de Piola-Kirchhoff de segunda espécie e o tensor de deformação de Green-Lagrange. A Equação 3.26 mostra a expressão generalizada da energia de deformação do modelo de Saint-Venant-Kirchhoff (SVK), onde $\mathfrak{C}$ é o tensor constitutivo elástico constante de quarta ordem definido, de forma geral, pela Equação 3.27.

$$
\begin{gathered}
u_{e}(E)=\frac{1}{2} E: \mathfrak{c}: E \\
\mathbb{C}=\frac{\partial^{2} u_{e}}{\partial E \otimes \partial E}
\end{gathered}
$$


Sendo a deformação de Green o conjugado energético da tensão de Piola-Kirchhoff de segunda espécie (Equação 3.28), a relação tensão/deformação é dada pela Equação 3.29.

$$
\begin{gathered}
S=\frac{\partial u_{e}}{\partial E} \\
S=\frac{\partial}{\partial E}\left(\frac{1}{2} E: \mathfrak{C}: E\right)=\mathfrak{C}: E
\end{gathered}
$$

Sendo IE o módulo de elasticidade longitudinal, Gr o módulo de elasticidade transversal e $v$ o coeficiente de Poisson, para o estado tridimensional têm-se as Equações 3.30 e 3.31. Destaca-se ainda que a relação expressa pela Equação 3.32 é válida pois a consideração é para materiais isotrópicos.

$$
\begin{gathered}
\left\{\begin{array}{l}
E_{11} \\
E_{22} \\
E_{33} \\
E_{12} \\
E_{13} \\
E_{23}
\end{array}\right\}=\left[\begin{array}{cccccc}
1 / \mathbb{E} & -v / \mathbb{E} & -v / \mathbb{E} & 0 & 0 & 0 \\
-v / \mathbb{E} & 1 / \mathbb{E} & -v / \mathbb{E} & 0 & 0 & 0 \\
-v / \mathbb{E} & -v / \mathbb{E} & 1 / \mathbb{E} & 0 & 0 & 0 \\
0 & 0 & 0 & 1 / 2 \mathbb{G} & 0 & 0 \\
0 & 0 & 0 & 0 & 1 / 2 \mathbb{G} & 0 \\
0 & 0 & 0 & 0 & 0 & 1 / 2 \mathbb{G}
\end{array}\right]\left\{\begin{array}{l}
S_{11} \\
S_{22} \\
S_{33} \\
S_{12} \\
S_{13} \\
S_{23}
\end{array}\right\} \\
\left\{\begin{array}{l}
S_{11} \\
S_{22} \\
S_{33} \\
S_{12} \\
S_{13} \\
S_{23}
\end{array}\right\}=\left[\begin{array}{ccccccc}
\frac{(1-v) \mathbb{E}}{(1+v)(1-2 v)} & \frac{v \mathbb{E}}{(1+v)(1-2 v)} & \frac{v \mathbb{E}}{(1+v)(1-2 v)} & 0 & 0 & 0 \\
\frac{v \mathbb{E}}{(1+v)(1-2 v)} & \frac{(1-v) \mathbb{E}}{(1+v)(1-2 v)} & \frac{v \mathbb{E}}{(1+v)(1-2 v)} & 0 & 0 & 0 \\
\frac{v \mathbb{E}}{(1+v)(1-2 v)} & \frac{v \mathbb{E}}{(1+v)(1-2 v)} & \frac{(1-v) \mathbb{E}}{(1+v)(1-2 v)} & 0 & 0 & 0 \\
0 & 0 & 0 & 2 \mathbb{G} & 0 & 0 \\
0 & 0 & 0 & 0 & 0 \\
0 & 0 & 0 & 0 & 2 \mathbb{G}
\end{array}\right]\left\{\begin{array}{l}
E_{11} \\
E_{22} \\
E_{33} \\
E_{12} \\
E_{13} \\
E_{23}
\end{array}\right\}
\end{gathered}
$$

Para o estado plano de deformação (EPD), têm-se as Equações 3.33, 3.34 e 3.35. O EPD é caracterizado quando se assume que as componentes de deformação $\mathrm{E}_{33}=\mathrm{E}_{13}=\mathrm{E}_{23}=0$. 


$$
\begin{gathered}
\left\{\begin{array}{l}
E_{11} \\
E_{22} \\
E_{12}
\end{array}\right\}=\left[\begin{array}{ccc}
1 / \mathbb{E} & -v / \mathbb{E} & 0 \\
-v / \mathbb{E} & 1 / \mathbb{E} & 0 \\
0 & 0 & 1 / 2 \mathbb{G}
\end{array}\right]\left\{\begin{array}{l}
S_{11} \\
S_{22} \\
S_{12}
\end{array}\right\} \\
\left\{\begin{array}{l}
S_{11} \\
S_{22} \\
S_{12}
\end{array}\right\}=\left[\begin{array}{ccc}
\frac{(1-v) \mathbb{E}}{(1+v)(1-2 v)} & \frac{v \mathbb{E}}{(1+v)(1-2 v)} & 0 \\
\frac{v \mathbb{E}}{(1+v)(1-2 v)} & \frac{(1-v) \mathbb{E}}{(1+v)(1-2 v)} & 0 \\
0 & 0 & 2 \mathbb{G}
\end{array}\right]\left\{\begin{array}{l}
E_{11} \\
E_{22} \\
E_{12}
\end{array}\right\} \\
S_{33}=\frac{v \mathbb{E}}{(1+v)(1-2 v)}\left(E_{11}+E_{22}\right)
\end{gathered}
$$

A consideração para este trabalho é de estado plano de tensões (EPT), que ocorre em peças que possuem uma dimensão muito menor do que as outras, ou seja, problemas de chapas. Dessa forma, o EPT se caracteriza por assumir $\mathrm{S}_{13}=\mathrm{S}_{23}=\mathrm{S}_{33}=0$.

$$
\begin{gathered}
\left\{\begin{array}{l}
E_{11} \\
E_{22} \\
E_{12}
\end{array}\right\}=\left[\begin{array}{ccc}
1 / \mathbb{E} & -v / \mathbb{E} & 0 \\
-v / \mathbb{E} & 1 / \mathbb{E} & 0 \\
0 & 0 & 1 / 2 \mathbb{G}
\end{array}\right]\left\{\begin{array}{l}
S_{11} \\
S_{22} \\
S_{12}
\end{array}\right\} \\
\left\{\begin{array}{l}
S_{11} \\
S_{22} \\
S_{12}
\end{array}\right\}=\left[\begin{array}{ccc}
\frac{\mathbb{E}}{\left(1-v^{2}\right)} & \frac{v \mathbb{E}}{\left(1-v^{2}\right)} & 0 \\
\frac{v \mathbb{E}}{\left(1-v^{2}\right)} & \frac{\mathbb{E}}{\left(1-v^{2}\right)} & 0 \\
0 & 0 & 2 \mathbb{G}
\end{array}\right]\left\{\begin{array}{l}
E_{11} \\
E_{22} \\
E_{12}
\end{array}\right\} \\
E_{33}=-\frac{v}{\mathbb{E}}\left(S_{11}+S_{22}\right)
\end{gathered}
$$

\subsubsection{Princípio da estacionariedade da energia mecânica}

As parcelas da energia mecânica são: energia potencial das forças externas ( $\mathbb{P}$ ), energia de deformação (IUI) e energia cinética (KK), conforme explicitado na Equação 3.39. Ressalta-se 
que as forças consideradas são conservativas, ou seja, não dependem da posição ocupadas no espaço.

$$
\Pi=\mathbb{P}+\mathbb{U}+\mathbb{K}
$$

De acordo com o princípio da estacionariedade da energia mecânica, a posição de equilíbrio de uma estrutura é aquela para a qual a energia mecânica total do sistema é estacionária, ou seja, não varia $(\delta \Pi=0)$. Enquanto a primeira variação nula refere-se ao equilíbrio, o sinal da segunda derivada refere-se à natureza desse equilíbrio (estável se maior que zero, indiferente se nulo e instável se menor do que zero). A Equação 3.41 mostra a aplicação do Princípio da Energia Mecânica Estacionária aplicado na dedução do MEF posicional escrito na forma integral.

$$
\begin{gathered}
\delta \Pi=\delta \mathbb{P}+\delta \mathbb{U}+\delta \mathbb{K}=0 \\
\delta \Pi=\int_{V_{0}} \rho_{0} \overrightarrow{\ddot{y}} \cdot \delta \vec{y} d V_{0}-\int_{V_{0}} \overrightarrow{b^{0}} \cdot \delta \vec{y} d V_{0}-\int_{A_{0}} \overrightarrow{p^{0}} \cdot \delta \vec{y} d A_{0}+\int_{V_{0}} S: \delta E d V_{0}=0
\end{gathered}
$$


48 Mecânica do Contínuo 


\section{FORMULAÇÃO NÃO LINEAR GEOMÉTRICA APLICADA A PROBLEMAS ESTÁTICOS}

\subsection{Considerações iniciais}

O método dos elementos finitos consiste em substituir o contínuo por um conjunto finito de subdomínios, chamados de elementos finitos. As variáveis de interesse são aproximadas nesses subdomínios, resultando em um problema com um número finito de incógnitas. A formulação posicional considera como variável a posição nodal do corpo em vez dos tradicionais deslocamentos. Este capítulo segue a abordagem e a formulação apresentada em Coda (2003).

Para a implementação do programa, é necessário retomar as formulações empregadas. O desenvolvimento da formulação parte do funcional de energia total escrito em função das posições nodais, ao invés dos deslocamentos. Em seguida, é aplicado o princípio da estacionariedade da energia mecânica para obter a configuração de equilíbrio. A resolução do sistema de equações de equilíbrio, que é não linear, é obtida com a aplicação do método iterativo de Newton-Raphson.

Destaca-se que, na formulação, as forças consideradas são conservativas, como já mencionado, e a medida de deformação utilizada é a de Green-Lagrange (Equação 3.12), com o modelo constitutivo de SVK.

\subsection{Elemento Finito de treliça}

A formulação exposta refere-se a barras de treliça com seção transversal constante. A Figura 4.1 ilustra o elemento finito de treliça com comprimento inicial $l_{0}$ que sofreu uma mudança de configuração $\vec{f}$. A deformação de Green-Lagrange, para o caso uniaxial, é dada pela Equação 4.1. Para barras de treliça, a lei constitutiva de Saint-Venant-Kirchhoff em função da deformação de Green fica expressa pela Equação 4.2, em que k é a constante elástica longitudinal. 
Figura 4.1- Elemento finito de treliça

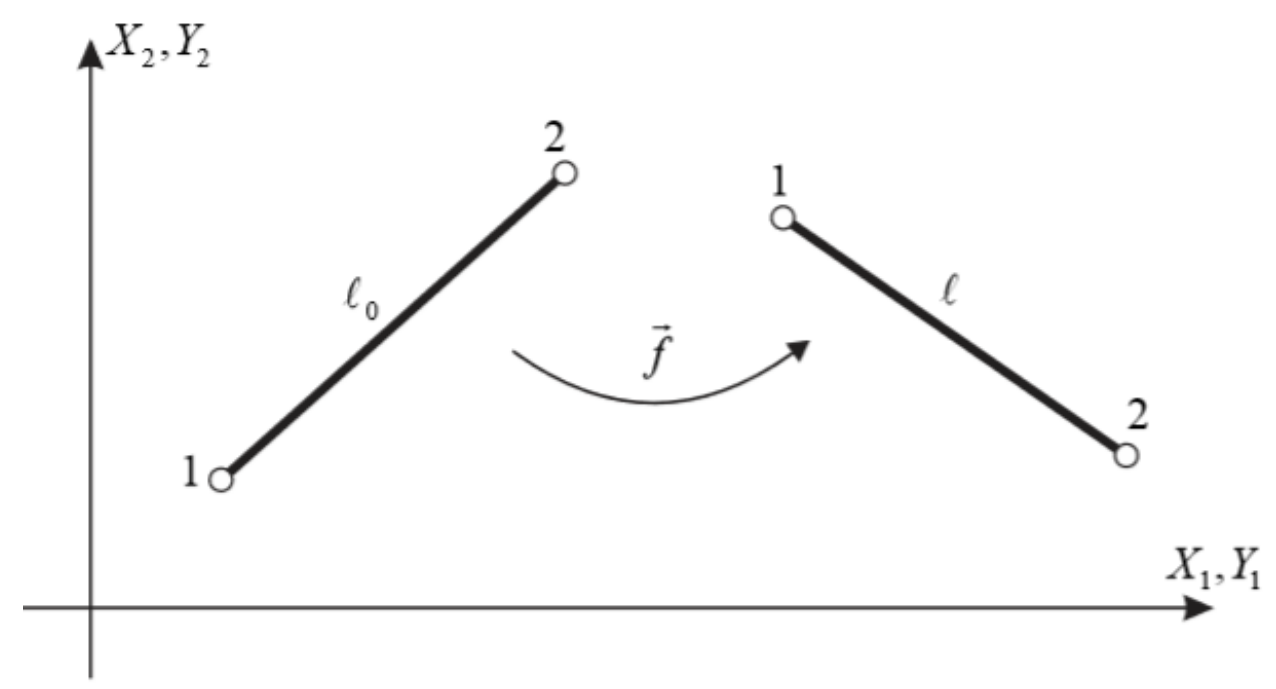

Fonte: Coda, 2017

$$
\begin{gathered}
E=\frac{1}{2} \cdot \frac{\left(l^{2}-l_{0}^{2}\right)}{l_{0}^{2}} \\
u_{e}^{S V K}(E)=\frac{k}{2} \cdot E^{2}
\end{gathered}
$$

A derivada da energia específica de deformação é a medida de tensão de Piola-Kirchhoff de segunda espécie. Para o caso uniaxial, tem-se:

$$
S=\frac{d u_{e}}{d E}=k . E
$$

Para a formulação estática do MEF posicional para treliça, parte-se então da energia total do sistema, Equação 3.39, desprezando a parcela cinética. Aplicando o princípio da estacionariedade da energia mecânica, tem-se:

$$
\delta \Pi=\delta \mathbb{P}+\delta \mathbb{U}=0
$$


Sendo o potencial das forças externas para o elemento de treliça indicado na Equação 4.5, em que i refere-se à direção e $\alpha$ ao nó, a sua derivada é expressa na Equação 4.6, ou seja, o negativo da força externa aplicada no grau de liberdade considerado $\left(F^{(e x t)}\right)$.

$$
\begin{gathered}
\mathbb{P}=-F_{i}^{\alpha(e x t)} \cdot Y_{i}^{\alpha} \\
\frac{\partial \mathbb{P}}{\partial Y_{i}}=\frac{\partial\left(-F_{k} \cdot Y_{k}\right)}{\partial Y_{i}}=-F_{k} \cdot \delta_{k i}=-F_{i}^{e x t}
\end{gathered}
$$

A energia de deformação da treliça é dada pela soma das energias de deformação dos nel elementos finitos (Equação 4.7). Assim, a sua derivada, expressa na Equação 4.8, pode ser entendida como uma força interna, $F^{(i n t)}$.

$$
\begin{gathered}
\mathbb{U}=\sum_{j=1}^{n e l} U_{e}^{j}\left(Y_{k}^{\beta}\right) \\
F_{i}^{\alpha(i n t)}=\frac{\partial \mathbb{U}}{\partial Y_{i}^{\alpha}}=\frac{\partial \sum_{j=1}^{n e l} U_{e}^{j}\left(Y_{k}^{\beta}\right)}{\partial Y_{i}^{\alpha}}=\sum_{j=1}^{n e l} \frac{\partial U_{e}^{j}\left(Y_{k}^{\beta}\right)}{\partial Y_{i}^{\alpha}}
\end{gathered}
$$

Sendo a derivada da deformação de Green expressa na Equação 4.9, a força interna para um elemento finito de treliça é calculada conforme a Equação 4.10.

$$
\begin{gathered}
\frac{\partial E}{\partial Y_{k}^{\beta}}=\frac{(-1)^{\beta}}{l_{0}^{2}} \cdot\left(Y_{k}^{2}-Y_{k}^{1}\right) \\
\left(F_{k}^{\beta(\text { int })}\right)^{j}=\frac{A_{0}^{j} S(-1)^{\beta}}{l_{0}} \cdot\left(Y_{k}^{2}-Y_{k}^{1}\right)
\end{gathered}
$$

Substituindo as Equações 4.6 e 4.8 na Equação 4.4, tem-se: 


$$
F_{i}^{i n t}-F_{i}^{e x t}=0_{i}
$$

Dessa forma, a força externa é dada diretamente pelo problema enquanto a força interna é calculada por tentativa e o equilíbrio é completamente atendido quando o vetor posição da tentativa coincidir com a posição atual da estrutura dentro da tolerância permitida, ou seja, a não linearidade geométrica é naturalmente atendida pelo processo iterativo.

O algoritmo usado para a solução é o de Newton-Raphson, tendo como primeira tentativa de solução a posição inicial, $Y_{k}^{0}=X_{k}$. A seguir, calcula-se a matriz Hessiana conforme a Equação 4.12 e a força interna para o passo. Assim, resolve-se o sistema linear expresso na Equação 4.13, onde $\vec{g}$ é o vetor de desbalanceamento mecânico (Equação 4.14). Com o valor de $\Delta Y_{k}$, é possível atualizar a posição (Equação 4.15) e verificar se os valores obtidos estão dentro da tolerância ( $\frac{\left|\Delta Y_{k}\right|}{\left|X_{k}\right|}<$ tol ): caso estejam, incrementa-se a carga (ou posição) para obter resultados para o próximo passo; se não, a matriz Hessiana e o vetor de força interna são recalculados com a nova posição para a nova iteração a fim de melhorar a precisão.

$$
\begin{gathered}
\left(H_{i k}^{\alpha \beta}\right)^{j}=\left.\frac{\partial^{2} \mathbb{U}}{\partial Y_{k} \partial Y_{j}}\right|_{Y^{0}}=(-1)^{\beta}(-1)^{\alpha} \frac{A_{0}^{j}}{l_{0}}\left(k(E) \frac{\left(Y_{i}^{2}-Y_{i}^{1}\right)}{l_{0}} \frac{\left(Y_{k}^{2}-Y_{k}^{1}\right)}{l_{0}}+S \delta_{i k}\right) \\
H_{k j} \cdot \Delta Y_{k}=-g_{j} \\
g_{j}=F_{j}^{i n t}-F_{j}^{e x t} \cong 0_{j} \\
Y_{k}^{0}=Y_{k}^{0}+\Delta Y_{k}
\end{gathered}
$$

Para a lei constitutiva de SVK, a elasticidade tangente é igual à constante elástica longitudinal. $\mathrm{O}$ delta de $\operatorname{Kronecker}\left(\delta_{i k}\right)$ vale 0 para índices diferentes e 1 para índices iguais. Após a montagem do sistema são aplicadas as condições de contorno para que a matriz fique inversível (ou deixe de ser singular). Dessa forma, basta zerar a linha e coluna da matriz 
hessiana correspondente aos graus de liberdade vinculados e colocar 1 na diagonal e zerar o vetor de desbalanceamento neste grau.

\subsection{Elemento Finito de sólidos bidimensionais}

\subsubsection{Polinômio de Lagrange e integração numérica}

A geometria dos elementos finitos é aproximada pelo polinômio de Lagrange, ou função de forma, de grau 3 para este trabalho. As funções de forma são escritas em função da coordenada adimensional $\xi$, definida no intervalo [0,1]. Para os elementos bidimensionais e triangulares, as funções de forma foram obtidas seguindo o estudo de Pascon (2008).

Para utilizar os polinômios de Lagrange, basta conhecer os valores da função a ser aproximada nos nós. Neste trabalho, foi usado o elemento triangular para a composição das malhas. Elementos triangulares possuem como vantagem em relação aos quadrangulares o fato das malhas se acomodarem melhor às geometrias dos sólidos. A Figura 4.2 mostra a posição padrão dos pontos geradores das funções de forma para um elemento de base triangular com aproximação cúbica.

Figura 4.2 - Coordenadas adimensionais para elemento triangular com aproximação cúbica

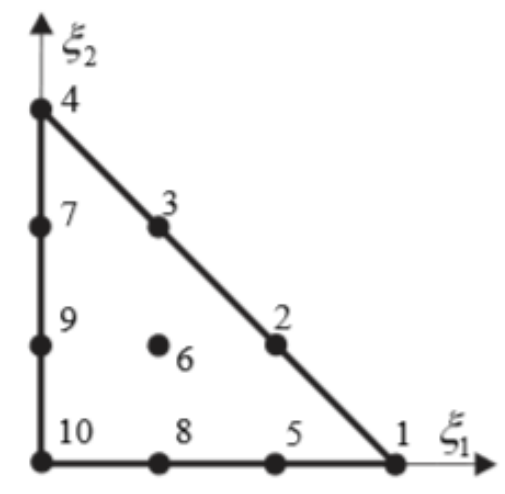

Fonte: Coda, 2017

O número total de nós do elemento, $\mathrm{N}$, pode ser determinado pela Equação 4.16 para um elemento finito bidimensional com grau de aproximação g.

$$
N=\frac{(g+1)(g+2)}{2}
$$


Sendo $f_{i}^{0}$ a função de mapeamento da configuração inicial do elemento i e $f_{i}^{1}$ a função de mapeamento da configuração atual, o gradiente da função mudança de configuração escrito em função dos gradientes de mapeamento estão representados nas Equações 4.17 e 4.18. Os tensores de segunda ordem $A^{0} \mathrm{e} A^{1}$ possuem a dimensão do espaço que representa, ou seja, para o caso plano, são matrizes $2 \times 2$.

$$
\begin{gathered}
A_{i j}^{0}=f_{i, j}^{0}=\frac{\partial f_{i}^{0}}{\partial \xi_{j}}=\phi_{l, j} X_{i}^{l} \\
A_{i j}^{1}=f_{i, j}^{1}=\frac{\partial f_{i}^{1}}{\partial \xi_{j}}=\phi_{l, j} Y_{i}^{l}
\end{gathered}
$$

Percebe-se, através da Equação 3.41, que diversas integrais de domínio e superfície devem ser realizadas. Dessa forma, a integração pretendida é realizada numericamente por meio da quadratura de Hammer (Equação 4.19), onde i é o ponto de integração e $\mathrm{w}_{\mathrm{i}}$ o peso da integração. Para este trabalho, foram utilizados 7 pontos de integração, que podem ser encontrados no Anexo A, assim como seus respectivos pesos w.

$$
\int \tilde{v}(\vec{x}) d V_{0}=\sum_{i=1}^{n q} \tilde{v}\left(\vec{x}\left(\overrightarrow{\xi_{l}}\right)\right) J_{0}\left(\overrightarrow{\xi_{(l)}}\right) w_{(i)}
$$

\subsubsection{Solução via MEF Posicional}

Sabendo que o gradiente da função mudança de configuração pode ser escrito conforme a Equação 4.20, substituindo na Equação 4.12, a deformação de Green sobre o elemento finito fica escrita conforme a Equação 4.21, sendo $\mathbf{A}^{0}$ e $\mathbf{A}^{1}$ funções das coordenadas iniciais $X_{i}^{l}$ e finais $Y_{i}^{l}$ definidos nas coordenadas adimensionais, respectivamente.

$$
\begin{gathered}
A=A^{1} \cdot\left(A^{0}\right)^{-1} \\
E=\frac{1}{2}\left(\left(A^{0}\right)^{-t} \cdot\left(A^{1}\right)^{t} \cdot A^{1} \cdot\left(A^{0}\right)^{-1}-I\right)
\end{gathered}
$$


De maneira similar à treliça, para a formulação estática do MEF posicional parte-se então da energia total do sistema, Equação 3.39, desprezando a parcela cinética. Aplicando o princípio da estacionariedade da energia mecânica, tem-se:

$$
\delta \Pi=\delta \mathbb{P}+\delta \mathbb{U}=0
$$

A versão estendida, Equação 4.22, considerando o caso estático resulta em:

$$
\delta \Pi=\int \overrightarrow{b^{0}} \cdot \delta \vec{y} d V_{0}-\int \overrightarrow{p^{0}} \cdot \delta \vec{y} d A_{0}+\int S: \delta E d V_{0}=0
$$

De maneira similar à treliça, as equações de equilíbrio resultam na Equação 4.24, onde a força interna é explicitada na Equação 4.25 com a aproximação da integração numérica por meio da quadratura de Hammer nos $n h$ pontos de integração adotados. A força externa é dada no problema e varia de acordo com o passo.

$$
\begin{gathered}
\left(F_{i}^{l}\right)^{i n t}-\left(F_{i}^{l}\right)^{e x t}=0_{i}^{l} \\
\left(F_{i}^{l}\right)_{e l}^{i n t}=\int f_{i}^{l} d V_{0}=\sum_{i h=1}^{n h} f_{i}^{l}(\vec{\xi}(i h)) J_{0}(\vec{\xi}(i h)) w_{i h}
\end{gathered}
$$

A componente $f_{\alpha}^{\beta}$ da força interna é expressa pela Equação 4.26. Sendo a tensão utilizada a de Piola-Kirchhoff de segunda espécie, $S_{i j}$ é dada pela Equação 4.27.

$$
\begin{gathered}
f_{\alpha}^{\beta}=S_{i j} \frac{\partial E_{i j}}{\partial Y_{\alpha}^{\beta}} \\
D E_{\alpha \beta}=\frac{\partial E}{\partial Y_{\alpha}^{\beta}}=\frac{1}{2}\left(\left(A^{0}\right)^{-t} \cdot\left(D A_{\alpha \beta}\right)^{t} \cdot A^{1} \cdot\left(A^{0}\right)^{-1}+\left(A^{0}\right)^{-t} \cdot\left(A^{1}\right)^{t} \cdot\left(D A_{(\alpha)(\beta)}\right) \cdot\left(A^{0}\right)^{-1}\right)
\end{gathered}
$$


Como $D A_{\alpha \beta}^{1}=\frac{\partial A_{i j}^{1}}{\partial Y_{\alpha}^{\beta}}$ é um tensor de quarta ordem, pode ser escrito como tensores de ordem 2, conforme a Equação 4.28.

$$
D A_{1 \beta}^{1}=\left[\begin{array}{cc}
\phi_{\beta, 1} & \phi_{\beta, 2} \\
0 & 0
\end{array}\right] \quad e \quad D A_{2 \beta}^{1}=\left[\begin{array}{cc}
0 & 0 \\
\phi_{\beta, 1} & \phi_{\beta, 2}
\end{array}\right]
$$

Para a solução do sistema da Equação 4.13, assim como para treliça, é utilizado o processo de solução de Newton-Raphson. O vetor de desbalanceamento é dado pela Equação 4.14. A matriz Hessiana para o caso de sólidos bidimensionais encontra-se na Equação 4.29 e os componentes necessários para seu cálculo encontra-se nas Equações de 4.30 a 4.33.

$$
\begin{aligned}
& H_{\alpha \beta \gamma z}^{e l}=\int h_{\alpha \beta \gamma z} d V_{0}=\sum_{i h=1}^{n h} h_{\alpha \beta \gamma z}(\vec{\xi}(i h)) J_{0}(\vec{\xi}(i h)) w_{i h} \\
& h_{\alpha \beta \gamma z}=D E_{\gamma z}: D S_{\alpha \beta}+S: D 2 E_{\alpha \beta \gamma z} \\
& \left\{\begin{array}{l}
D S_{11} \\
D S_{22} \\
D S_{12} \\
D S_{21}
\end{array}\right\}_{\alpha \beta}=\left[\begin{array}{cccc}
k & k v & 0 & 0 \\
k v & k & 0 & 0 \\
0 & 0 & 2 G & 0 \\
0 & 0 & 0 & 2 G
\end{array}\right]\left\{\begin{array}{l}
D E_{11} \\
D E_{22} \\
D E_{12} \\
D E_{21}
\end{array}\right\}_{\alpha \beta} \\
& D S_{\alpha \beta}=\left[\begin{array}{ll}
D S_{11} & D S_{12} \\
D S_{21} & D S_{22}
\end{array}\right]_{\alpha \beta} \\
& D 2 E_{\alpha \beta \gamma z}=\frac{\partial^{2} E}{\partial Y_{\alpha}^{\beta} \partial Y_{\gamma}^{z}}=\frac{1}{2}\left(\left(A^{0}\right)^{-t} \cdot\left(D A_{\alpha \beta}^{1}\right)^{t} \cdot\left(D A_{\gamma z}^{1}\right) \cdot\left(A^{0}\right)^{-1}+\left(A^{0}\right)^{-t} \cdot\left(D A_{\gamma z}^{1}\right)^{t} \cdot\left(D A_{\alpha \beta}^{1}\right) \cdot\left(A^{0}\right)^{-1}\right)
\end{aligned}
$$

A Figura 4.3 mostra o algoritmo para o processo de solução. 
Figura 4.3 - Solução de Newton-Raphson para sólidos bidimensionais

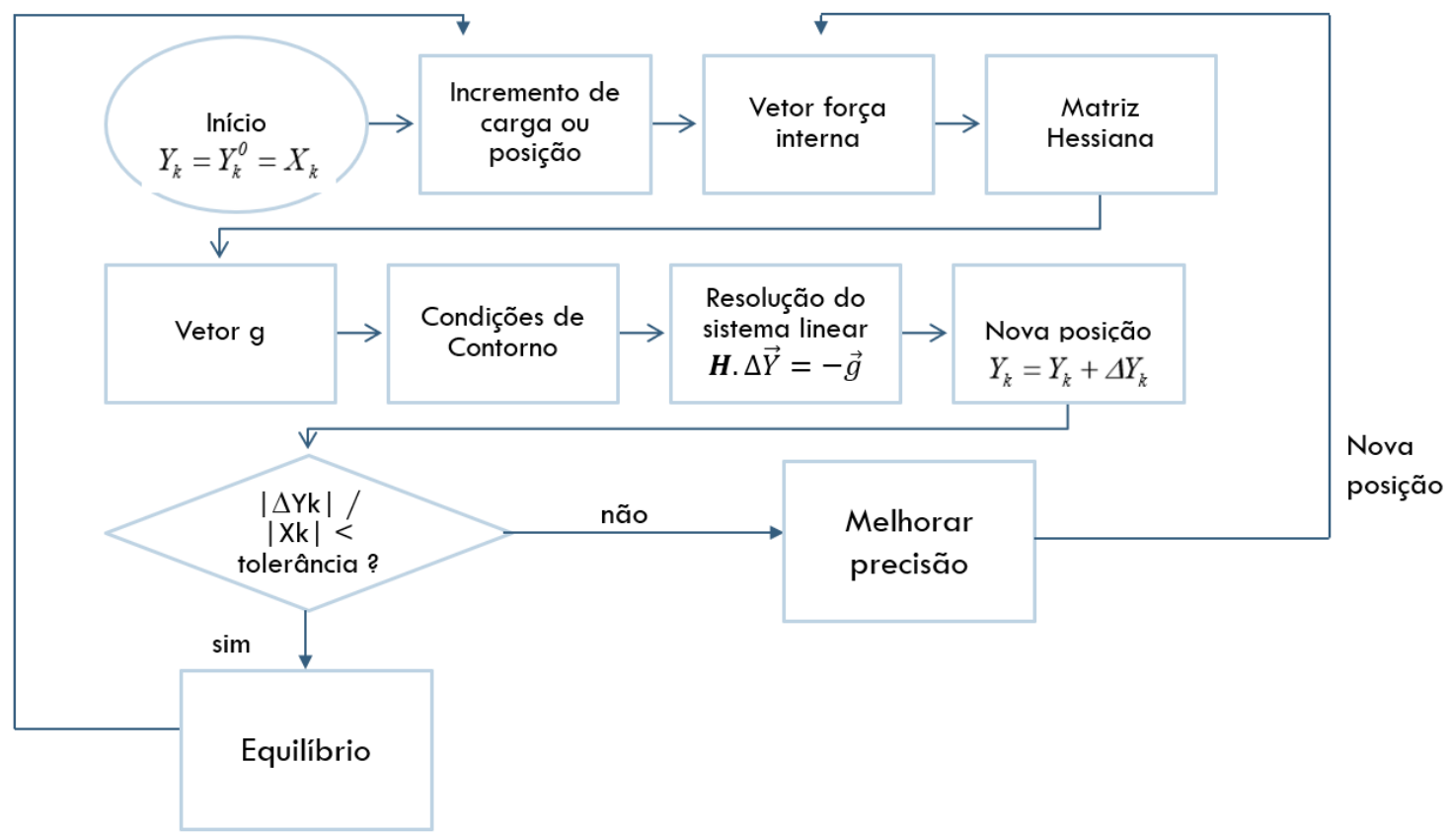

\subsection{Exemplos: Validação da formulação do elemento finito de chapa}

A fim de validar as formulações implementadas, alguns exemplos numéricos são apresentados ao longo deste capítulo. Em todos os exemplos apresentados, as malhas dos exemplos foram geradas com aproximação cúbica no programa AcadMesh (PIEDADE NETO, FAGÁ JÚNIOR, PACCOLA, 2012), e para o pós-processamento dos resultados, foi utilizado o software AcadView (PACCOLA, CODA, 2005), ambos desenvolvido pelo Departamento de Engenharia de Estruturas da EESC-USP.

Para a resolução do sistema linear resultante do método de Newton-Raphson foi utilizada a biblioteca Sparse Set (PIEDADE NETO, PACCOLA, 2010), para a montagem e resolução de sistemas lineares com matrizes esparsas e simétricas.

Com o intuito de avaliar a implementação da formulação posicional para elementos de chapa, dois exemplos são apresentados: o primeiro consiste em uma viga engastada e o segundo uma coluna submetida a compressão. Em ambos os exemplos, os resultados obtidos foram comparados com os obtidos por Mattiasson (1981). 


\subsubsection{Exemplo 4.1: Viga engastada}

O primeiro exemplo trata-se de uma um caso numérico hipotético para validar a não linearidade e consiste na avaliação do comportamento de uma viga isostática engastada com um carregamento concentrado na extremidade livre, conforme ilustra a Figura 4.4. A viga tem comprimento de 10 metros e seção transversal quadrada com $4,890 \cdot 10^{-2}$ metros de lado. As propriedades elásticas do material adotadas são: módulo de elasticidade $E=210 \mathrm{GPa}$; coeficiente de Poisson $v=0,0$.

Figura 4.4- Geometria e condições de contorno

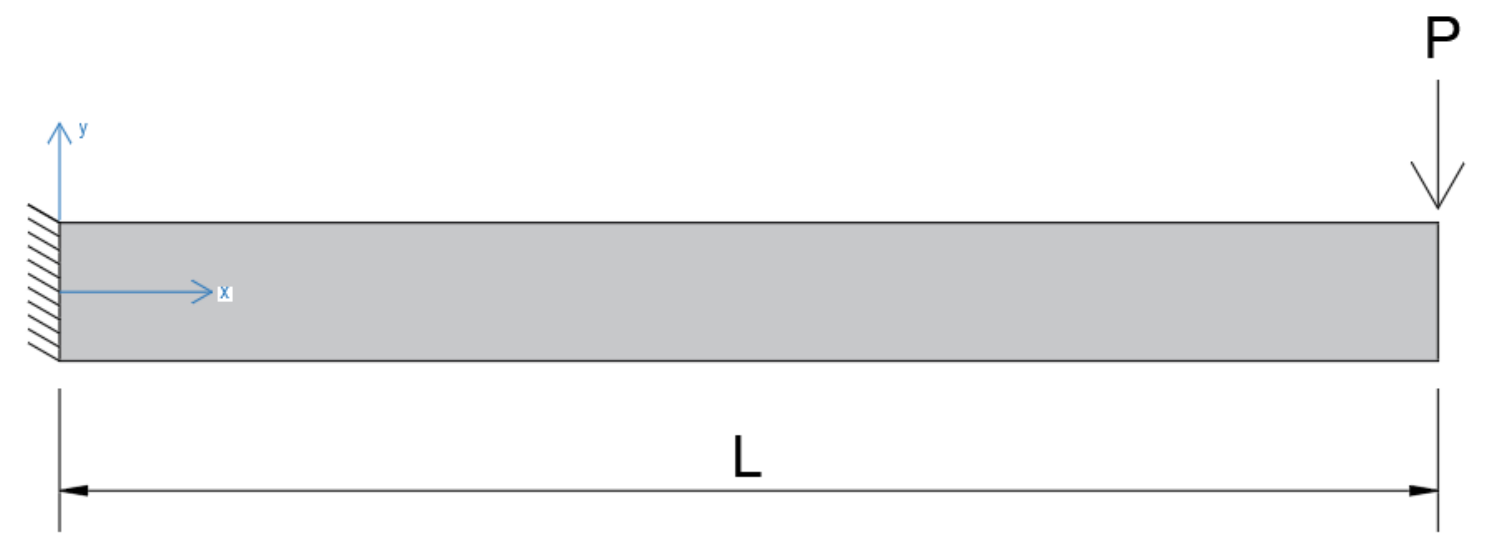

Nesse exemplo, o carregamento foi aplicado $10 \mathrm{kN}$ em 20 passos. A malha utilizada possui 220 elementos triangulares com aproximação cúbica e 1324 nós. A Figura 4.5 ilustra os deslocamentos verticais obtidos por meio da simulação realizada no presente trabalho.

Mattiasson (1981) apresentou resultados numéricos para problemas não linear geométricos por meio de integrais elípticas. A

Figura 4.6 compara os deslocamentos da extremidade livre da viga na direção z (w) para diferentes níveis de carga, dados os resultados obtidos e Mattiasson (1981). Nota-se uma grande concordância entre os resultados obtidos no presente trabalho e os fornecidos em Mattiasson (1981) para grandes deslocamentos em vigas. 
Figura 4.5- Validação exemplo 4.1. - Deslocamento vertical
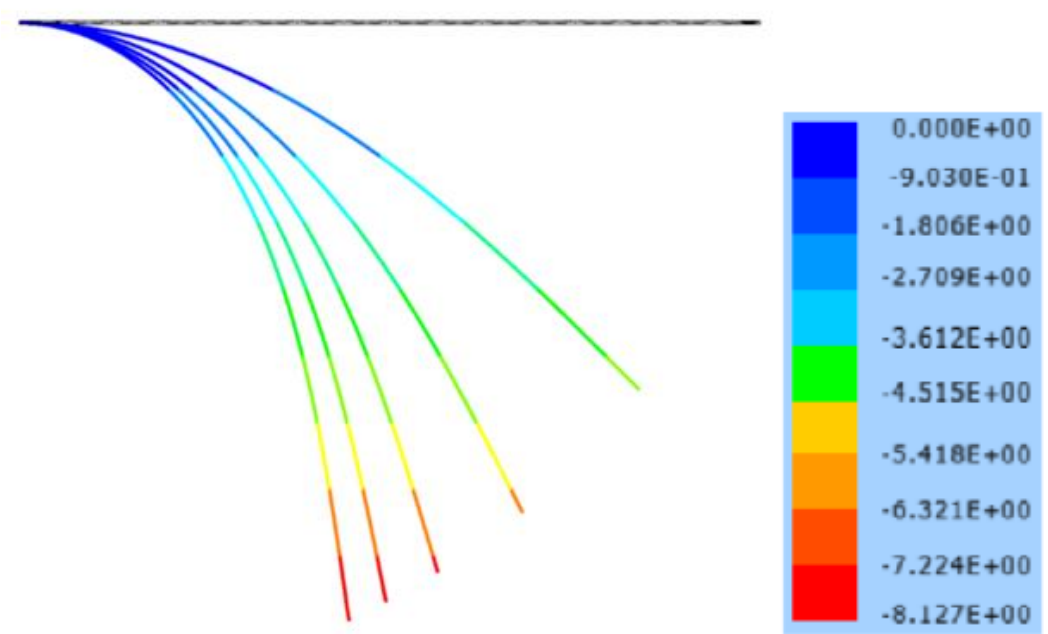

Figura 4.6- Resultados exemplo 4.1.

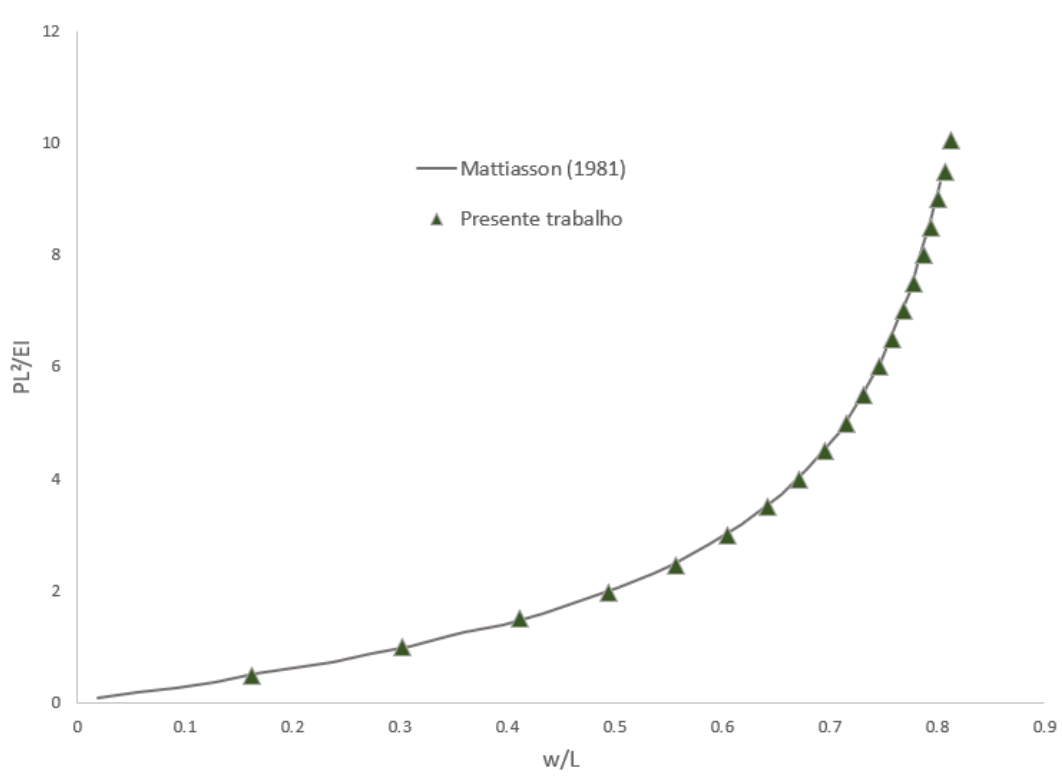

\subsubsection{Exemplo 4.2: Coluna engastada}

Esse exemplo visa verificar o comportamento não linear geométrico das implementações realizadas por meio da formulação posicional para elementos de chapa. Para isso, uma coluna engastada e livre foi submetida à compressão. Para representar a instabilidade 
do problema (flambagem elástica de Euler), foi adotado um defeito inicial de L/100 entre as seções engastadas e livres, tido como um desaprumo para a coluna. A Figura 4.7 ilustra a estrutura considerada e as suas condições de contorno e carregamento.

Neste exemplo, foi aplicada uma força de $37100 \mathrm{~N}$ em 100 passos de carga, visando obter o primeiro modo de flambagem. A seção transversal do pilar é quadrada com 1,75 . $10^{-2} \mathrm{~m}^{2}$, o comprimento $\mathrm{L}$ é de 2 metros e o momento de inércia de $2,552 \cdot 10^{-5} \mathrm{~m}^{4}$. O material tem módulo de elasticidade de $210 \mathrm{GPa}$ e coeficiente de Poisson igual a 0.

Figura 4.7- Geometria e condições de contorno

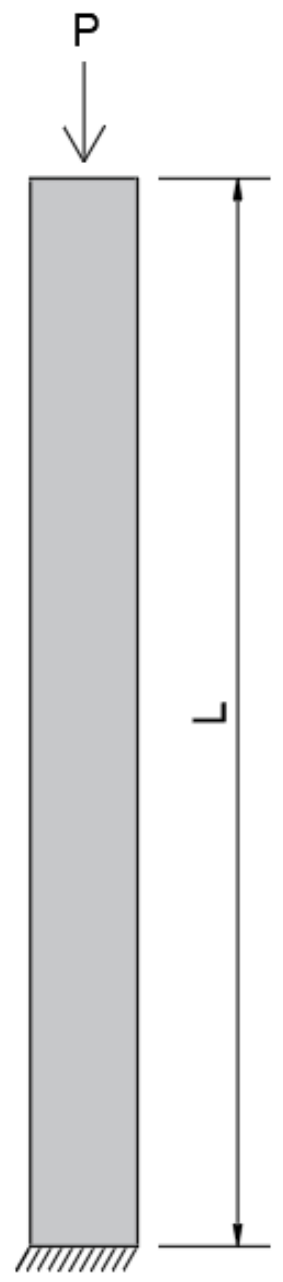

Nessa situação, a carga crítica é calculada conforme a Equação 4.34 e vale 3305,8 kN. 


$$
P_{c r}=\frac{E \cdot I \cdot \pi^{2}}{L_{f}^{2}}
$$

A malha utilizada possui 30 elementos triangulares com aproximação cúbica e 184 nós. Para os deslocamentos laterais, a Figura 4.8 compara os resultados obtidos no presente trabalho com o valor da carga crítica calculada.

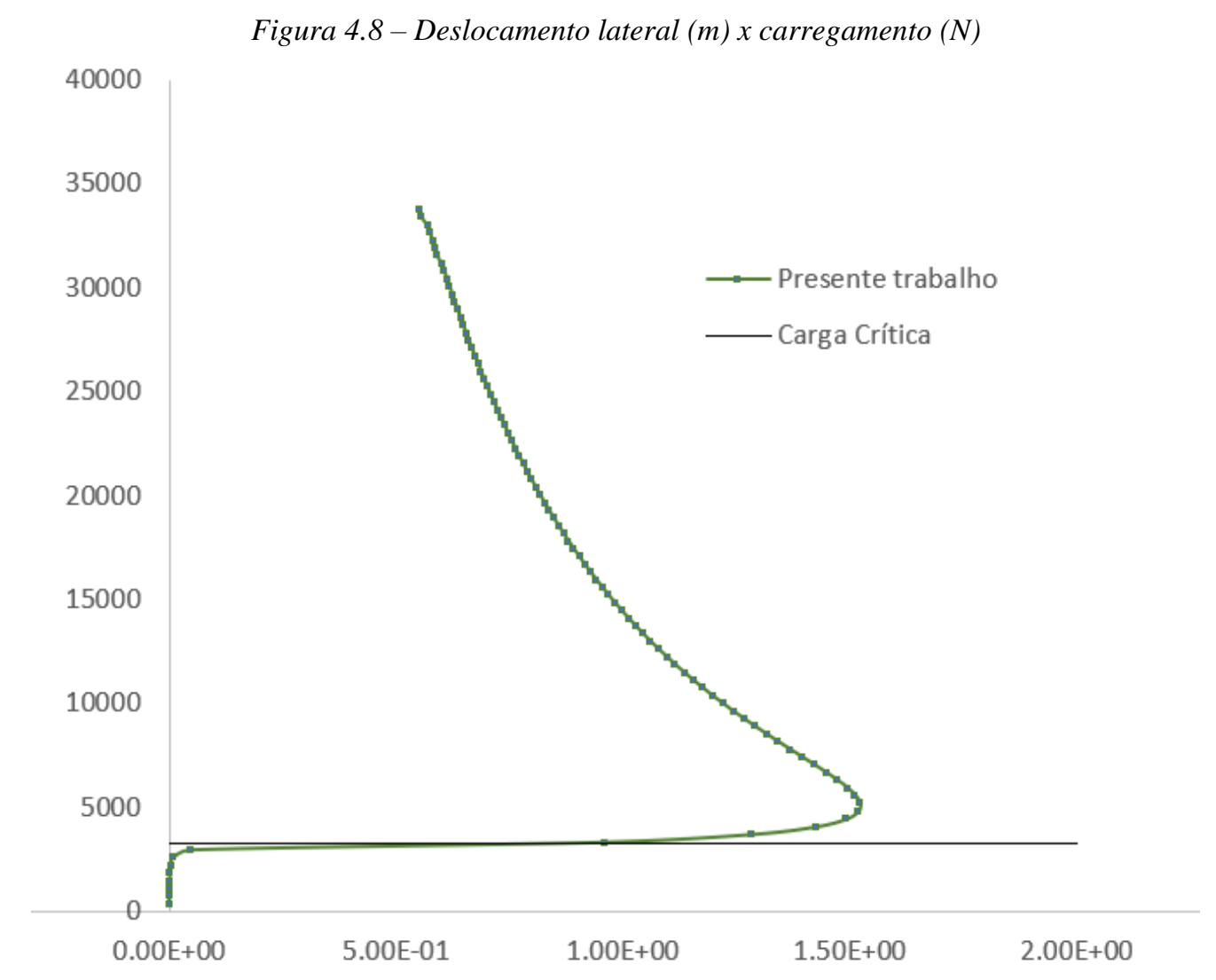

Por fim, na Figura 4.9 são representadas as configurações deslocadas com os seus respectivos valores de deslocamento lateral para diferentes níveis de carga em relação à $\mathrm{P}$. 
Figura 4.9- Configuração deslocada e mapa de cores ( $m$ )

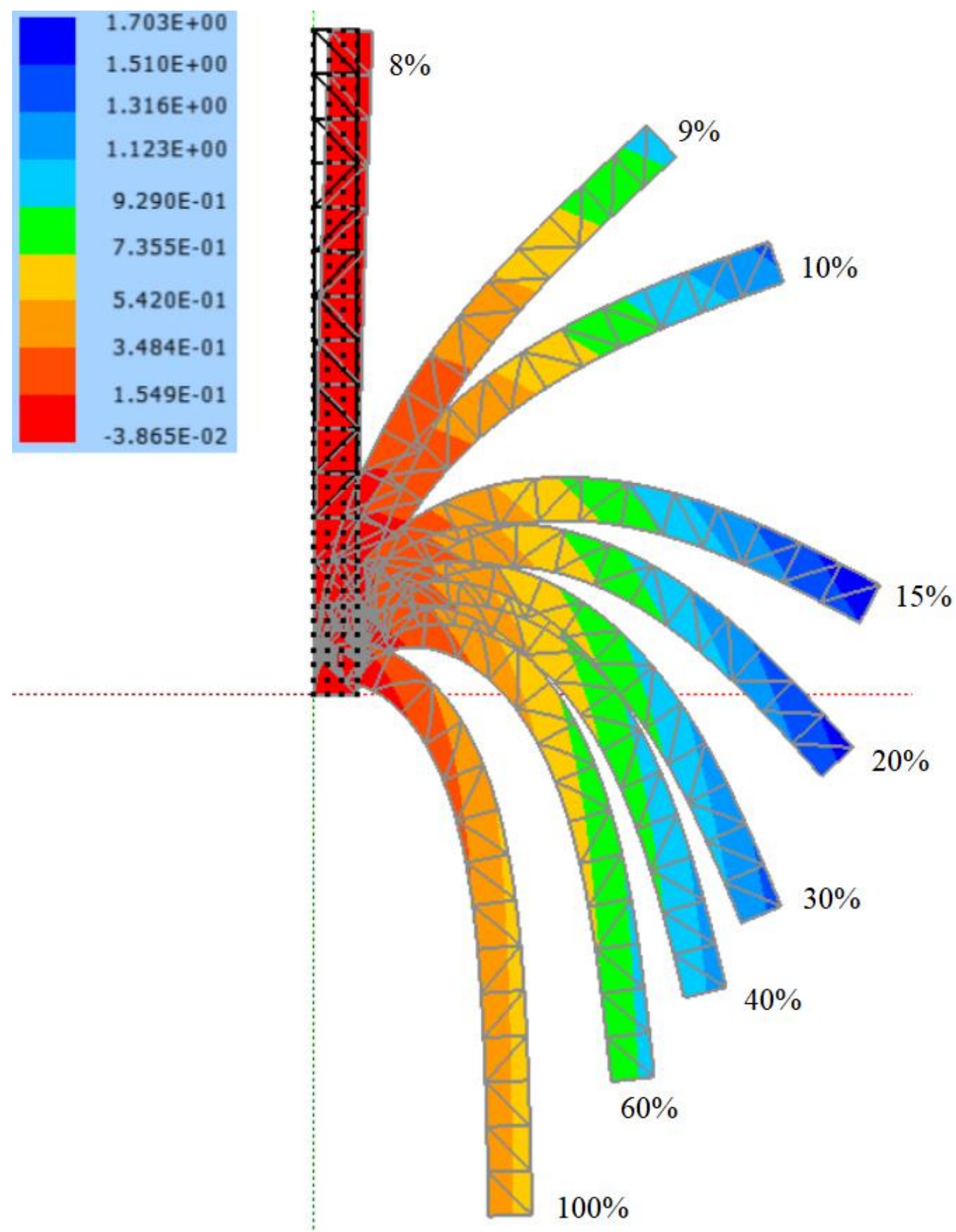

A partir das análises apresentadas nesses dois exemplos, nota-se que em ambos os casos o programa implementado correspondeu aos resultados esperados. Como a formulação posicional permite a análise não linear geométrica exata, foi possível avaliar até mesmo o comportamento instável da estrutura. Desta forma, conclui-se que os resultados obtidos por meio do código implementado são confiáveis para elementos de chapa. 


\subsection{Acoplamento Fibra-Matriz}

As fibras (elementos de barras) são utilizados para a representação da armadura de aço e as partículas (elementos de chapa triangulares com aproximação linear) são utilizados para representar a recuperação da estrutura.

A estratégia utilizada neste trabalho para incorporar as fibras na matriz cimentícia segue o estudo realizado na tese de Sampaio (2014) para elemento de barra simples e reto para as fibras. Os elementos de fibras são introduzidos na matriz usando relações cinemáticas nodais que garantem a aderência dos nós da fibra à matriz sem aumentar os graus de liberdade do sistema resultante e sem a necessidade de coincidência dos nós. (VANALLI, 2004; VANALLI; PACCOLA; CODA, 2008)

No material compósito, a eficiência do reforço com fibras pode ser avaliada de acordo com a melhoria de resistência e de tenacidade do conjunto comparado com a matriz frágil. As matrizes têm como função principal transferir as solicitações mecânicas às fibras e protegê-las do ambiente externo. (VANALLI, 2004)

Os vetores de força interna e a matriz Hessiana dos elementos bidimensionais e de barra foram apresentados separadamente. Nesse item, as derivadas são desenvolvidas considerando as contribuições simultâneas. O procedimento para inserir as fibras sem aumentar os graus de liberdade do sistema e sem a necessidade de coincidência dos nós foi apresentado por Vanalli (2004) e posteriormente por Sampaio (2014).

\subsubsection{Energia de deformação}

A energia de deformação armazenada em um corpo reforçado por fibras é a soma das energias de deformação armazenadas na matriz e na fibra. Dessa forma, a força interna na direção $a$ em um nó $b$ considerando a contribuição da fibra é expressa na Equação 4.36.

$$
\begin{gathered}
\mathbb{U}=\mathbb{U}_{\text {matriz }}+\mathbb{U}_{\text {fibras }} \\
\frac{\partial \mathbb{U}}{\partial\left(Y_{\alpha}^{\beta}\right)_{\text {matriz }}}=\left(F_{\alpha}^{\beta}\right)^{\text {int }}
\end{gathered}
$$


A matriz Hessiana é obtida através da segunda derivada da energia de deformação armazenada no corpo reforçado com fibras retas em relação aos parâmetros nodais da matriz, conforme a Equação 4.37.

$$
H_{\alpha \beta \gamma z}=\frac{\partial^{2} \mathbb{U}_{f i b r a}}{\left(\partial Y_{\alpha}^{\beta} \partial Y_{\gamma}^{z}\right)_{\text {matriz }}}
$$

\subsubsection{Acoplamento fibra reta - matriz / partícula - matriz}

As fibras imersas na matriz cimentícia funcionam como enrijecedores, aumentando a rigidez total do meio, ou seja, a fibra contribui com a rigidez do elemento finito no qual ela está inserida. O procedimento para a introdução das fibras é generalizado pois não há necessidade de coincidência dos nós das fibras com os da matriz, ou seja, os nós das fibras podem estar em quaisquer elementos da matriz. A Figura 4.10 mostra as configurações que dois nós da fibra podem apresentar ao serem inseridos no elemento de chapa.

Figura 4.10 - Arranjo das fibras no domínio bidimensional

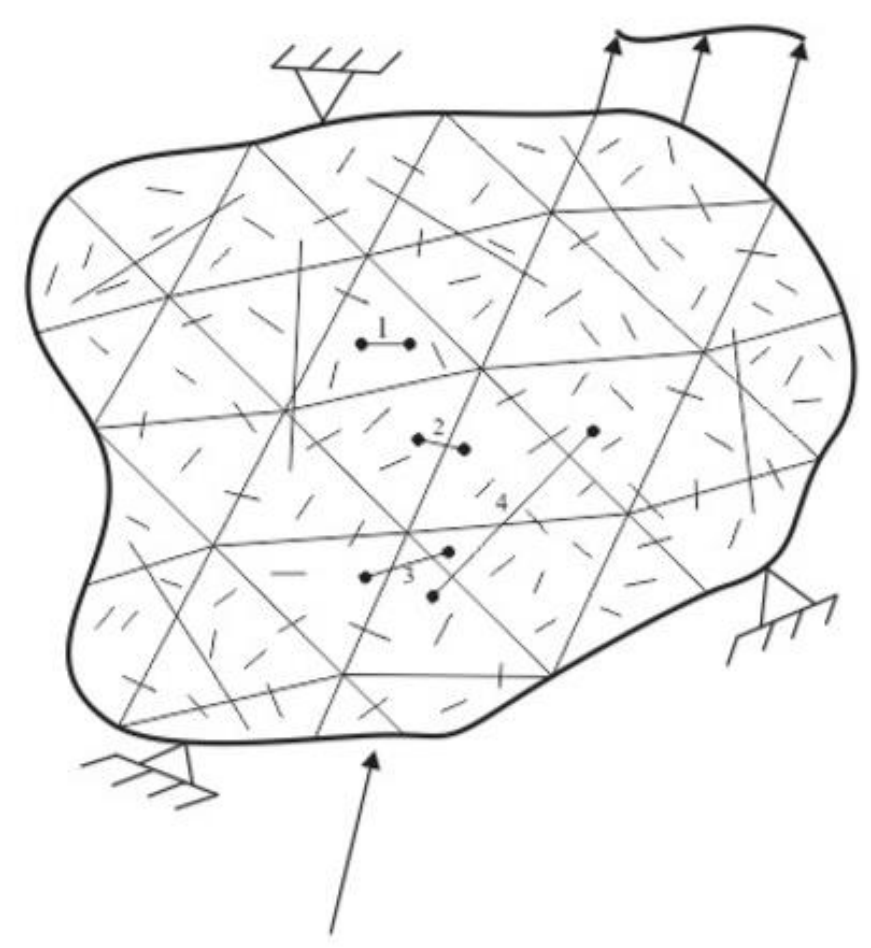

Fonte: Sampaio, 2014 
Para expandir a matriz Hessiana local da fibra em uma matriz de ordem ( $4 \mathrm{~N} \mathrm{x} 4 \mathrm{~N})$, onde N é o número de nós dos elementos de chapa obtido pela Equação 4.16, faz-se o uso da matriz de transformação expressa na Equação 3.39. Dessa forma, a operação matricial da Equação 4.38 resulta em uma matriz de hessiana expandida para cada fibra contida no domínio que deve contribuir na matriz hessiana global do problema.

$$
\begin{aligned}
{\left[H_{f}\right]_{4 N x 4 N}=\left[\phi^{\beta}\right]_{4 N x 4}^{t} \cdot\left[H^{f}\right]_{4 x 4 \cdot} \cdot\left[\phi^{\beta}\right]_{4 x 4 N} } \\
{\left[\phi^{\beta}\right]_{4 x 4 N}=\left[\begin{array}{cccccccccccc}
\phi_{1}^{i} & 0 & \phi_{2}^{i} & \ldots & \phi_{n}^{i} & 0 & 0 & 0 & 0 & \ldots & 0 & 0 \\
0 & \phi_{1}^{i} & 0 & \ldots & 0 & \phi_{n}^{i} & 0 & 0 & 0 & \ldots & 0 & 0 \\
0 & 0 & 0 & \ldots & 0 & 0 & \phi_{1}^{j} & 0 & \phi_{2}^{j} & \ldots & \phi_{n}^{j} & 0 \\
0 & 0 & 0 & \ldots & 0 & 0 & 0 & \phi_{1}^{j} & 0 & \ldots & 0 & \phi_{n}^{j}
\end{array}\right] } \\
=\left[\begin{array}{cc}
{\left[\phi_{1}^{i}\right]} & {[0]} \\
{[0]} & {\left[\phi_{1}^{j}\right]}
\end{array}\right]
\end{aligned}
$$

O subscrito e sobrescrito $\mathrm{f}$ em $[\mathrm{H}]$ fazem distinção entre a matriz Hessiana expandida da fibra reta a ser contribuída na matriz Hessiana global e a matriz Hessiana local, respectivamente. Na Equação 4.39 os índices $i$ e $j$ referem-se aos nós iniciais e finais da fibra.

De forma similar à da matriz Hessiana, utilizando a mesma matriz de funções de forma, Equação 4.39, a compatibilização das forças internas é calculada conforme a Equação 4.40.

$$
\left\{F_{f}\right\}_{4 N x 1}=\left[\phi^{\beta}\right]_{4 N x 4}^{t} \cdot\left\{F^{f}\right\}_{4 x 1}
$$

Destaca-se que a malha das fibras é gerada independentes da malha da matriz, ou seja, é necessário conhecer a que elemento de chapa pertence o nó da fibra para proceder à contribuição. Por meio desse método, a contribuição de rigidez da armadura ocorre pela distribuição da rigidez dos nós iniciais e finais dos elementos de barra para os nós do elemento de chapa nos quais esses nós estão inseridos.

Como limitação dessa técnica, apesar de não ser um problema físico, deve-se tomar cuidado na discretização da armadura para que não haja elementos de chapa entre os nós iniciais e finais da fibra (fibra 4 da Figura 4.10) para a geração da malha. Portanto, deve-se ter um refinamento da malha compatível com a discretização da armadura para garantir a 
compatibilidade do tamanho dos elementos e assegurar uma boa representatividade dos resultados.

Para a determinação das coordenadas adimensionais de um ponto cartesiano é necessário resolver um sistema não linear. A estratégia para a resolução desse sistema de equações é através do método de Newton-Raphson.

Sendo $\left(\xi_{1}^{p}, \xi_{2}^{p}\right)$ o par de variáveis adimensionais do domínio bidimensional, $\phi_{l}$ as funções de forma desse domínio, $X_{i}^{p}$ as coordenadas dos nós da fibra e $\widehat{X}_{i}^{l}$ as coordenadas dos nós do elemento, pode-se escrever a Equação 4.41.

$$
X_{i}^{p}=\phi_{l}\left(\xi_{1}^{p}, \xi_{2}^{p}\right) \hat{X}_{i}^{l}
$$

Expandindo a Equação 4.41 em série de Taylor para um par de coordenadas adimensionais tentativas $\left(\xi_{1}^{t}, \xi_{2}^{t}\right)$, tem-se:

$$
X_{i}^{p} \cong \phi_{l}\left(\xi_{1}^{t}, \xi_{2}^{t}\right) \hat{X}_{i}^{l}+\left.\frac{\partial \phi_{l}\left(\xi_{1}, \xi_{2}\right) \hat{X}_{i}^{l}}{\partial \xi_{j}}\right|_{\left(\xi_{1}^{t}, \xi_{2}^{t}\right)} \Delta \xi_{j} \quad \text { ou } \quad X_{i}^{p}=X_{i}^{t}+\mathrm{H}_{\mathrm{ij}} \Delta \xi_{j}
$$

Em que:

$X_{i}^{t}$ é a posição tentativa dos nós da fibra calculada a partir da geometria do elemento e das coordenadas adimensionais tentativa

$H_{i j}$ é uma matriz bidimensional de ordem $2 \times 2$

$\Delta \xi_{j}$ é a correção obtida resolvendo o sistema.

Para verificar se o nó testado se encontra dentro do elemento, é necessário que o par de coordenadas adimensionais encontrado na resolução do sistema não linear (Equação 4.43) seja positivo e que $\xi_{1}+\xi_{2} \leq 1$.

$$
\mathrm{H}_{\mathrm{ij}} \Delta \xi_{j}=X_{i}^{p}-X_{i}^{t}
$$


O valor tentativa necessário para o método de Newton-Raphson é calculado conforme Vanalli (2004), que apresentou uma solução para elementos de três nós com aproximação linear, conforme a Equação 4.44, considerando que as variáveis respeitem a relação cíclica $\alpha=1,2,3 ; m=2,3,1 ; k=3,1,2$.

$$
\xi_{\alpha}^{q}=\frac{1}{2 A}\left(2 A_{0}^{\alpha}+b^{\alpha} x_{1}^{q}+\alpha^{\alpha} x_{2}^{q}\right)
$$

Em que:

$a^{\alpha}=x_{1}^{k}-x_{1}^{m}$

$b^{\alpha}=x_{2}^{m}-x_{2}^{k}$

$2 A_{0}^{\alpha}=x_{1}^{m} x_{2}^{k}-x_{1}^{k} x_{2}^{m}$

$A=\frac{1}{2}\left(b^{1} a^{2}-b^{2} a^{1}\right)$

Como é considerada a perfeita aderência entre a fibra e a matriz, a posição atual dos nós da fibra em função das posições dos nós do elemento bidimensional é calculada conforme a Equação 4.45, em que $\hat{Y}_{i}^{l}$ é a posição atual dos nós do elemento da matriz.

$$
Y_{i}^{p}=\phi_{l}\left(\xi_{1}^{p}, \xi_{2}^{p}\right) \hat{Y}_{i}^{l}
$$

De maneira análoga, a formulação para a análise não linear geométrica do sólido elástico bidimensional reforçado segue a mesma rotina de cálculo. No presente trabalho, uma malha de elementos triangulas com aproximação linear foi adicionada na malha original (viga) para representar a recuperação (adição de novo matéria) na estrutura.

O trabalho de Moura (2015) descreve a análise bidimensional para compósitos particulados detalhando o roteiro de cálculo que foi utilizado, ou seja, a forma de consideração do reforço sem o acréscimo de graus de liberdade ao problema e sem a necessidade de coincidência de malhas entre estrutura existente e material reforçante.

Assim, a estratégia utilizada para o acoplamento de partículas foi apresentada por Moura (2015). Dessa forma, maiores detalhes podem ser encontrados no referido trabalho. 


\subsection{Exemplo 4.3: Validação acoplamento Fibra-Matriz}

Neste exemplo, o objetivo é validar o acoplamento fibra (barras) x matriz (chapa) em uma análise com grandes deslocamentos. Essa situação é ilustrativa e fictícia utilizada para a validação do acoplamento considerando a não linearidade geométrica. Para isso, este item simula uma viga de concreto armado engastada - livre e submetida a um carregamento distribuído.

O problema analisado é representado na Figura 4.11. A viga possui comprimento $L=$ $3 \mathrm{~m}$ com um carregamento uniformemente distribuído na face superior de $q=25 \mathrm{MN} / \mathrm{m}^{2}$. A malha da matriz utilizada possui 4582 nós e 986 elementos triangulares de aproximação cúbica; a malha dos elementos de barra utilizados possui 402 nós e 400 elementos com aproximação linear.

A seção transversal é retangular com $b=20 \mathrm{~cm}$ e $h=60 \mathrm{~cm}$. O material da matriz possui módulo de elasticidade $E=21 G P a$ e $v=0,0$. As armaduras de aço possuem módulo de elasticidade $E=210 \mathrm{GPa}$, área da seção transversal $A=2 \cdot 10^{-4} \mathrm{~m}^{2}$ e cobrimento $c=$ 2,67 cm. Os resultados foram comparados com os obtidos por Pereira (2015).

Figura 4.11- Geometria e condições de contorno

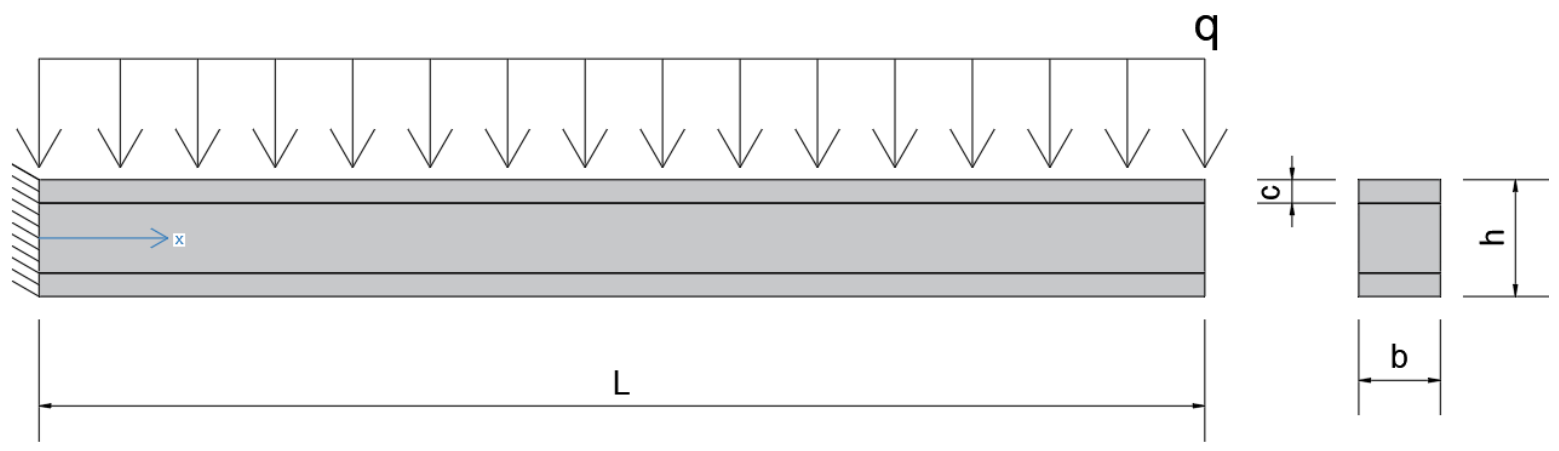

O maior deslocamento vertical obtido em Pereira (2015) foi de 63,292 centímetros. Os resultados para o último passo de carga no presente trabalho encontram-se na Figura 4.12. Desta forma, é possível confirmar o bom desempenho da formulação para problemas de acoplamento considerando grandes deslocamentos. 
Figura 4.12- Deslocamento vertical (m)
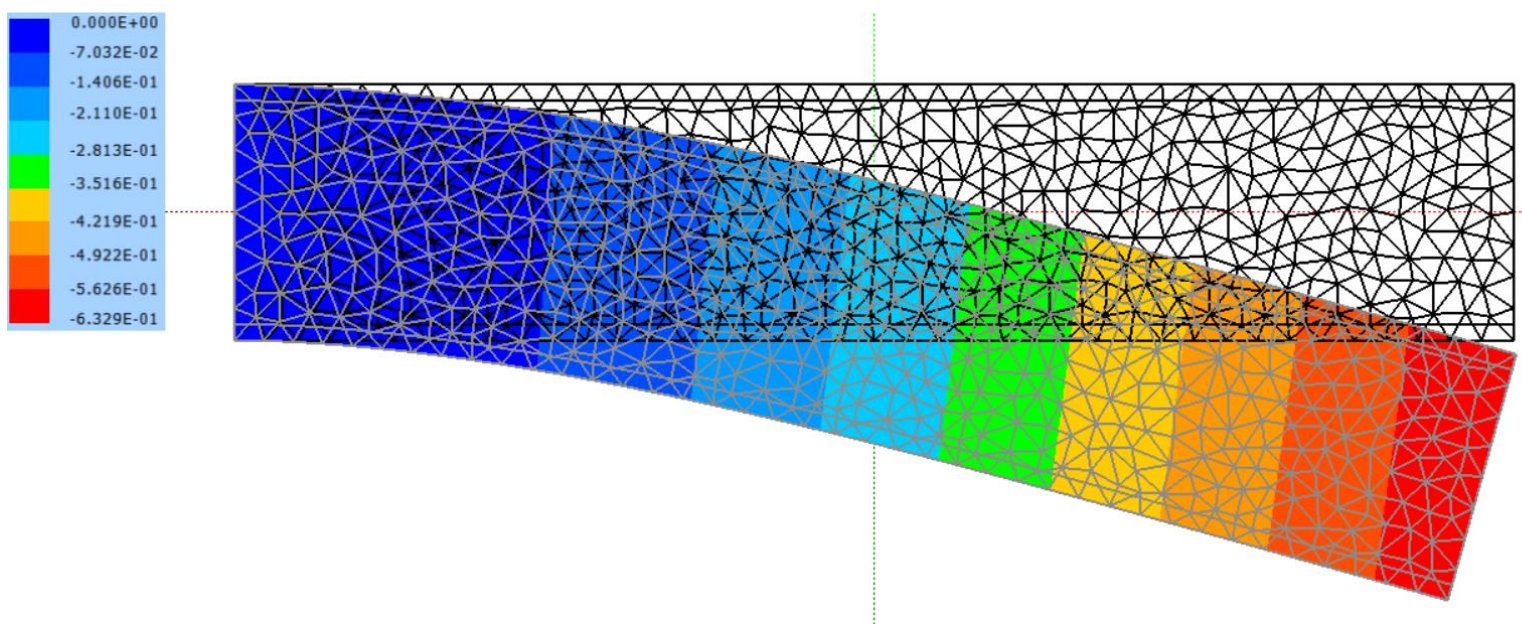

Comparativamente, a Figura 4.13 mostra os resultados deste exemplo para a mesma situação (materiais e carregamento). O gráfico foi montado considerando 20 passos de carga, com os resultados com e sem armadura. Conforme o esperado, a adição das fibras para representar as barras de aço enrijeceu a estrutura.

Figura 4.13- Comparação do exemplo: com e sem armadura

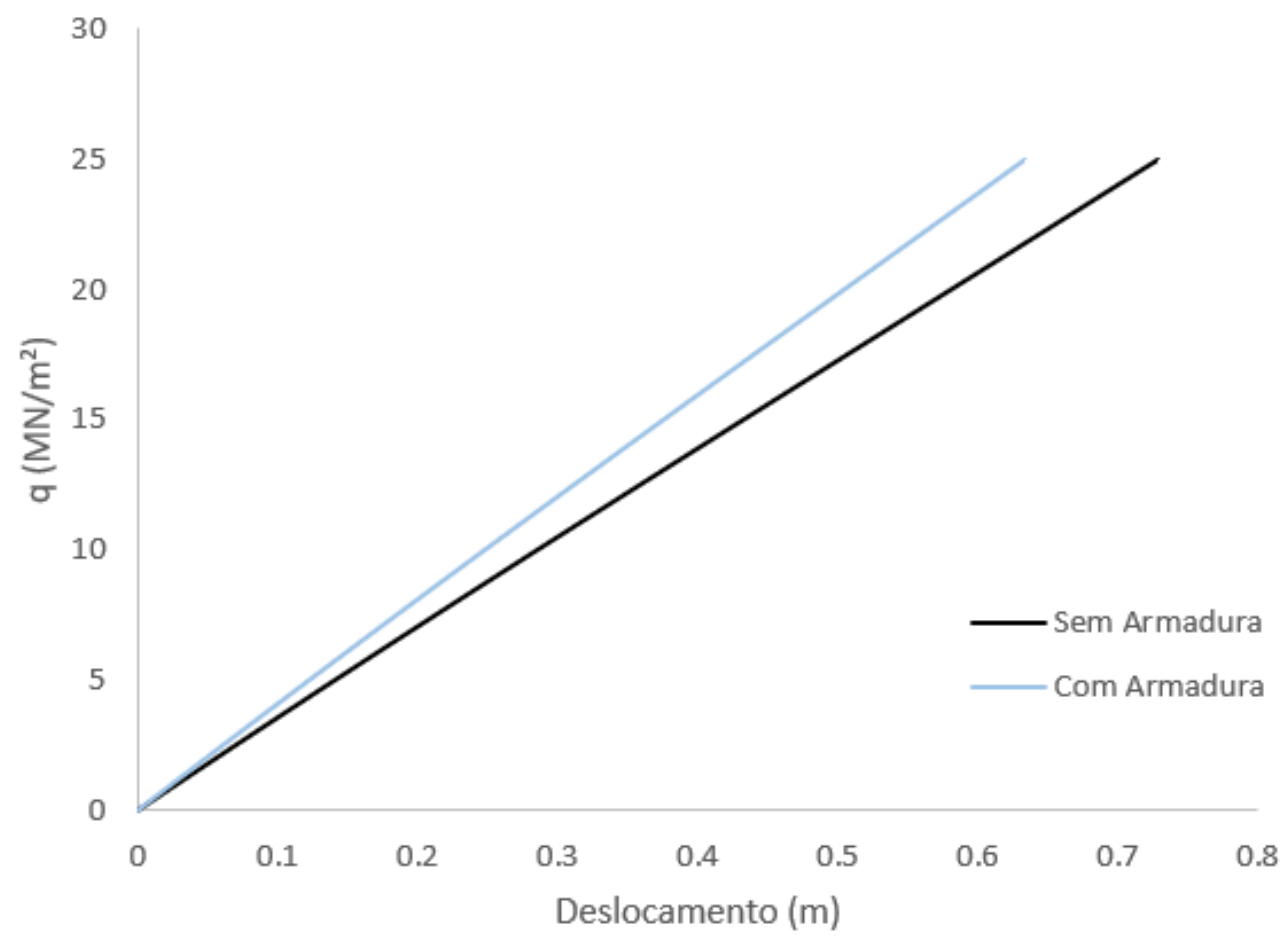




\subsection{Exemplo 4.4: Validação acoplamento Partícula-Matriz}

Esta aplicação visa validar o acoplamento entre os elementos de chapa com aproximação linear (partículas) com os elementos de chapa da matriz. Para isso, este exemplo verifica a influência das propriedades, geometria e fração volumétrica dos agregados graúdos na avaliação do módulo de elasticidade longitudinal de concretos leves. As análises foram realizadas considerando células periódicas. Os resultados obtidos foram comparados com Moura (2015), que teve como referência o trabalho numérico utilizando a técnica de Homogeneização por Expansão Assintótica (AEH) de Farage et al. (2009).

Em relação às propriedades físicas, para a argamassa (matriz) foram utilizados 442 elementos (2062 nós) com módulo de elasticidade $E=28.58 \mathrm{GPa}$ e coeficiente de Poisson $v=0.2$. Para o agregado (partículas), foram utilizados 364 elementos (205 nós) com $E=$ 6.47 GPa e $v=0.2$. A fração volumétrica empregada foi de $45 \%$, como ilustra a Figura 4.14. Conforme apresentado anteriormente, a malha das partículas não coincide com a malha da matriz.

Figura 4.14- Célula periódica: fração volumétrica $45 \%$

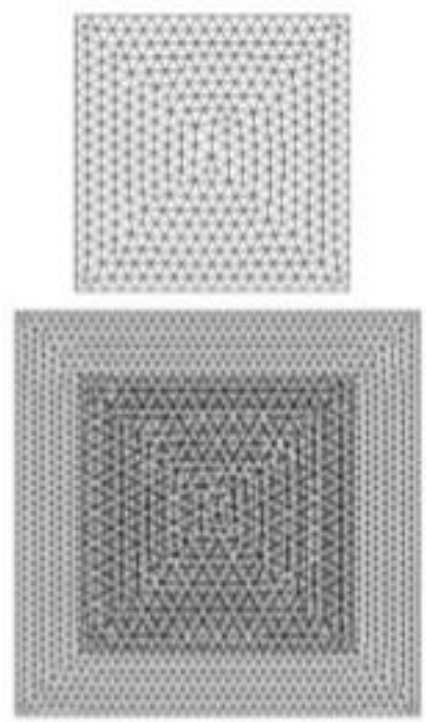

FONTE: Moura (2015)

A simulação numérica foi realizada com controle de deslocamento em uma das faces e, na face oposta, foram adicionadas as vinculações. O deslocamento prescrito utilizado foi da 
ordem de $10^{-3}$ da dimensão da célula utilizada (matriz). Desta forma, a análise foi realizada no regime dos pequenos deslocamentos e pequenas deformações, sendo possível a aplicação direta da Lei de Hooke para a obtenção do valor do módulo de elasticidade longitudinal do concreto $\left(E_{c}\right)$ homogeneizado.

Os resultados da simulação encontram-se na Figura 4.15. Pode-se observar o comportamento linear desejado. O módulo de elasticidade obtido no presente trabalho foi de 15.5 GPa. Para essa situação, Moura (2015) obteve, por meio do MEF-P, $E_{c}=15.65$ GPa e Farage et al. (2009) pela análise numérica via MEF e AEH obteve $E_{c}=15.61 \mathrm{GPa}$.

Figura 4.15- Curva força x deslocamento para a extremidade da célula

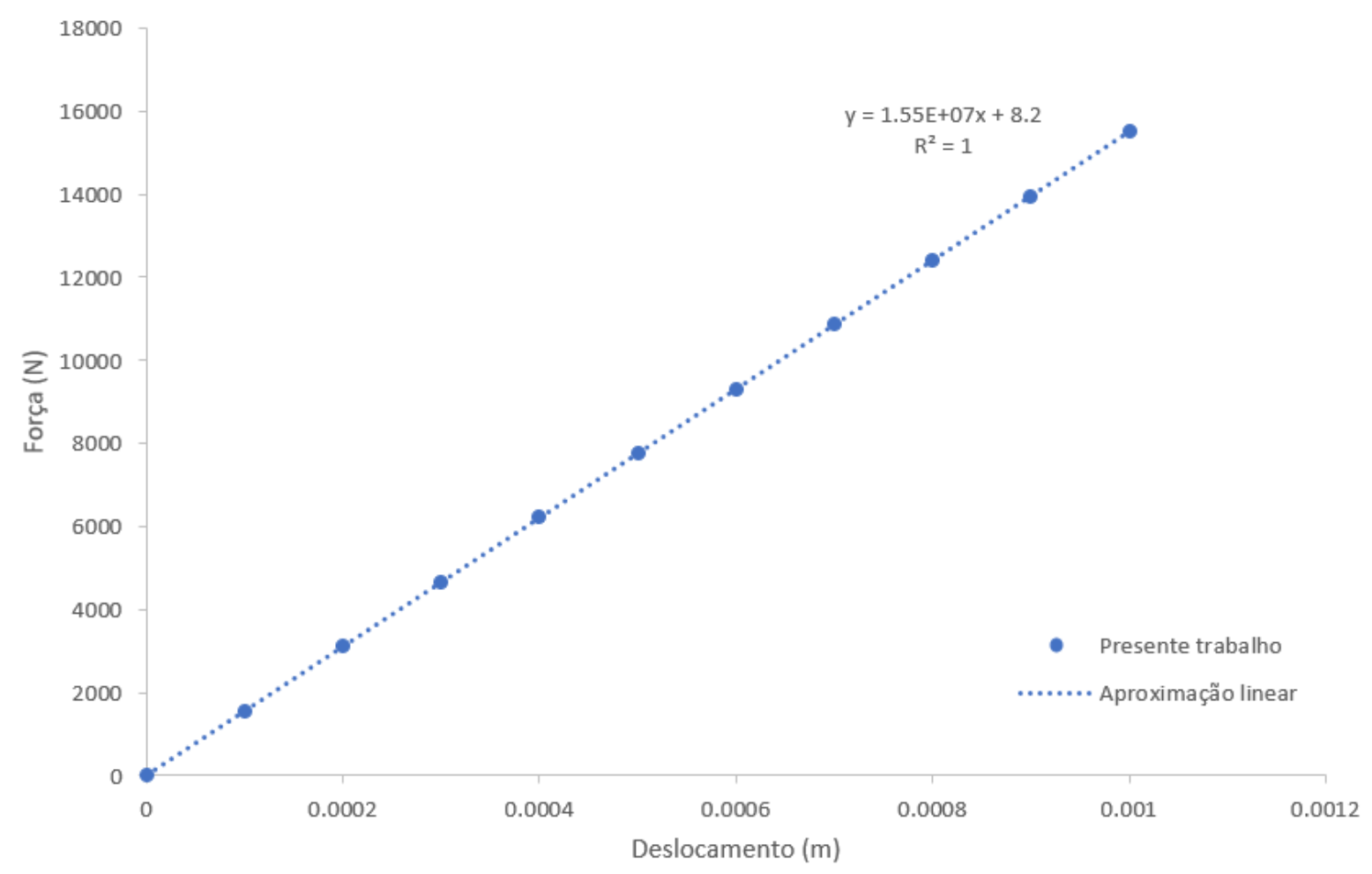

As pequenas diferenças entre os resultados encontrados neste trabalho são, possivelmente, devidas às diferentes malhas utilizadas, tanto para a matriz quanto para as partículas em relação ao trabalho de Moura (2015). Um refinamento maior (Moura (2015) utilizou 3632 elementos para a matriz) pode levar a resultados mais precisos. 


\subsection{Exemplo 4.5: Acoplamento Partícula-Matriz}

Para uma análise complementar do comportamento do código implementado frente ao acoplamento da matriz com as partículas, este exemplo foi feito em duas partes. Primeiramente, foi analisada a resposta de apenas um elemento de chapa com aproximação cúbica submetida à uma situação de carregamento concentrado.

Para a segunda análise, tanto o módulo de elasticidade quanto a espessura dos elementos de chapa da matriz foram penalizados para que ficassem próximos de zero, enquanto o módulo de elasticidade e a espessura das partículas foram adotadas iguais à primeira situação. Foram também inseridas 9 partículas coincidentes com a malha da Figura 4.16, de forma que ambas situações fossem equivalentes e resolvessem o mesmo problema. Ressalta-se que 9 elementos com aproximação linear não são totalmente iguais ao único elemento com aproximação cúbica da primeira situação. Neste exemplo, há a coincidência dos nós para verificar a estratégia do acoplamento.

Figura 4.16- Geometria e condições de contorno

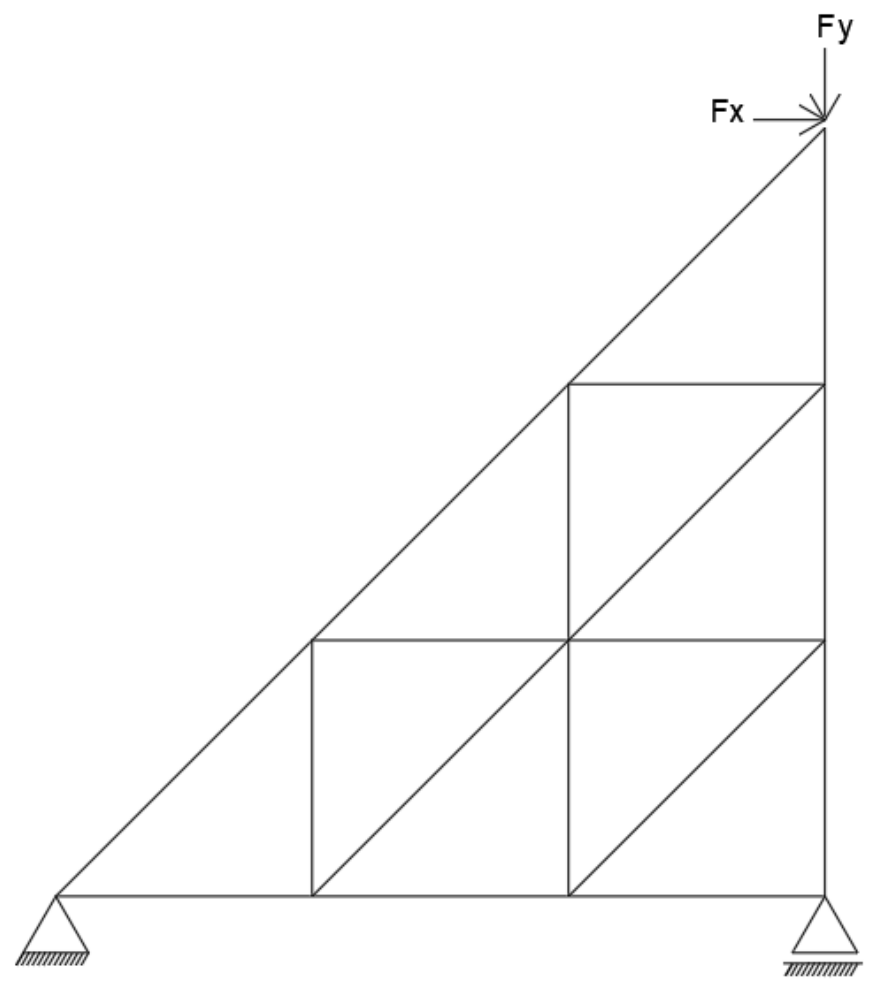


O elemento de chapa utilizado possui 10 metros de altura e 10 metros de largura. Foi adotado o módulo de elasticidade $E=20 G P a$ e o coeficiente de Poisson $v=0.0$. Aplicou-se uma força de $100 \mathrm{kN}$, tanto em x quanto em y, em 20 passos de carga. A Figura 4.17 ilustra os resultados obtidos para o elemento único de chapa com aproximação cúbica e a Figura 4.18 apresenta os resultados para os 9 elementos de partícula lineares acoplados na chapa de $E \approx 0$.

Figura 4.17- Primeira situação: (a) Deslocamento em x (m); (b) Deslocamento em y (m).

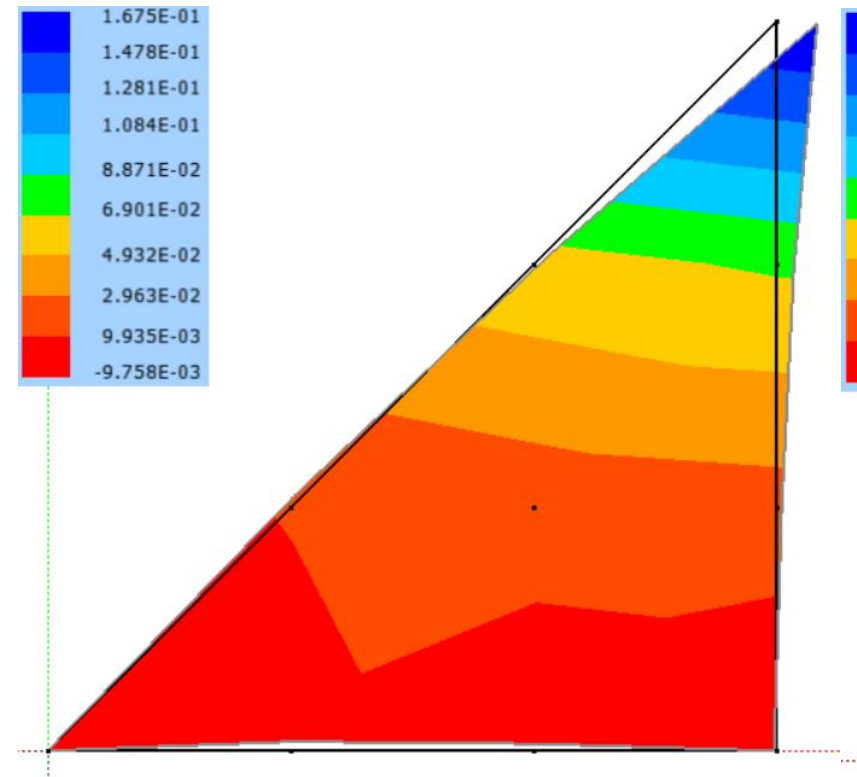

(a)

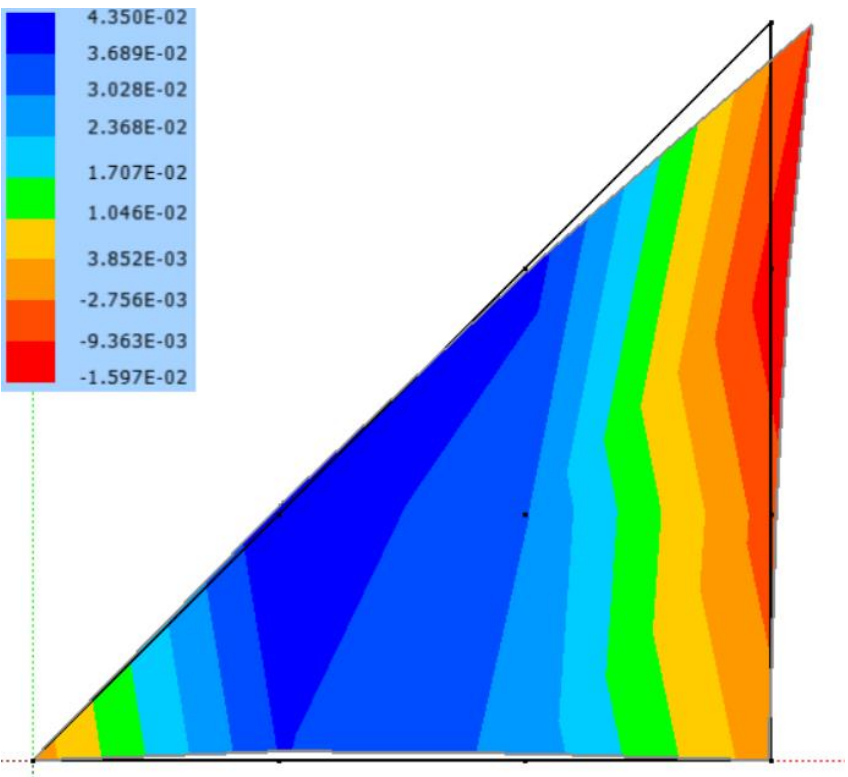

(b)

Figura 4.18- Segunda situação: (a) Deslocamento em x (m); (b) Deslocamento em y (m).

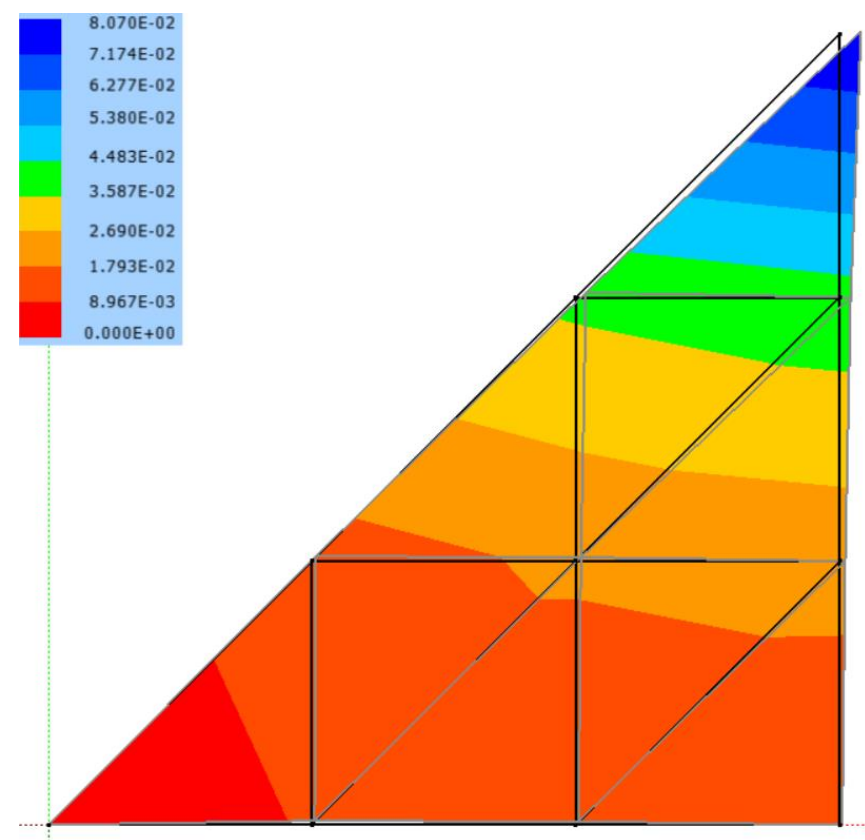

(a)

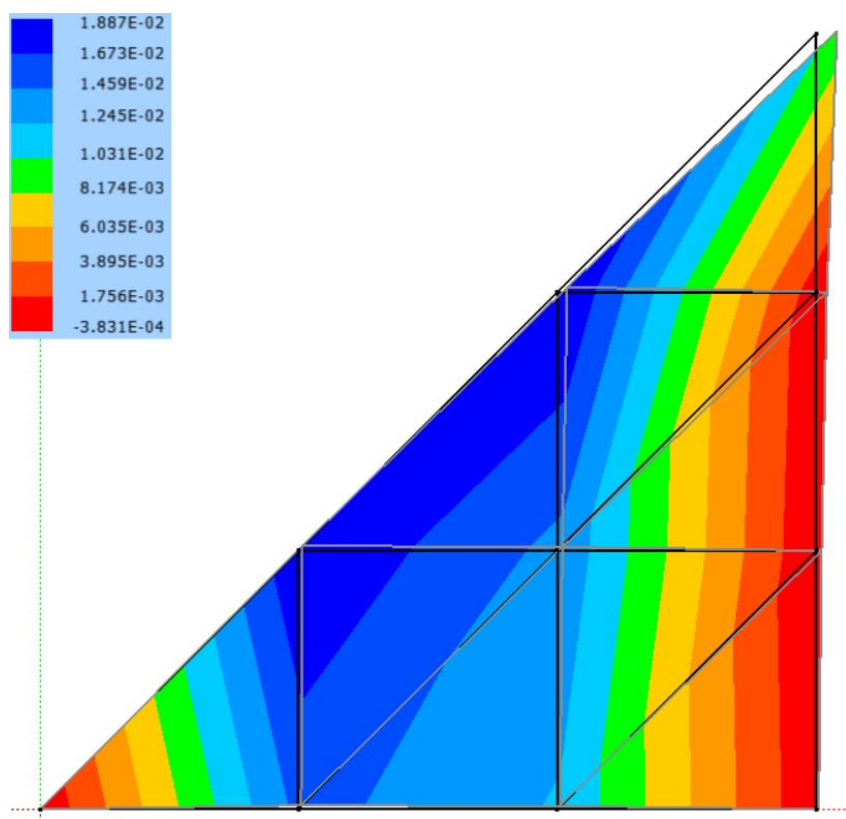

(b) 
Os resultados obtidos mostraram-se coerentes e dentro do esperado. A fim de verificar o comportamento da segunda situação (partículas acopladas na matriz sem rigidez), simulou-se a estrutura sem a matriz, ou seja, considerando um caso composto por 9 elementos de chapa com aproximação linear. Nesse caso, o resultado obtido coincide exatamente com o apresentado na Figura 4.18, como era esperado.

\subsection{Reforço e recuperação}

No presente trabalho, a simulação da recuperação e reforço de uma viga foi realizado empregando-se fases de carga diferentes. Para isso, em cada uma dessas fases uma determinada condição de análise foi considerada.

Primeiramente, com a viga modelada e a armadura acoplada aos elementos de chapa da viga com elementos de barra, foi iniciado o carregamento. A carga foi incrementada até que se atingiu o critério de parada adotado como indicativo da necessidade de recuperação e reforço. Para este trabalho, o critério foi definido com base no nível de dano da estrutura, sendo que esse tipo de não linearidade física foi levado em conta na formulação por meio da implementação do modelo de dano de Mazars.

A seguir, a estrutura foi macaqueada em pontos escolhidos para posição inicial, sem a remoção do carregamento. Com a estrutura macaqueada, prosseguiu-se com a reabilitação da estrutura, que foi feita em duas partes: a recuperação do concreto e o reforço na flexão com a adição de manta polimérica. Para representar o reforço na flexão por meio de mantas, foram inseridos elementos de barra na região inferior da viga.

De forma análoga ao acoplamento das fibras, que representam as barras de aço na matriz cimentícia e o reforço da estrutura, a recuperação do concreto foi realizada com base na estratégia de inclusão de partículas, baseado em Moura (2015) para representar o material utilizado na recuperação da viga. Para isso, os elementos de chapa substituídos tiveram as suas constantes elásticas penalizadas. As partículas adicionadas foram de elementos triangulares com aproximação linear.

Por fim, a estrutura foi liberada para deslocar-se livremente. 


\subsection{Fases de carga: estratégia numérica para reforço/recuperação da viga}

Conforme comentado, o procedimento para reforço e recuperação adotado no presente trabalho conta com 6 fases de carga para a análise do problema. Segue abaixo os detalhes e características de cada uma delas.

1. Carregamento: a viga, inicialmente descarregada, sofreu um carregamento crescente. Essa fase foi cessada quando atingido o critério de parada com base no dano de Mazars.

2. Macaqueamento: com a viga ainda carregada, a estrutura foi macaqueada em pontos pré-definidos para a sua posição inicial.

3. Retirada de material: a região da estrutura a ser recuperada teve seus elementos penalizados a fim de remover o material danificado.

4. Recuperação: novos elementos foram adicionados por meio de uma malha de partículas (elementos triangulares com aproximação linear) para representar um novo material íntegro na viga.

5. Reforço: o reforço foi adicionado na região inferior (na forma de fibra) para representar a manta utilizada como reforço na flexão. Ressalta-se que, após a fase do carregamento, a carga atuante não foi modificada, ou seja, todos os deslocamentos obtidos são referentes à estrutura carregada

6. Deslocamento livre: após a reabilitação, a viga foi solta para deslocar-se livremente para a análise do novo comportamento estrutural. Nessa última fase, a carga total utilizada foi $10 \%$ maior do que o carregamento do critério de parada. 
76 | Formulação NLG Aplicada à Problemas Estáticos 


\section{MECÂNICA DO DANO}

\subsection{Considerações iniciais}

O comportamento mecânico de estruturas após o processo de plastificação e fissuração é representado com maior precisão por meio de análises não lineares físicas. As três maiores teorias que descrevem o processo de falha mecânica do material são: teoria da plasticidade, mecânica da fratura e mecânica do dano.

A teoria da plasticidade é utilizada, principalmente, para a representação do comportamento de materiais dúcteis e é assumida a hipótese de continuidade do material. Nessa teoria, a determinação dos limites entre o regime plástico e elástico é realizada através de um critério de resistência. Dessa forma, essa abordagem não contempla as descontinuidades e nem considera a redução de resistência do material após a carga crítica ser atingida. O início da teoria da plasticidade deu-se com o trabalho de Tresca (1864), no qual foi proposto um critério de plastificação em que um metal se deforma plasticamente quando a máxima tensão de cisalhamento atinge o valor limite.

A mecânica da fratura representa a degradação de um material por meio das fissuras presentes. O crescimento e a evolução da degradação são representados pela propagação das fissuras. O estudo da mecânica da fratura teve início com o engenheiro alemão Kirsch (1898), que resolveu, de forma analítica, o problema de uma chapa tracionada com um furo circular e observou o aumento das tensões normais nas regiões das bordas do furo.

Por fim, a mecânica do dano começou a se desenvolver após o trabalho de Kachanov (1958), que estudou a ruptura de materiais em regime de deformação lenta e introduziu a variável dano para a medição de deterioração. A mecânica do dano contínuo foi formalizada com base na termodinâmica dos processos irreversíveis por Lemaitre e Chaboche (1985). Em relação ao estudo clássico do dano, a teoria desenvolvida por Mazars (1984) é uma das mais utilizadas devido à sua simplicidade. Os trabalhos que utilizam a modelagem mecânica baseada nos conceitos de dano de Mazars apresentam bons resultados (SANCHES JUNIOR; VENTURINI, 2007; PITUBA; LACERDA, 2012).

Na mecânica do dano o material é tratado assumindo a hipótese da continuidade. Nessa teoria, as microfissuras são consideradas como distribuídas de forma aleatória e homogênea ao longo do material, sendo as propriedades mecânicas do material alteradas em função do grau de degradação. Dessa forma, a perda de rigidez é efetuada por meio do parâmetro dano. 
No âmbito do estudo do dano, a teoria desenvolvida por Mazars (1984) é uma das mais utilizadas devido à sua simplicidade e por esse motivo foi escolhida para ser aplicada neste trabalho. Este capítulo segue a abordagem e formulação descrita em Leonel (2018) para a apresentação do Modelo de Dano de Mazars.

\subsection{Parâmetros gerais}

Empregando-se o modelo de dano isotrópico, a variável dano penaliza igualmente a rigidez do material em todas as direções. A variável dano, D, é definida como sendo a razão entre as áreas danificadas e totais de uma seção, conforme a Equação 5.1. Nota-se que a variável D se encontra no intervalo $0 \leq D \leq 1$ e que quanto mais próximo de zero, menor o dano no material.

$$
D=\frac{S_{0}}{S}
$$

Em que:

$\mathrm{S}_{0}$ é a área danificada

S é a área total

D é a variável dano.

A área útil é definida como sendo a diferença entre a área total e a área danificada (Equação 5.2).

$$
\widetilde{S}=S-S_{0}
$$

Em que $\tilde{S}$ é a área útil.

Sendo a tensão efetiva a relação entre a força e a área útil, pode-se obter a tensão efetiva em função da variável dano, conforme apresenta a Equação 5.3. 


$$
\tilde{\sigma}=\frac{F}{\widetilde{S}}=\frac{F}{\left(\frac{S}{S}-\frac{S_{0}}{S}\right) \cdot S} \rightarrow \quad \tilde{\sigma}=\frac{F}{(1-D) \cdot S}=\frac{\sigma}{1-D}
$$

Partindo da Lei de Hooke e utilizando a Equação 5.3, obtém-se a deformação considerando o dano na estrutura. Assim, a partir do denominador da Equação 5.4 pode-se definir um tensor com os módulos de elasticidade efetivos do material, conforme a Equação 5.5 .

$$
\varepsilon=\frac{\tilde{\sigma}}{E} \rightarrow \varepsilon=\frac{\sigma}{(1-D) \cdot E}
$$

Em que:

E é o módulo de elasticidade longitudinal

$\varepsilon$ é a deformação

$$
\widetilde{E}=(1-D) \cdot E
$$

\subsection{Modelo de Dano de Mazars}

Conforme Leonel (2018), os modelos de dano buscam representar as perdas progressivas de rigidez e resistência devido ao processo de degradação. Embora a degradação mecânica ocorra devido à presença de descontinuidades, a mecânica do dano trata o material como contínuo, penalizando a rigidez de forma homogênea. Dentre os modelos de dano encontrados na literatura, o de Mazars (1984), apesar de ser o mais simples, é capaz de apresentar adequadamente os processos de degradação estrutural.

Uma das características do modelo de Mazars é a consideração crescente de carregamento. Esse modelo assume que os efeitos mecânicos causados pelo descarregamento não são significativos. São ainda admitidas 4 hipóteses básicas para o modelo:

a) Na evolução do dano, o material apresenta o comportamento mecânico elástico;

b) O dano é causado somente pela existência de alongamentos. Para que haja evolução do dano, é preciso que pelo menos uma das componentes do tensor de deformações principais seja de tração; 
c) Análises experimentais evidenciam que a degradação mecânica conduz a um estado de anisotropia induzida no material. Para reduzir o número de variáveis internas, o modelo é simplificado considerando-se o dano isótropo, ou seja, o estado de danificação em um ponto é definido por uma única grandeza escalar, sendo a mesma para todas as direções;

d) O dano é representado localmente por uma variável escalar D, que pode variar de zero a um. A evolução da variável de dano ocorre quando um determinado valor de referência para o alongamento (deformação) é superado pela deformação equivalente.

Sendo $\left(\varepsilon_{i}\right)_{+}^{2}$ as componentes positivas do tensor de deformações principais, de forma que $\varepsilon_{i}=\varepsilon_{i}$ se $\varepsilon_{i}>0$ e $\varepsilon_{i}=0$ se $\varepsilon_{i} \leq 0$, a grandeza deformação equivalente (Equação 5.6) é utilizada para representar o estado do alongamento em um determinado ponto material.

$$
\tilde{\varepsilon}=\sqrt{\left(\varepsilon_{1}\right)_{+}^{2}+\left(\varepsilon_{2}\right)_{+}^{2}+\left(\varepsilon_{3}\right)_{+}^{2}}
$$

Na convenção adotada pelo modelo, o início da danificação material ocorre quando o valor da deformação equivalente atingir o valor dado pela deformação correspondente ao pico de tensão em um ensaio uniaxial de tração, o $\varepsilon_{d 0}$. De acordo com a ABNT NBR 6118:2014, na falta de resultados experimentais de resistência à tração para o concreto, pode-se considerar um valor médio (Equação 5.7), um valor característico inferior (Equação 5.8) ou um valor característico superior (Equação 5.9).

$$
\begin{gathered}
f_{c t, m}= \\
=\left\{\begin{array}{r}
0,3 \cdot \sqrt[3]{f_{c k}^{2}} \\
2,12 \cdot \ln \left(1+0,11 \cdot f_{c k}\right) \\
\text { para concreto classe entre as classes } C 55 \text { e } C 90
\end{array}\right. \\
f_{c t k, \text { inf }}=0,7 \cdot f_{c t, m} \\
f_{c t k, \text { sup }}=1,3 \cdot f_{c t, m}
\end{gathered}
$$


Assumindo que a resistência à tração do concreto seja igual a seu valor inferior e aplicando a lei de Hooke, o valor da deformação normal é obtido conforme a Equação 5.10.

$$
\varepsilon_{d 0}=\frac{f_{c t k, i n f}}{E_{c i}}
$$

Em que $E_{\text {ci }}$ é o módulo de elasticidade longitudinal.

Com a função de resistência para determinar o estado de danificação do material definida conforme a Equação 5.11, percebe-se que a danificação terá início somente quando $f$ $=0$. Na primeira iteração do processo incremental, a variável $\tilde{S}(D)$ recebe o valor da deformação inicial $\varepsilon_{d 0}$.

$$
f(\widetilde{\varepsilon}, D)=\tilde{\varepsilon}-\widetilde{S}(D)
$$

Em que $\widetilde{S}$ representa a deformação equivalente em função do dano

Segundo o modelo de dano de Mazars, para o equacionamento adequado do comportamento mecânico de materiais são definidas duas variáveis independentes, $D_{t}$ e $D_{c}$. A Equação 5.12 mostra a variável de dano relacionada a tração e a Equação 5.13 a compressão. Essas variáveis são independentes e necessárias uma vez que o processo de fissuração acontece de maneira distinta para cada tipo de solicitação.

$$
\begin{aligned}
& D_{t}=1-\varepsilon_{d 0} \cdot \frac{\left(1-A_{t}\right)}{\tilde{\varepsilon}}+\frac{A_{t}}{e^{\left[B_{t} \cdot\left(\tilde{\varepsilon}-\varepsilon_{d 0}\right)\right]}} \\
& D_{c}=1-\varepsilon_{d 0} \cdot \frac{\left(1-A_{c}\right)}{\tilde{\varepsilon}}+\frac{A_{c}}{e^{\left[B_{c} \cdot\left(\tilde{\varepsilon}-\varepsilon_{d 0}\right)\right]}}
\end{aligned}
$$

Em que $A_{t}, B_{t}, A_{c}, B_{c}$ e $\varepsilon_{d 0}$ são parâmetros característicos do material.

Mazars (1984) propõe limites de variação para esses parâmetros internos do modelo baseado nas análises experimentais:

$$
0,7 \leq A_{t} \leq 1,0
$$




$$
\begin{gathered}
1,0 \leq A_{c} \leq 1,5 \\
10^{4} \leq B_{t} \leq 10^{5} \\
10^{3} \leq B_{c} \leq 2,0.10^{3} \\
10^{-5} \leq \varepsilon_{d 0} \leq 10^{-4}
\end{gathered}
$$

Dessa forma, a variável dano pode ser definida como uma combinação linear de $D_{t} e$ $\mathrm{D}_{\mathrm{c}}$, conforme a Equação 5.14

$$
D=\alpha_{t} \cdot D_{t}+\alpha_{c} \cdot D_{c}
$$

Em que:

$\alpha_{t}=\frac{\sum_{i}\left(\varepsilon_{T i}\right)_{+}}{\varepsilon_{V^{+}}}$

$\alpha_{c}=\frac{\sum_{i}\left(\varepsilon_{C i}\right)_{+}}{\varepsilon_{V^{+}}}$

$\varepsilon_{V^{+}}=\sum_{i}\left(\varepsilon_{T i}\right)_{+}+\sum_{i}\left(\varepsilon_{C i}\right)_{+}$

$\varepsilon_{T}=\frac{1+v}{E} \cdot \sigma_{+}-\frac{v}{E} \cdot \sum_{i}\left(\sigma_{i}\right)_{+} \cdot I ;$

$\varepsilon_{C}=\frac{1+v}{E} \cdot \sigma_{-}-\frac{v}{E} \cdot \sum_{i}\left(\sigma_{i}\right)_{-} . I$

I é o tensor identidade de quarta ordem;

E é o módulo de elasticidade longitudinal do material;

$v$ é o coeficiente de Poisson do material;

$\left(\sigma_{i}\right)_{+}$e $\left(\sigma_{i}\right)_{-}$são as partes positivas e negativas do tensor de tensões de um estado de tensão principal fictício, obtido a partir do estado de deformação atual.

Ressalta-se que o modelo foi implementado considerando diretamente a Lei de SaintVenant-Kirchhoff e os resultados de validação são apresentados a seguir. 


\subsection{Exemplos de validação}

A fim de validar as formulações implementadas, alguns exemplos numéricos são apresentados a seguir.

Assim, as últimas validações do presente trabalho consistem nas análises da implementação do modelo de dano de Mazars. Para isso, o primeiro exemplo consiste em um ensaio de compressão simples. No segundo exemplo, é verificado um ensaio de tração simples. Por fim, no terceiro exemplo, tem-se a análise do ensaio de uma viga de concreto a quatro pontos, comparando os resultados aos obtidos experimentalmente no trabalho de Álvarez (1993).

É importante mencionar que o valor do dano crítico utilizado foi o mesmo para todos os exemplos e foi adotado conforme a Equação 5.15.

$$
D_{\text {crit }}=1-\frac{\text { tensão de ruptura }}{\text { tensão última }}=0,929
$$

\subsubsection{Exemplo 5.1: Compressão e Tração}

Neste exemplo, dois elementos de chapa com aproximação cúbica foram utilizados com o objetivo de simular um ensaio à compressão e tração simples no concreto. Para o modelo de dano, os valores dos parâmetros do modelo de dano de Mazars utilizados estão representados na Tabela 5.2. Os valores das constantes do modelo de dano foram adaptados de Álvares (1993) e seguiram as recomendações de Mazars (1984).

As propriedades elásticas adotadas foram: módulo de elasticidade de $E=32 \mathrm{GPa}$; coeficiente de Poisson $v=0,2$. Em relação à geometria, foram considerados elementos com altura e largura unitárias. A simulação foi realizada com controle de deslocamentos em 50 passos.

Tabela 5.2- Constantes para o modelo de dano

\begin{tabular}{|c|c|c|c|c|}
\hline $\boldsymbol{\varepsilon}_{\boldsymbol{d} 0}$ & $\boldsymbol{A}_{\boldsymbol{t}}$ & $\boldsymbol{B}_{\boldsymbol{t}}$ & $\boldsymbol{A}_{\boldsymbol{c}}$ & $\boldsymbol{B}_{\boldsymbol{c}}$ \\
\hline $1,08 \cdot 10^{-4}$ & 0,95 & 13000 & 1,00 & 1700 \\
\hline
\end{tabular}


A Figura 5.1 representa o problema de compressão simulado.

Figura 5.1- Geometria e condições de contorno

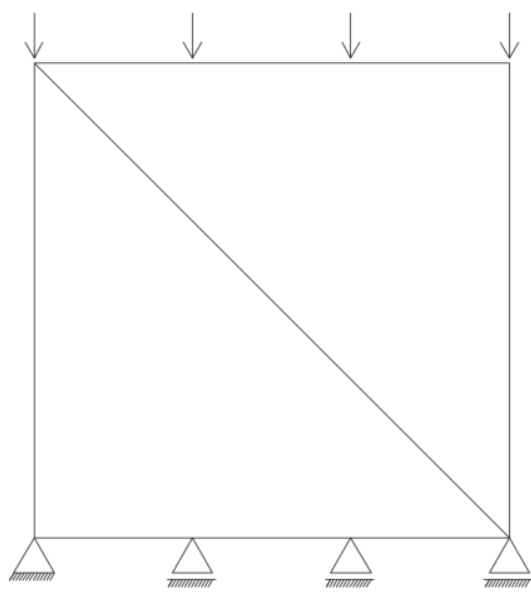

A Figura 5.2 contém os resultados obtidos para a relação tensão x deformação, comparando-se com os resultados apresentados em Álvares (1993). Conforme o esperado, a simulação sem a consideração de dano retornou com precisão apenas a parte elástica da curva do diagrama tensão x deformação. Por outro lado, pôde-se verificar que o modelo de dano implementado resulta em valores coerentes com os obtidos experimentalmente em Álvares (1993).

Figura 5.2- Curva tensão x deformação para ensaio de compressão

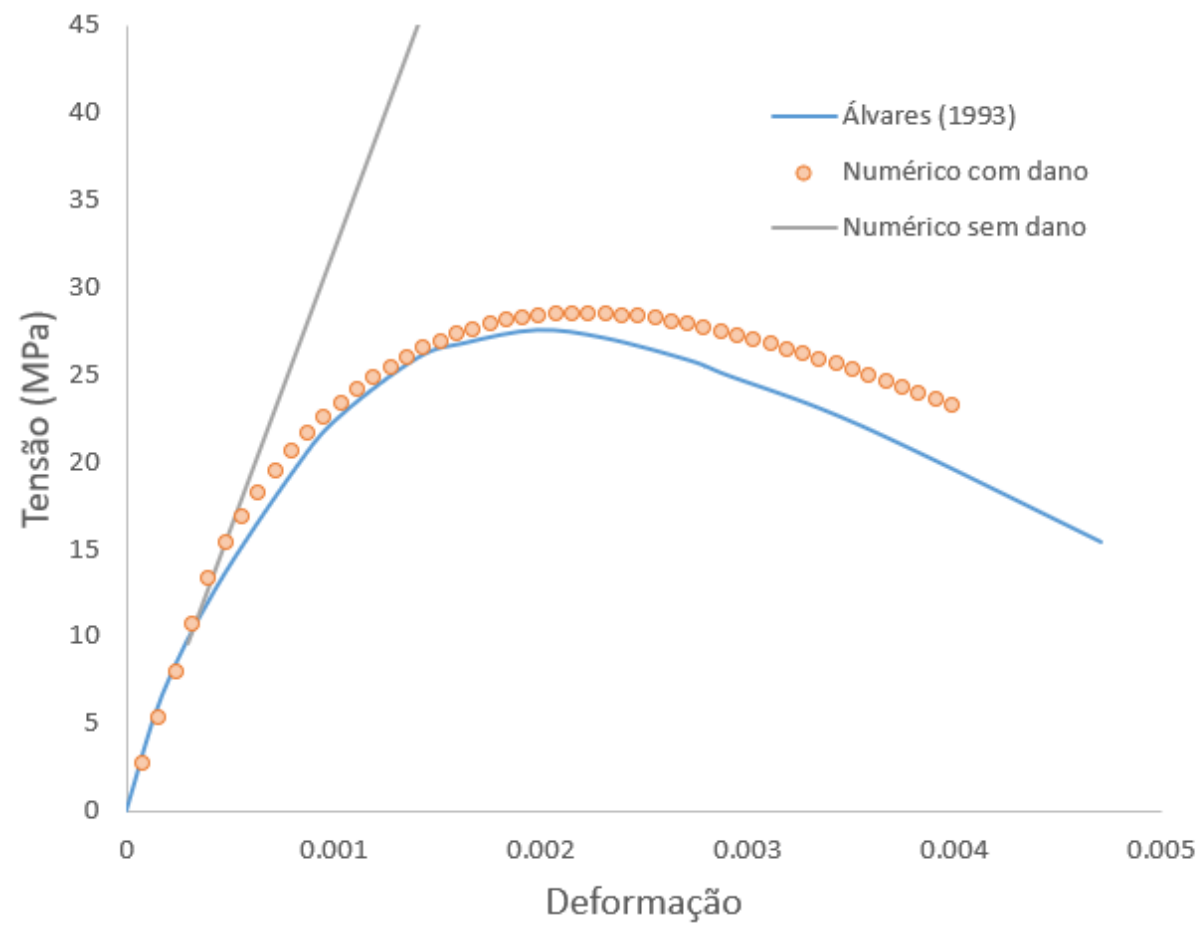


De maneira similar ao ensaio de compressão, foi simulada a situação de tração simples no concreto. O material utilizado, bem como as constantes elásticas e os parâmetros do modelo de Mazars, são os mesmos dos apresentados no Exemplo 5.1. A simulação foi realizada com controle de deslocamentos em 50 passos. A Figura 5.3 representa o problema simulado.

\section{Figura 5.3- Geometria e condições de contorno}

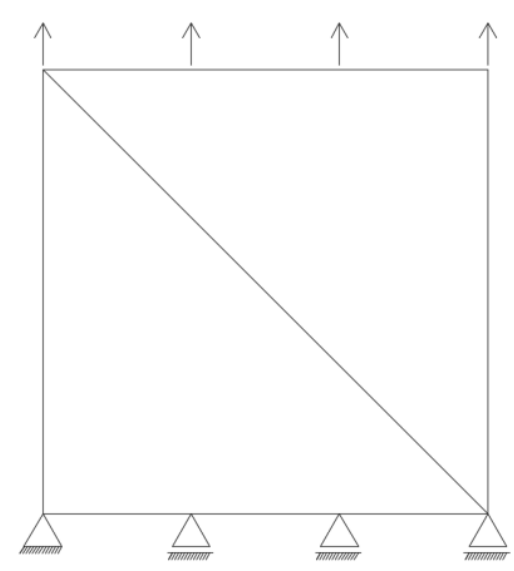

Na Figura 5.4 apresenta-se os resultados obtidos. Conclui-se, por meio destes dois exemplos, que a formulação implementada é compatível com o comportamento esperado do material. Embora haja uma diferença entre as curvas pós-pico experimental e numérica, por se tratar de um modelo simples de dano, acredita-se que os resultados possam ser considerados adequados para as simulações aqui desejadas. 
Figura 5.4- Curva tensão x deformação para ensaio de tração

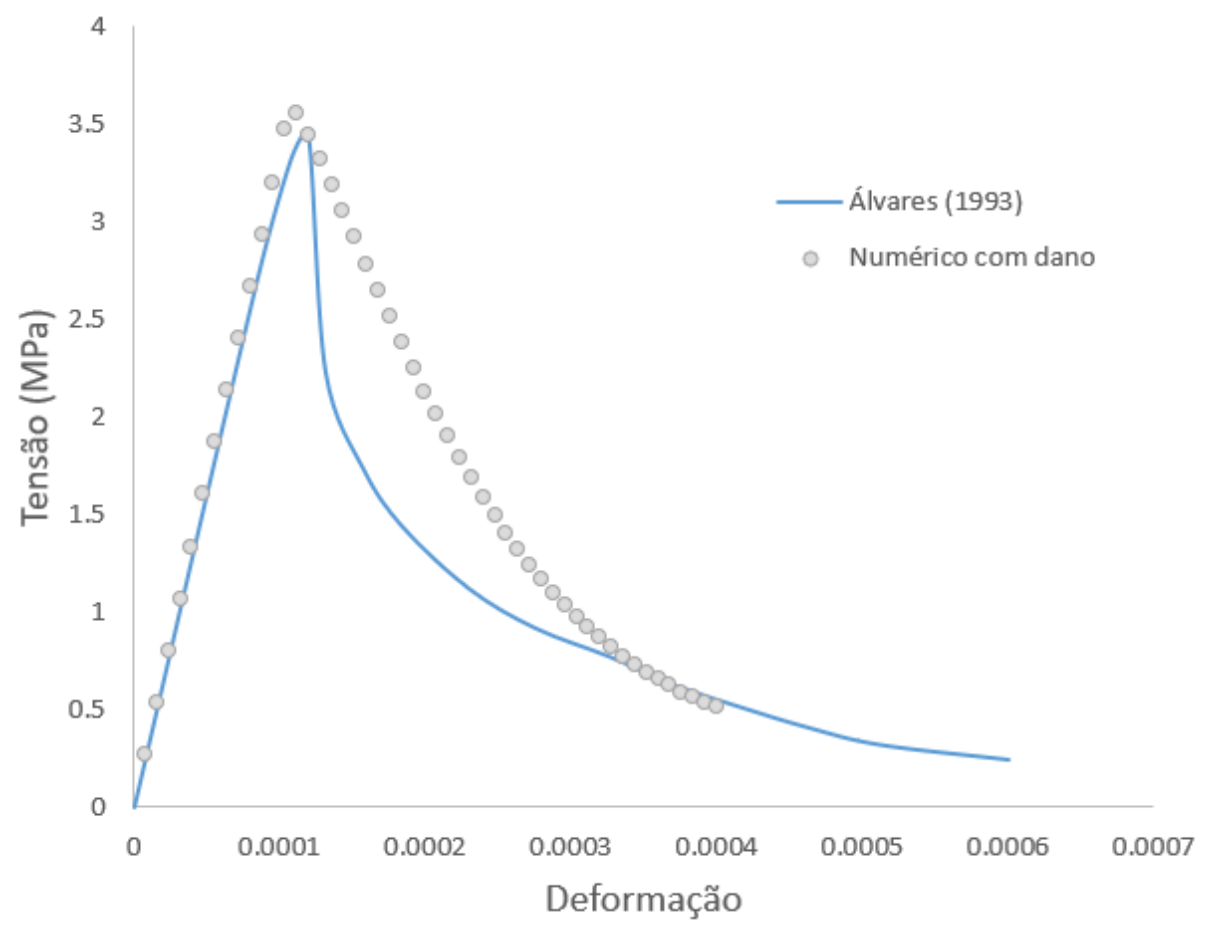

\subsubsection{Exemplo 5.2: Ensaio 4 pontos}

Este exemplo foi inspirado no ensaio de uma viga a 4 pontos apresentado em Álvares (1993). Trata-se de uma viga biapoiada com duas forças iguais e concentradas, conforme ilustra a Figura 5.5. A viga possui comprimento $L=240 \mathrm{~cm}$, com uma distância de $10 \mathrm{~cm}$ entre os apoios e as extremidades das vigas (comprimento total de $260 \mathrm{~cm}$ ). A seção transversal possui $h=30 \mathrm{~cm}$ e $b=12 \mathrm{~cm}$. As propriedades elásticas do material da matriz são: módulo de elasticidade $E=29,2 \mathrm{GPa}$; coeficiente de Poisson $v=0,2$. Para as armaduras (elementos de barra), foi utilizado o módulo de elasticidade $E=196 \mathrm{GPa}$, área de 2,355 $\mathrm{cm}^{2}$ e um cobrimento $c=3,3 \mathrm{~cm}$.

Nesse exemplo, a malha da matriz (elementos de chapa) foi gerada com aproximação linear no programa comercial Ansys 19.1 (Student), de forma que a malha utilizada fosse regular. Posteriormente, essa malha gerada foi adaptada por meio de um algoritmo para inclusão dos nós necessários para a consideração da aproximação cúbica de posições. 
Figura 5.5- Geometria e condições de contorno
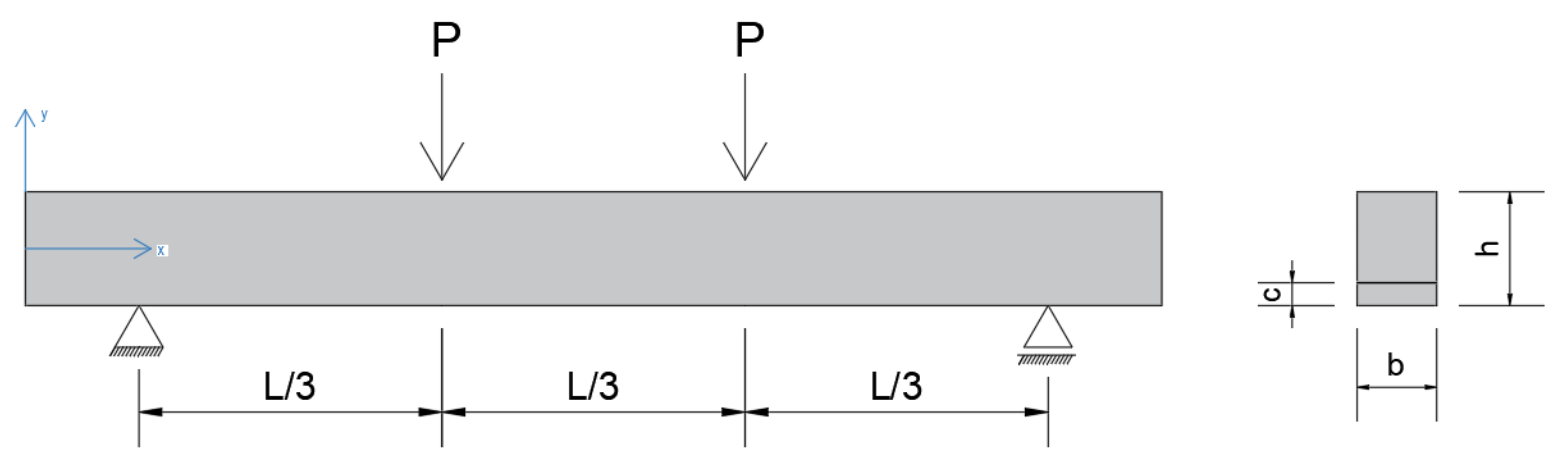

O carregamento $P=38 k N$ foi aplicado em 100 passos. Como a estrutura é simétrica, a malha utilizada possui 1248 elementos triangulares de aproximação cúbica e 5809 nós, representando um comprimento total de $130 \mathrm{~cm}$ da viga. Desta forma, foi simulada metade da estrutura. A malha dos elementos de barra utilizados para representar as armaduras de aço possui 154 nós e 153 elementos com aproximação linear. A Figura 5.6 ilustra a malha utilizada.

Figura 5.6- Malha Exemplo 5.3.

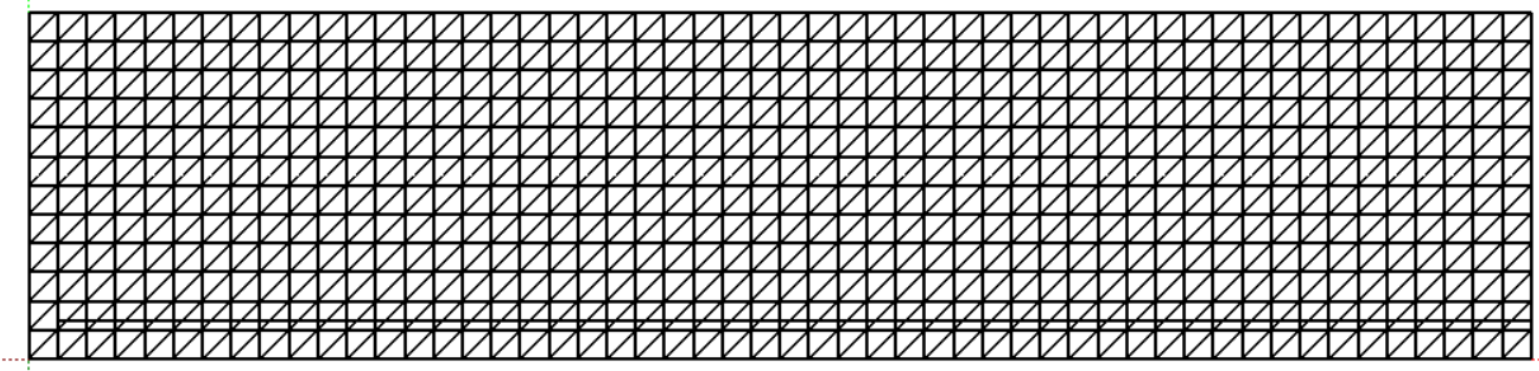

Para o modelo de dano, o material utilizado foi concreto C30 e o valor dos parâmetros do modelo de Mazars utilizados estão representados na Tabela 5.3. Os valores das constantes do modelo de dano foram adaptados de Álvares (1993) e seguiram as recomendações de Mazars (1984).

Tabela 5.3- Constantes para o modelo de dano

\begin{tabular}{|c|c|c|c|c|}
\hline $\boldsymbol{\varepsilon}_{\boldsymbol{d} \mathbf{0}}(\boldsymbol{C 3 0})$ & $\boldsymbol{A}_{\boldsymbol{t}}$ & $\boldsymbol{B}_{\boldsymbol{t}}$ & $\boldsymbol{A}_{\boldsymbol{c}}$ & $\boldsymbol{B}_{\boldsymbol{c}}$ \\
\hline $7,0 \cdot 10^{-5}$ & 0,995 & $1,0 \cdot 10^{4}$ & 1,00 & 1620 \\
\hline
\end{tabular}


A Figura 5.7 compara deslocamentos verticais no ponto central da viga obtidos por meio da simulação realizada no presente trabalho com os deslocamentos apresentados por Álvares (1993). Os resultados de Álvares (1993) representam uma nuvem de pontos experimentais.

Figura 5.7- Diagrama Força aplicada x Deslocamento vertical

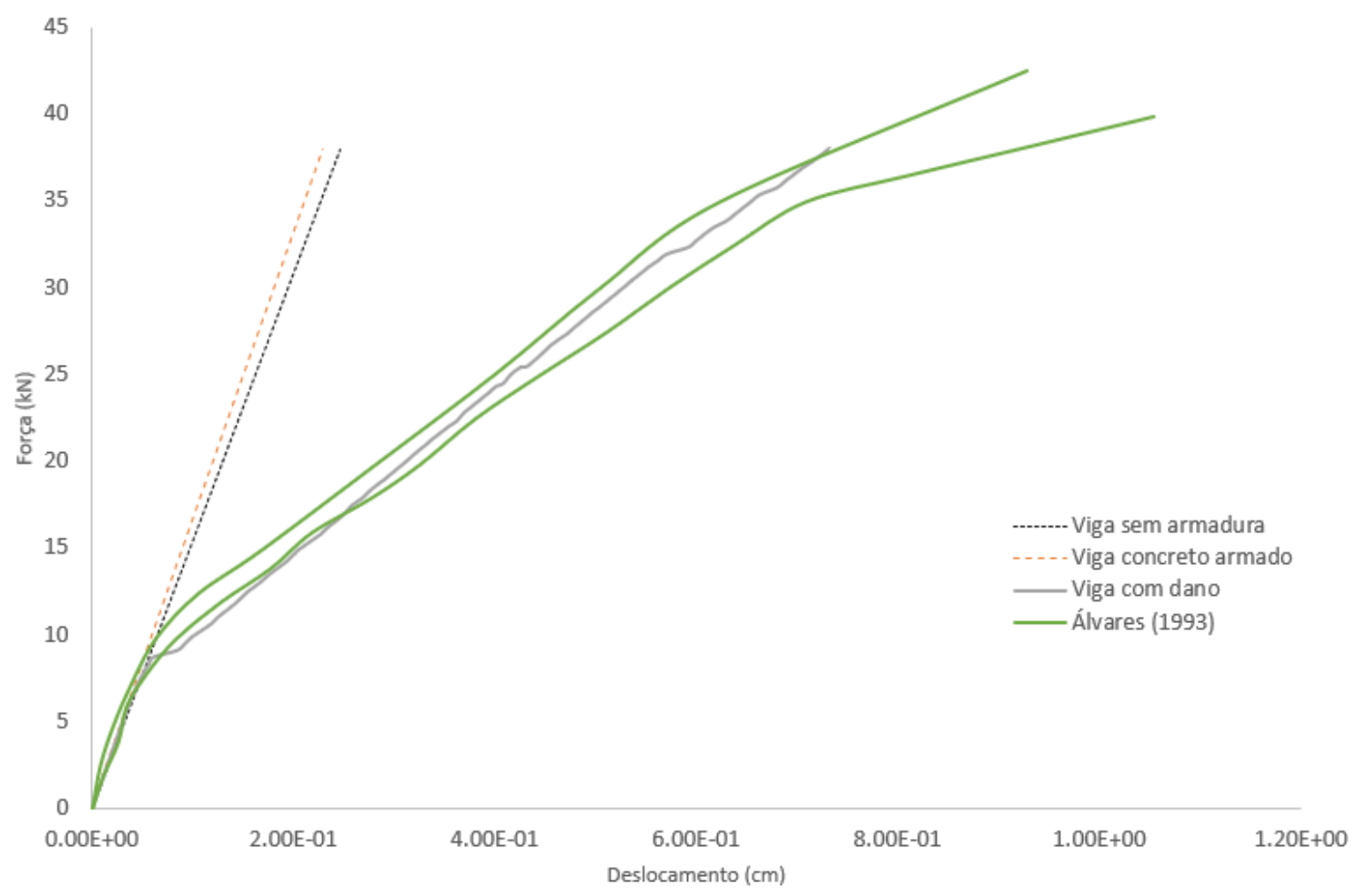

Em relação ao comportamento experimental obtido por Álvares (1993), a curva Força X Deslocamento resultante do código implementado representou, com boa aproximação, o comportamento da estrutura em questão frente ao carregamento proposto. É importante salientar que o programa não considera a possibilidade de plastificação na armadura, uma vez que não era o objetivo do trabalho, justificando a divergência dos resultados na parte final da curva.

Neste exemplo, foram obtidos resultados compatíveis com o esperado. Dessa forma, a implementação do modelo de dano de Mazars enriqueceu e complementou a presente pesquisa, sendo possível retornar, com uma boa aproximação, o comportamento não linear físico e geométrico de estruturas submetidas a grandes deslocamentos.

É interessante notar que a variável de dano do modelo deixa de ser nula a partir do passo 14, conforme ilustra a Figura 5.8. Nesse passo, a força aplicada é de 5,34 kN. O início da 
danificação com baixa carga era previsto devido a baixa resistência à tração do concreto. Aumentando o carregamento, a área danificada aumenta de maneira quase homogênea, até o passo 23, com a força de $8,74 k N$, conforme ilustra a Figura 5.9. A partir do passo 24, é possível visualizar o dano na viga com formatos semelhantes aos das fissuras (Figura 5.10).
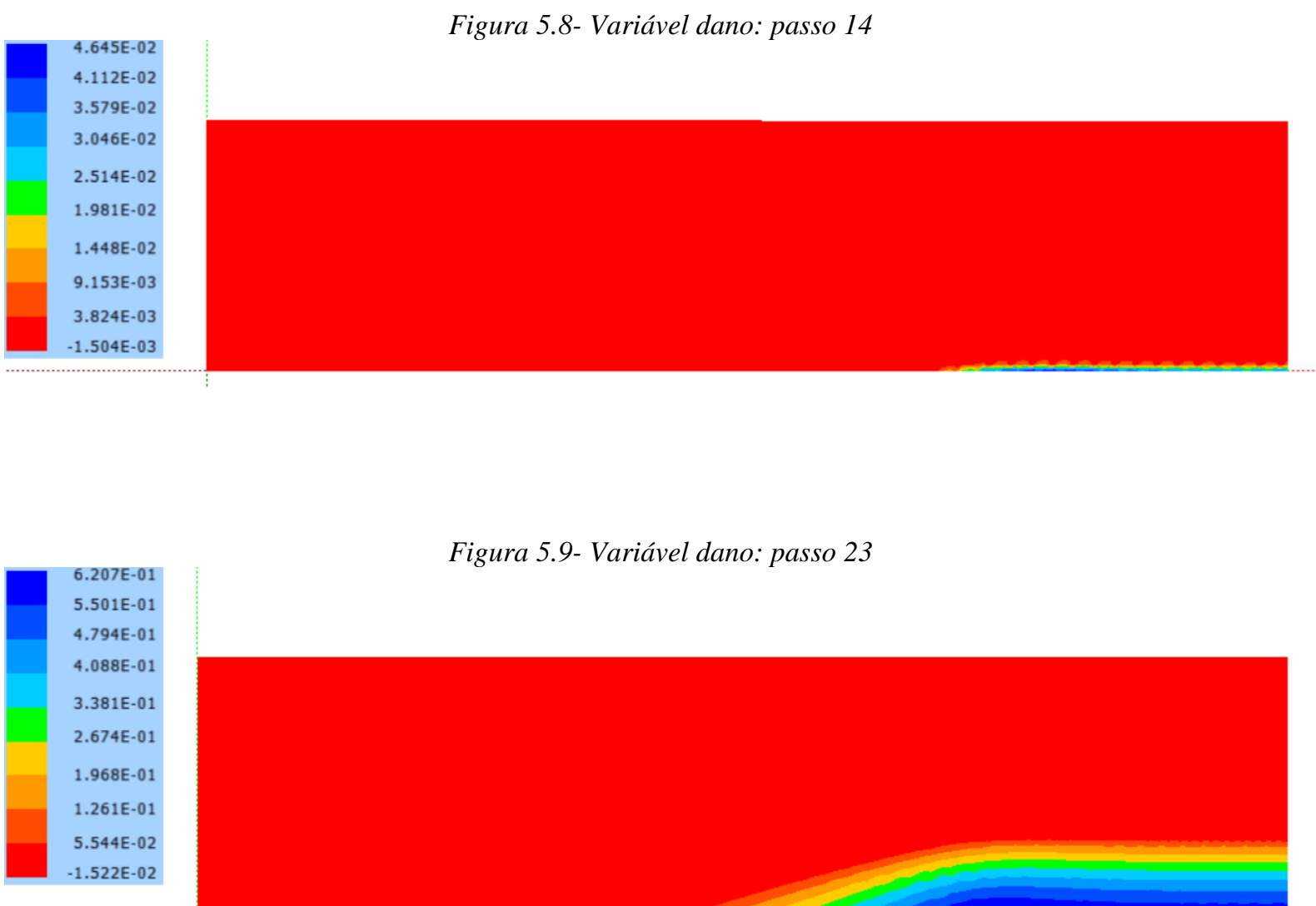

Figura 5.9- Variável dano: passo 23
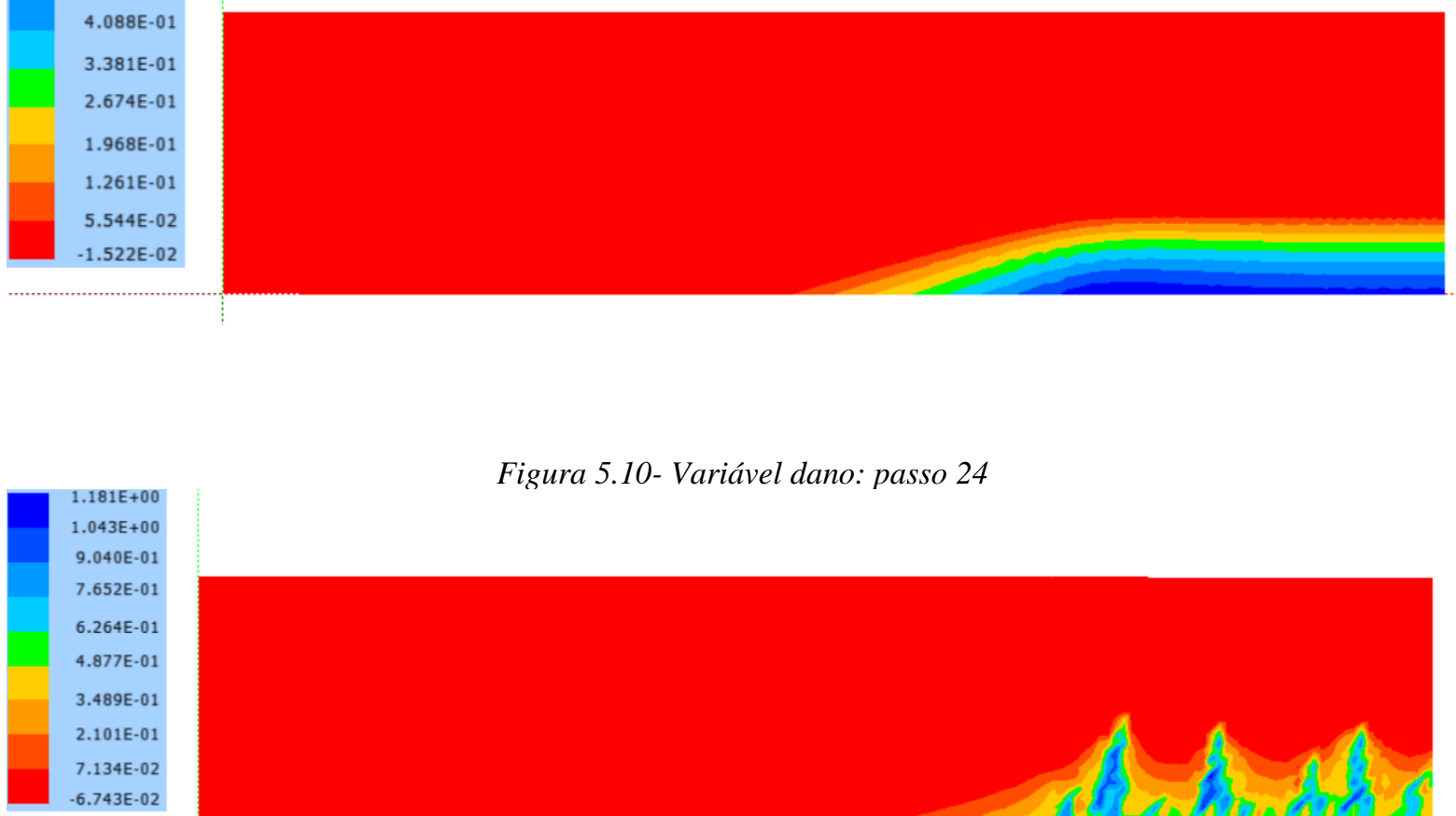

Figura 5.10- Variável dano: passo 24 
No último passo de carga, Figura 5.11, a estrutura encontra-se extremamente danificada. É interessante notar que as regiões de aplicação da força e do apoio também foram danificadas. Uma última observação relevante é o comportamento das fissuras próximas ao apoio. Nesta região, a danificação foi inclinada de, aproximadamente, $45^{\circ}$. Esse comportamento é característico de fissuras por cisalhamento e a representação obtida é compatível com o comportamento esperado em um ensaio experimental.

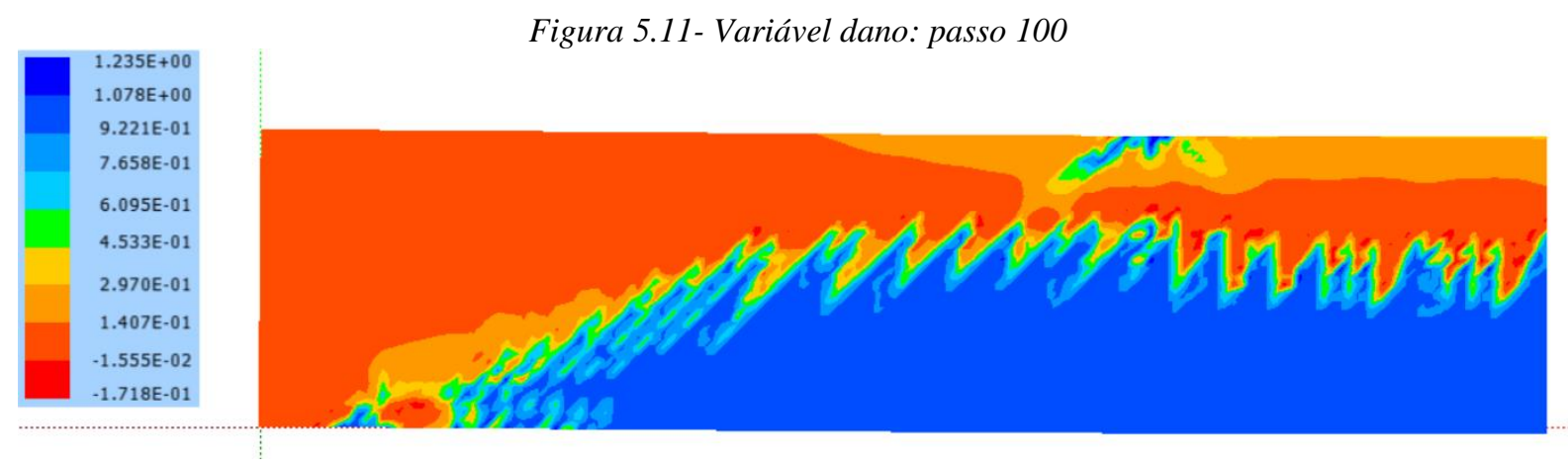

Concluindo a apresentação das aplicações, demonstrou-se que as abordagens propostas conduziram a resultados satisfatórios. Os códigos implementados para resolução de elementos de chapa acoplado com fibras e consideração de dano mostrou-se eficiente e confiável. 


\section{EXEMPLOS GERAIS DE APLICAÇÃO}

\subsection{Considerações iniciais}

Buscando explorar a potencialidade da formulação apresentada e implementada nesta pesquisa, alguns exemplos de aplicação são mostrados a seguir. Ressalta-se que não foram esgotadas todas as possibilidades de análises fornecidas pelo código desenvolvido. Entretanto, acredita-se que com os exemplos apresentados é possível verificar o funcionamento, utilização, vantagens e diferenciais da formulação obtida.

Os conceitos e formulações apresentadas nos capítulos anteriores são complementares, de forma que foram acoplados em um único programa para análise do comportamento de uma viga de concreto armado, com possibilidade da simulação de reforço e recuperação da mesma com aplicação de diferentes fases de carga. O programa desenvolvido foi aplicado para três exemplos usando a mesma estrutura, possibilitando a comparação entre as situações apresentadas. O primeiro exemplo consiste na avaliação do comportamento de uma viga reforçada. Para isso, um critério de parada foi utilizado para cessar o carregamento, macaquear a estrutura e adicionar o reforço. De maneira análoga, no segundo exemplo analisa-se a recuperação da parcela de matriz danificada da viga seguindo mesmo procedimento de macaqueamento da estrutura. Por fim, o terceiro exemplo avalia o comportamento da estrutura recuperada e reforçada, ou seja, representando as intervenções realizadas separadamente nos dois primeiros exemplos agora atuando em conjunto.

Conforme já apresentado, as discretizações adotadas foram sempre as mesmas: elementos isoparamétricos com aproximação cúbica para a discretização da matriz de concreto e elementos lineares para a representação das fibras, armaduras e partículas. Um cuidado adicional foi tomado para que os elementos de fibra e de chapa tivessem aproximadamente as mesmas dimensões.

A viga utilizada nos exemplos a seguir possui as mesmas dimensões, constantes elásticas e parâmetros de dano do Exemplo 5.3. Assim, foi possível comparar o comportamento da viga de concreto armado antes e após as considerações da aplicação de reforço e da recuperação da parcela de matriz danificada.

Para a execução do programa, são necessários quatro arquivos de entrada de dados, todos em formato de texto, contendo: 1) as considerações iniciais e constantes (estado plano, constantes do dano de Mazars, número de nós macaqueados); 2) a malha da viga (com o mesmo 
formato gerado pelo AcadMesh); 3) a malha da armadura; e 4) as informações da recuperação/reforço (constantes elásticas do material íntegro e da manta para o reforço).

\subsection{Exemplo 6.1: Viga com reforço (manta de PRFC)}

O objetivo deste exemplo é avaliar a progressão do dano do Exemplo 5.3 para estabelecer um critério de parada, como instrumento para determinar o momento da intervenção e realização de possível reforço/recuperação da estrutura, bem como avaliar o deslocamento desta estrutura após o referido reforço/recuperação. Ao avaliar os resultados do Exemplo 5.3, nota-se que a variável dano deixa de ser nula a partir do passo 14 (Figura 5.8). Uma ressalva sobre as representações visuais da variável dano deve ser mencionada: os valores em cada um dos pontos de integração (pontos de Hammer) foram extrapolados para os dez nós dos elementos. Dessa forma, justifica-se que alguns valores apresentados nas escalas contidas nas figuras podem assumir valores negativos ou acima de um, uma vez que o intervalo para os valores da variável de dano do modelo de Mazars é entre 0 e 1.

Para a avaliação do comportamento da estrutura reforçada, após o carregamento, a viga foi macaqueada para a adição do reforço com comportamento de uma manta de PRFC, colada na face inferior da viga. A seguir, a estrutura foi liberada para a análise do novo deslocamento. Como não é interessante adicionar o reforço em estruturas condenadas, julgou-se uma situação coerente para a reabilitação estrutural quando a viga possuísse pelo menos um elemento totalmente danificado.

Assim, quando todos os pontos de integração de pelo menos um elemento atingirem valor máximo para a variável dano o carregamento foi cessado para realização do macaqueamento e posterior reforço da estrutura. O critério utilizado, parada na danificação máxima nos 7 pontos de Hammer de um elemento, possui uma representação física equivalente a perda de cobrimento da armadura. Segue-se esse mesmo critério de parada para os próximos exemplos.

O ponto de imposição dos deslocamentos simulando-se o macaqueamento da estrutura foi escolhido de tal forma que não interferisse na reabilitação estrutural. Assim, optou-se por retornar o nó 30 da malha (distante 40 centímetros da extremidade da viga) para a posição inicial. O macaqueamento foi realizado em cinco passos de carga e, após o reforço, a estrutura foi liberada em um único passo para desloca-se livremente novamente. 
Seguindo o exemplo 5.3, o critério de parada seria o passo 24 , com uma força de 9,12 kN. Como uma tentativa de obter uma situação intermediária entre os passos 23 e 24, o programa foi alterado para rodar em 200 passos. Dessa forma, a Figura 6.1 apresenta o passo de carga de carregamento em que foi atingido o critério de parada, o passo 47, com uma força de 8,93 kN. A Figura 6.2 ilustra a estrutura após o macaqueamento. Para facilitar a visualização dos deslocamentos, todas as figuras estão representadas em uma escala 50 vezes maior.

Para a representação gráfica, $\triangle$ representa o ponto apoiado da viga; $\downarrow$ representa o ponto de aplicação da força; $\mathbf{x}$ representa o ponto da imposição do deslocamento simulando-se o macaqueado da estrutura e • representa o nó 93, usado para controle de deslocamento.

Figura 6.1- Variável dano: passo 47 (deslocamento aumentado 50x)

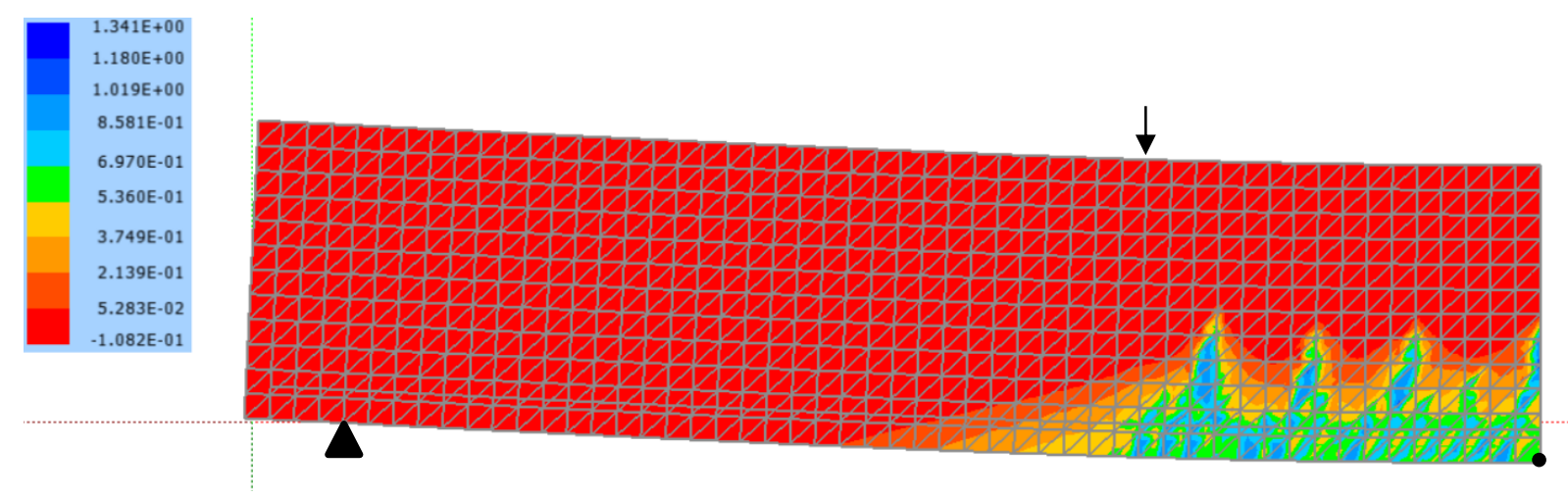

Figura 6.2- Deslocamento: passo (a) 47 (b) 52 (deslocamento aumentado 50x)

(a)

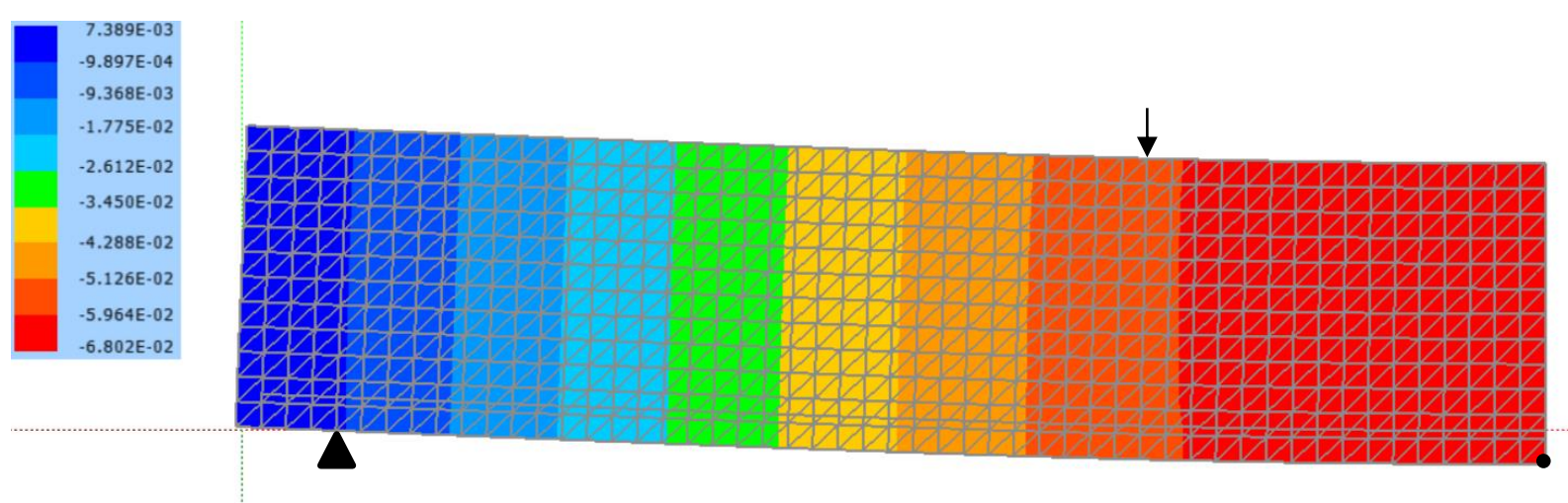


(b)
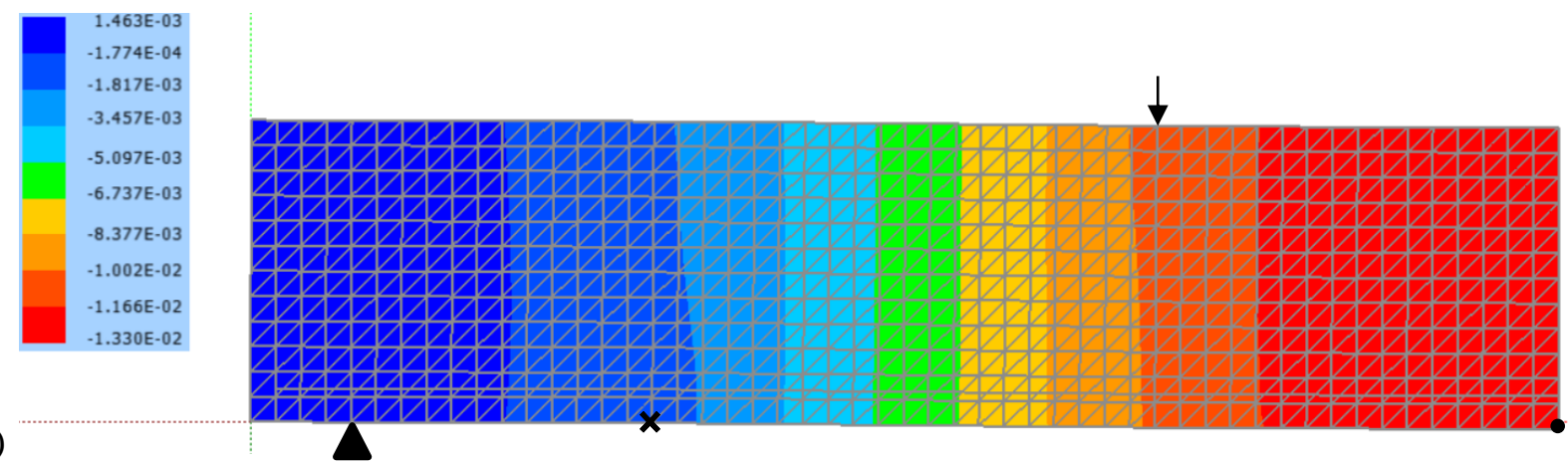

Destaca-se que durante o macaqueamento, a força máxima obtida por meio do critério de parada não foi retirada. Dessa forma, o macaqueamento deu-se no nó 30 (um nó na estrutura simétrica equivalente, ou seja, em dois pontos da estrutura completa) da viga danificada e carregada. Assim, no passo 52, a estrutura não retorna inteiramente a posição inicial, garantindo-se somente o retorno no ponto escolhido para ser macaqueado.

Partindo da Tabela 2.1, o módulo de elasticidade utilizado nos elementos representativos da a manta de PRFC foi de $220 \mathrm{GPa}$. A região a ser reforçada foi obtida por meio de uma relação com a região danificada. Admitiu-se uma reabilitação por elementos de barra em um comprimento de, aproximadamente, $40 \%$ maior do que a dimensão danificada. Portanto, a área da manta utilizada foi do comprimento a ser reabilitado multiplicado pela largura da viga, no caso, 12 centímetros.

A Figura 6.3 mostra o diagrama Força x Deslocamento referente ao exemplo, para todas as fases de carga. É importante lembrar que após o macaqueamento, a estrutura foi liberada para deslocar novamente em apenas um passo. Para o passo seguinte, foi adicionada uma força $10 \%$ maior do que a força anterior, prosseguindo o carregamento. 
Figura 6.3- Força aplicada x Deslocamento vertical nó 93 (meio do vão)

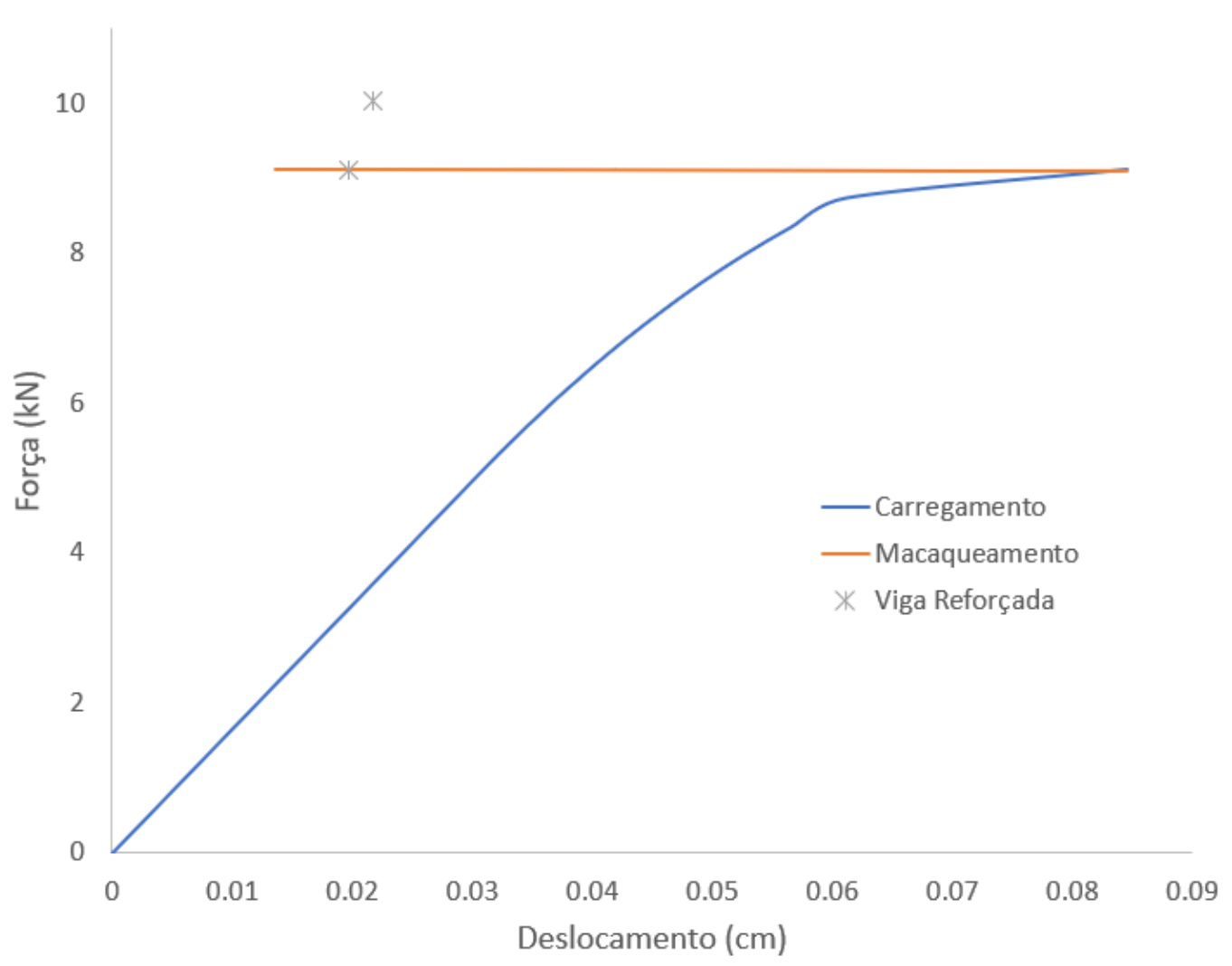

Portanto, nota-se que o deslocamento final após o reforço é menor do que o deslocamento para a mesma carga sem o reforço, conforme o esperado. Após o reforço, a estrutura não apresentou mais danificação além das resultantes da etapa de carregamento.

\subsection{Exemplo 6.2: Viga recuperada}

Neste exemplo, a viga danificada foi recuperada utilizando partículas (elementos de chapa com aproximação linear. O critério de parada estabelecido foi o mesmo do Exemplo 6.1. Inicialmente, o módulo de elasticidade adotado para o material de recuperação (partículas) foi de (a) 29,2 GPa, ou seja, o mesmo valor utilizado para o material íntegro. Depois, foi avaliado o comportamento da estrutura substituindo a região danificada por um material mais rígido, com módulo de elasticidade de (b) $33 G P a$.

Para a recuperação, todos os elementos danificados foram substituídos pelo novo material íntegro, considerando uma altura de recuperação não menor do que duas vezes a altura de um elemento finito triangular da malha. É importante citar que, após o macaqueamento, os elementos danificados foram retirados, levando-se o módulo de elasticidade dos mesmo à quase zero, e apenas após a adaptação da estrutura à essa situação, que ocorreu em 1 passo de carga, 
foi adicionada a recuperação (elementos de partícula) e a estrutura foi liberada novamente para se deslocar livremente. Assim como no exemplo anterior, a força final foi $10 \%$ maior do que a força do critério de parada.

A Figura 6.5 mostra o diagrama Força x Deslocamento para a primeira situação (a). Observa-se que os resultados obtidos após o reforço foram semelhantes ao caso elástico. Essa situação já era esperada, uma vez que todos os elementos danificados foram substituídos pelo mesmo material inicial íntegro. Ressalta-se que não foi permitido que o material de recuperação (partículas) fosse danificado, resultando-se então na resposta obtida.

A malha do material recuperado possui 8424 nós e 2808 elementos triangulares com aproximação linear (partículas). A Figura 6.4 apresenta a malha adotada com a área a ser recuperada destacada.

Figura 6.4- Ilustração da malha recuperação

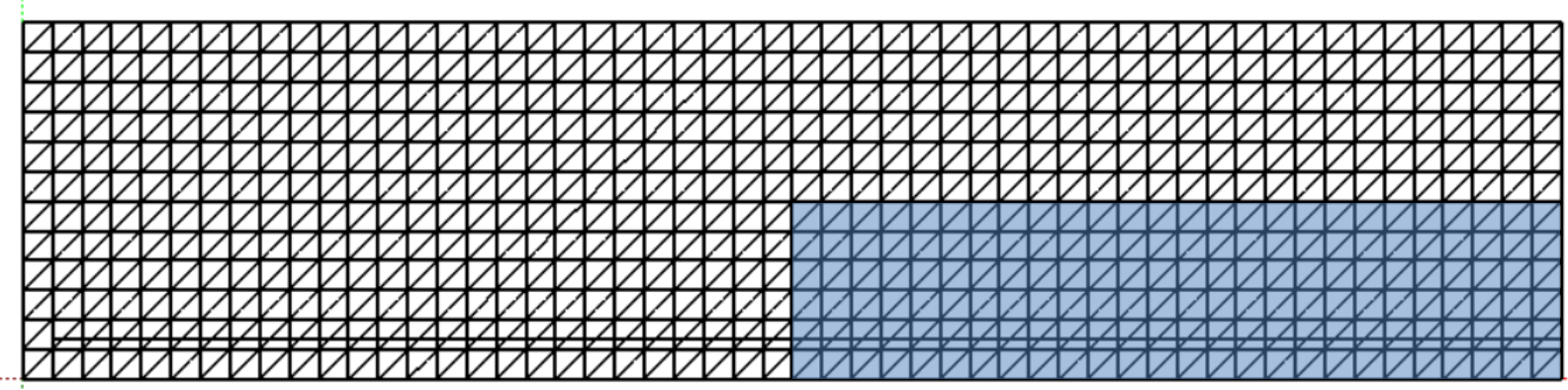


Figura 6.5- Força aplicada x Deslocamento vertical nó 93, situação (a)

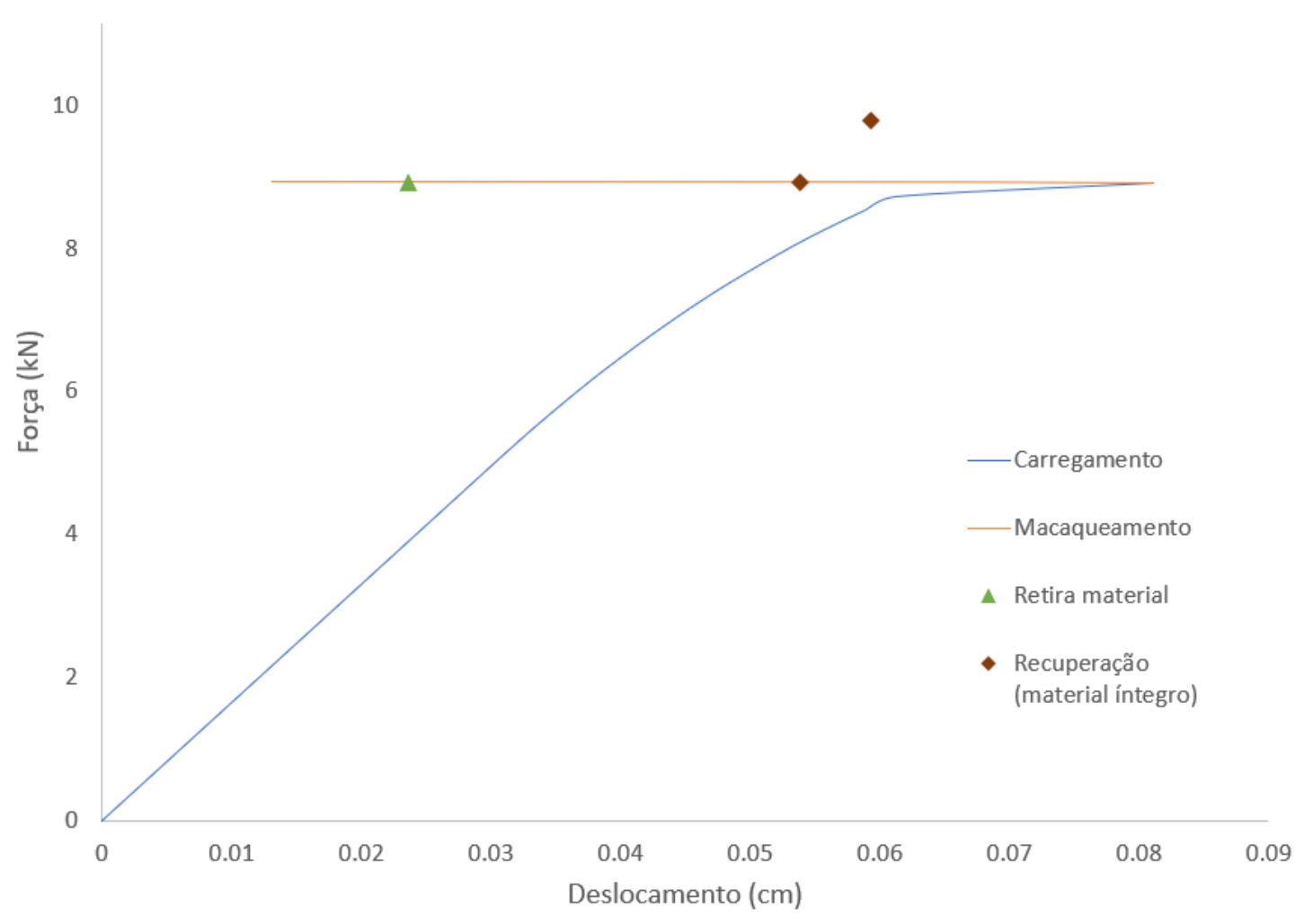

Para comparar com os exemplos anteriores, a Figura 6.6 ilustra o diagrama obtido para a consideração (b). Conforme o esperado, a viga recuperada apresentou um deslocamento inferior à situação antes da recuperação. Em relação ao deslocamento após o reforço, nota-se que a diferença entre os deslocamentos das considerações (a) e (b) foi sutil uma vez que a diferença entre os módulos de elasticidade dos materiais utilizados para o material de recuperação (partículas) não foi grande. 
Figura 6.6- Força aplicada x Deslocamento vertical nó 93, situação (b)

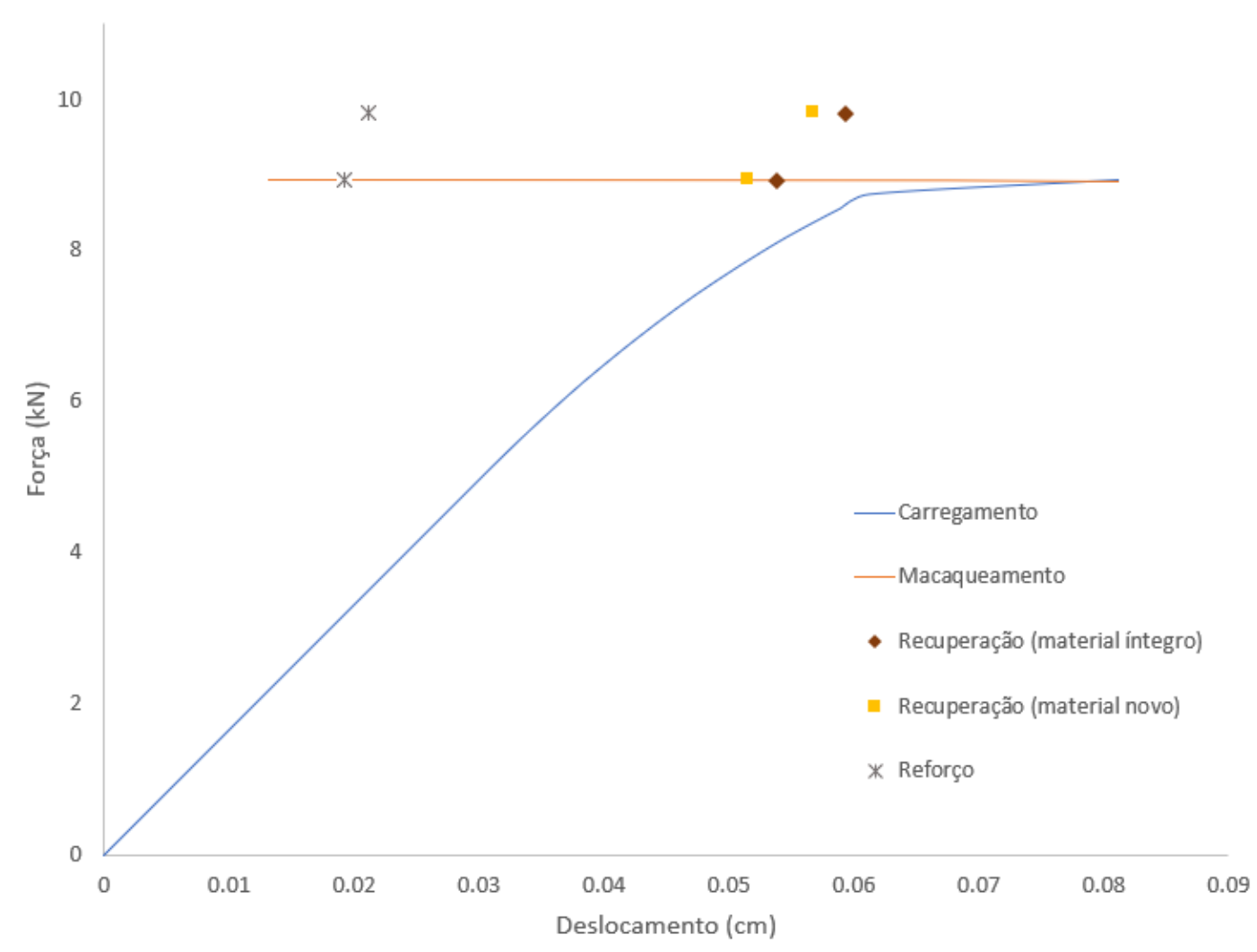

\subsection{Exemplo 6.3: Viga reabilitada (Recuperação + Reforço)}

Neste exemplo, a estrutura sofreu intervenção dos dois processos, o de recuperação e de reforço. De maneira análoga aos exemplos anteriores, o critério de parada estabelecido para, pelo menos, um elemento inteiramente danificado.

O material utilizado para o reforço foi o mesmo do Exemplo 6.1, enquanto o material da recuperação foi o mesmo do Exemplo 6.2, de 33 GPa.

A comparação de todos os exemplos apresentados encontra-se na Figura 6.7. 
Figura 6.7- Força aplicada x Deslocamento vertical nó 93

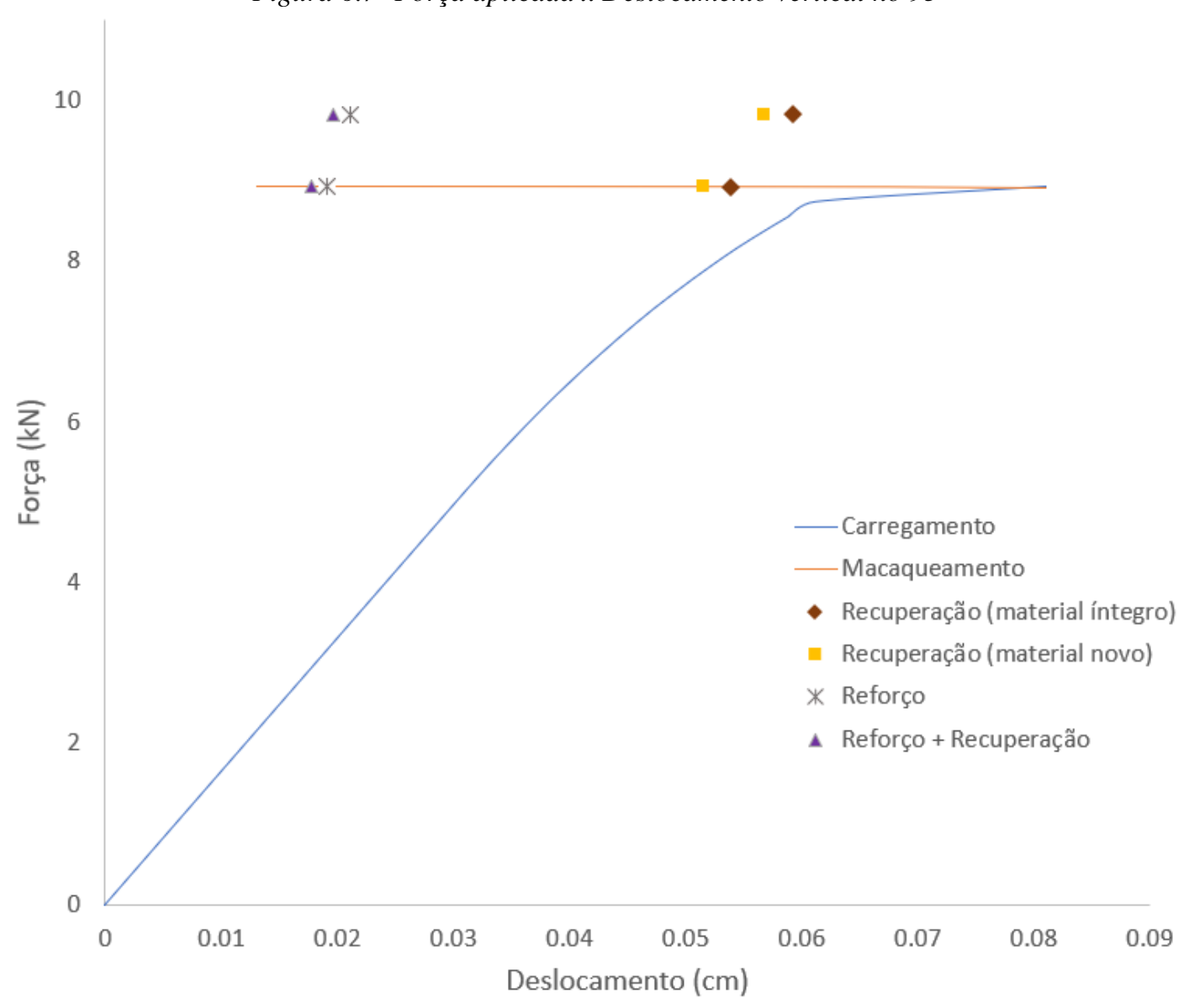

Conclui-se que o reforço simulando o comportamento de manta, no caso de PRFC, mostrou-se muito mais efetivo para o controle de deslocamentos de estruturas danificadas do que a recuperação do material estrutural. Este fato ocorre, principalmente, pelo fato de a resistência à tração do concreto ser cerca de 10 vezes menor do que a de compressão. Dessa forma, a resistência à tração em vigas é responsabilidade da armadura longitudinal, sendo, portanto, a adição de um reforço para a tração mais eficiente, que é o caso da manta.

Por fim, destaca-se que cada processo de reabilitação possui o seu propósito. Apesar da recuperação do material danificado não contribuir muito para o aumento da rigidez da estrutura, ela assegura o cobrimento das armaduras de forma a prevenir a sua corrosão por percolação de água nas fissuras ou ainda desplacamento do concreto danificado (ou delaminação do concreto de cobrimento), por exemplo. 


\section{CONSIDERAÇÕES FINAIS}

Diante do aumento na necessidade de manutenção, reforço, recuperação e reabilitação de estruturas e de aumentar a durabilidade e assegurar estabilidade e segurança das estruturas de concreto armado, torna-se essencial o estudo do comportamento do concreto. Esse tema engloba, portanto, assuntos de aplicação direta nos projetos de engenharia. Nesse panorama, a proposta inicial deste trabalho foi inspirada na ausência de padrões normativos nacionais para avaliar o comportamento de estruturas reforçadas. Esse aspecto foi abordado no primeiro capítulo desta dissertação. Na sequência, foram citados os embasamentos teóricos e necessários para o desenvolvimento da pesquisa.

O terceiro e o quarto capítulos apresentam os conceitos e formulações que permitiram o desenvolvimento do algoritmo para a resolução do problema por meio do MEFP. O quinto capítulo abrange a consideração da não linearidade física implementada. A utilização da formulação de dano de Mazars proporcionou um enriquecimento do programa obtido, uma vez que é possível a consideração desta não linearidade para a representação do comportamento global da viga fissurada. O sexto capítulo foi exclusivamente dedicado aos exemplos finais, visando demonstrar as potencialidades do programa gerado.

Para este último capítulo, retomam-se as informações e resultados apresentadas no decorrer do texto do trabalho. Assim, algumas conclusões e considerações podem ser citadas. Partindo-se do pressuposto que o principal objetivo desta pesquisa foi a análise do comportamento de estruturas reabilitadas através da implementação de um modelo numérico, bem como a representação das fases de carga de uma viga de concreto armado reforçada por meio de simulações bidimensionais obtidas pela elaboração de um código computacional não linear geométrico e físico, pode-se concluir que tais objetivos foram alcançados de forma plena. Os resultados dos exemplos gerais, que foram formulados para a verificação e a validação das etapas da formulação, inferiram a confiabilidade da implementação. Os exemplos apresentados geraram resultados dentro do esperado.

Para alcançar os objetivos propostos, foram utilizados métodos numéricos com a finalidade de estimar a resposta estrutural para representar, de forma simplificada, o comportamento de uma estrutura de concreto armado com reforço. Foram implementados códigos na linguagem FORTRAN para simular a viga de concreto armado antes e após o reforço. As análises foram não lineares geométricas, intrínseca da formulação posicional, e físicas, 
'através do modelo de dano de Mazars considerado na formulação. O código implementado foi integralmente desenvolvido na pesquisa, utilizando-se apenas a biblioteca Sparse Set externa.

Alguns dos comentários a seguir certamente já foram apresentados no decorrer do texto e estão aqui resumidos. Optou-se pela utilização de elementos finitos triangulares com aproximação cúbica para a representação da malha da chapa (matriz cimentícia). De forma geral, a aproximação adotada satisfaz as exigências para a modelagem dos problemas. Para os elementos acoplados, nas fibras (elementos de barra para representação da armadura de aço e reforço por meio de mantas) foram usados elementos lineares e nas partículas (elementos de chapa para representação da recuperação) foram adotados elementos triangulares com aproximação linear.

Não foram analisados nesse trabalho o estudo matemático e nem a verificação de uma solução analítica para a resolução do problema proposto. Desta forma, foram analisadas as respostas obtidas nos exemplos, que foram feitos por meio de simulações numéricas. Verificouse que a presente formulação, quando utilizada em problemas cujo refinamento das malhas da viga e armadura permitem uma boa representação da geometria, apresentou resultados compatíveis com os esperados.

A técnica utilizada para o acoplamento entre os diferentes elementos mostrou-se eficiente, como pode-se perceber pelos resultados apresentados. A formulação posicional desenvolvida considerou a interação entre partículas, fibras e matriz sem a necessidade de coincidência entre as malhas. Destaca-se que foi considerada aderência perfeita entre as fibras (armadura), partículas (material para a recuperação) e os elementos de chapa (concreto). Assim, a formulação proporcionou a realização do acoplamento de forma direta, fácil e sem aumentar os graus de liberdade do problema de chapa inicial.

Um comentário adicional sobre o programa implementado é que as formulações estão contidas em um único programa, ou seja, à medida que as formulações se desenvolveram, estas foram incluídas no programa geral resultado desta pesquisa. Por não se tratar de um dos objetivos estabelecidos, os desenvolvimentos relativos à implementação da malha e do código para a análise visual dos resultados, bem como a otimização de memória e tempo de processamento, não foram realizados. Destaca-se ainda que a calibração das variáveis do modelo também não foi um objetivo do trabalho.

É válido citar algumas das possibilidades de ampliação deste trabalho. Como proposta para trabalhos futuros, menciona-se a ampliação do modelo bidimensional para o 
tridimensional, bem como mudanças nos métodos de entrada de dados para que fiquem mais intuitivos e com uma interface gráfica. Pode-se também implementar o modelo de dano nas partículas, para representar a não linearidade física no material de recuperação, e nas fibras, para considerar o escoamento da armadura. É possível ainda realizar estudos para otimizar a memória e tempo de processamento do código.

Por fim, acredita-se que os objetivos propostos foram alcançados e que, mesmo com as dificuldades enfrentadas, a implementação da formulação mostrou-se confiável, satisfatória e precisa, concluindo o presente trabalho com êxito. 


\section{REFERÊNCIAS}

ÁLVARES, M. S. Estudo de um modelo de dano para o concreto: formulação, identificação paramétrica e aplicação com o emprego do método dos elementos finitos. Dissertação (Mestrado). Escola de Engenharia de São Carlos, Universidade de São Paulo, São Carlos, 1993.

ARQUEZ, A. P. Aplicação de laminado de polímero reforçado com fibras de carbono (PRFC) inserido em substrato de microconcreto com fibras de aço para reforço à flexão de vigas de concreto armado. 242 p. Dissertação (Mestrado) - Escola de Engenharia de São Carlos - Universidade de São Paulo, 2010.

ASSAN, AE. Método dos Elementos Finitos - Primeiros Passos. Campinas: Editora da Unicamp, 2003, 304 p.

ASSOCIAÇÃO BRASILEIRA DE NORMAS TÉCNICAS. NBR 6118: Projeto de estruturas de concreto - Procedimento. Rio de Janeiro, p. 256. 2014.

BATOZ, J. L.; DHATT, G. (1979). Incremental displacement algorithms for nonlinear problems. International journal for numerical methods in engineering, v.14, p.1262-1267.

BAIOCCO, M.H.; CODA, H.B.; PACCOLA, R.R. A simple way to introduce skeletal muscles by fem. In: 22nd International Congress of Mechanical Engineering - COBEM 2013, 2013, Ribeirão Preto - SP. Proceedings of COBEM 2013, 2013.

BEBER, A. J.; CAMPOS FILHO, A.; CAMPAGNOLO, J. L. (2000). Reforço de estruturas e concreto armado com tecidos pré-impregnados de fibras de carbono. Revista Téchne, São Paulo, n.45, p. 52-55, mar - abr.

BISSHOPP, K.E.; DRUCKER, D.C. (1945). On the deflection of a cantilever beam. Quarterly of applied mathematics, v.3, p.272-275.

BONET, J., WOOD, R.D. Nonlinear continuum mechanics for finite element analysis. Cambridge University Press, 1997.

BONET, J,; WOOD, R. D.; MAHANEY, J.; HEYWOOD, P. Finite element analysis of air supported membrane structures. Computer Methods in Applied Mechanics and Engineering, v. 190, n. 5-7, p. 579-595, 2000.

CARRAZEDO, R. Estudo e desenvolvimento de código computacional para análise de impacto entre estruturas levando em consideração efeitos térmicos. Tese (Doutorado). Escola de Engenharia de São Carlos, Universidade de São Paulo, São Carlos, 2009.

CASTRO, E. K. Reforço em Vigas "T" de Concreto Armado com Vários Tipos de Compósitos em Entalhes no Cobrimento de Concreto (CEC). 2005. Tese (Doutorado), Universidade de Brasília, Distrito Federal, 2005 
CLOUGH, Ray W. The finite element method in plane stress analysis. In: Proceedings of 2nd ASCE Conference on Electronic Computation, Pittsburgh Pa. 1960.

CODA, H.B. An exact FEM geometric non-linear analysis of frames based on position description. In: XVIII CONGRESSO BRASILEIRO DE ENGENHARIA MECÂNICA, São Paulo, 2003.

CODA, H.B. O método dos elementos finitos baseado em posições para a análise não linear geométrica de estruturas e sólidos. 2017. 193 p. Notas de Aula. Escola de Engenharia de São Carlos, Universidade de São Paulo, São Carlos, 2017.

CODA, H.B.; GRECO, M. A simple FEM formulation for large deflection 2D frame analysis based on position description. Computer methods in applied mechanics and engineering. Universidade de São Paulo, São Carlos, 2003.

CODA, H.B.; GRECO, M. Positional FEM formulation for flexible multi-body dynamic analysis. Journal of Sound and Vibration, 290, 1141-1174, 2006.

CODA, H. B.; PACCOLA, R. R. An alternative positional FEM formulation for geometrical non-linear analysis of shells: curved triangular isoparametric elements. Computational Mechanics, 40(1), 185-200, 2007.

CODA, H. B.; PACCOLA, R. R.. A positional FEM formulation for geometrical non-linear analysis of shells. Latin American Journal of Solids and Structures(5), 205-223, 2008.

CODA, H. B.; PACCOLA, R. R. Unsconstrained finite element for geometrical nonlinear dynamic of shells. Mathematical Problems in Engineering, Article ID 575131(2009), 32, 2009.

CODA, H. B.; PACCOLA, R. R. Improved finite element for 3D laminate frame analysis including warping for any cross-section. Applied Mathematical Modelling, 34(4), 11071137, 2010.

CODA, H. B.; PACCOLA, R. R. A FEM procedure based on positions and unsconstrained vectors applied to non-linear dynamic of 3D frames. Finite Elements in Analysis and Design, 47(4), 319-333, 2011.

CODA, H. B.; PACCOLA, R. R.; SAMPAIO, M. S. M. Positional description applied to the solution of geometrically non-linear plates and shells. Finite Elements in Analysis and Design, 67, 66-75, 2013

CODA, H. B.; PACCOLA, R. R. A total-Lagrangian position-based FEM applied to physical and geometrical nonlinear dynamics of plane frames including semi-rigid connections and progressive collapse. Finite Elements in Analysis and Design, v. 91, p. 1-15, 2014.

COOK, R. D.; MALKUS, D. S.; PLESHA, M. . Concepts and Applications of Finite Element Analysis. Wiley, 2002. 
COURANT, R. Variational Methods for the Solution of Problems of Equilibrium and Vibrations. Bulletin of the American Mathematical Society, v. 49, n. 1, p. 1-24, 1943. American Mathematical Society.

CRISFIELD, M. A. A fast incremental-iterative solution procedure that handles snap-through. Computer \& structures, v.13, p.55-620. 1981.

CRISFIELD, M. Non-linear Finite Element Analysis of Solids and Structures. Volume 1: Essentials. John Wiley \& Sons, 1991.

CRISFIELD, M. A. Non-linear Finite Element Analysis of Solids and Structures, Vol. 1. Chichester, England: John Wiley \& Sons Ltd., 2000. ISBN 0471929565 (v. 1).

FARAGE, M.C.R., BEAUCOUR, A.L., BARRA, L.P.S., KE,Y., SANÁBIO, D.F.S., FERREIRA, A.P.G. Multiscale modeling of the elastic moduli of lightweight aggregate concretes: numerical estimation and experimental validation. REM: Revista Escola de Minas, Ouro Preto, v. 62, n. 4, p. 455-462, 2009.

FÉDERATION INTERNATIONALE DU BETÓN (2010). FIB Model Code 2010 - final draft, vol. 1, Bulletin 65, and vol. 2, Bulletin 66, Lausanne, Switzerland.

FERNANDES, V. A. Análise elastoplástica bidimensional de meios reforçados com fibras. São Carlos, SP. Dissertação (Mestrado). Departamento de Engenharia de Estruturas, Escola de Engenharia de São Carlos, Universidade de São Paulo: São Carlos. 2016

FERRARI, V. J. Reforço à flexão de vigas de concreto armado com manta de polímero reforçado com fibras de carbono (PRFC) aderido ao subestrato de transição constituído por compósito cimentício de alto desempenho. [s.l.] Escola de Enegnharia de São Carlos Universidade de São Paulo, 2007.

FONSECA, T. C. C. S. Reforço e incremento da rigidez à flexão de ligações viga-pilar de struturas de concreto pré-moldado com polímero reforçado com fibra de carbono (PRFC). [s.l.] Escola de Engenharia de São Carlos - Universidade de São Paulo, 2007.

FUJII, F.; CHOONG, K.K; GONG, S.X. (1992). Variable displacement control to overcome turning points of nonlinear elastic frames. Computer \& Structures, v.44, p.133-136

GADALA, M.S.; DOKAINISH, M.A.; ORAVAS, G. A. (1984). Formulation methods of geometric and material nonlinearity problems. International journal for numerical methods in engineering, v.20, p.887-914.

GRIBNIAK, V.; TAMULÉNAS, V.; NG, P.L.; ARNAUTOV, A.K.; GUDONIS, E.; MISIUNAITE, I. Mechanical Behavior of Steel Fiber-Reinforced Concrete Beams Bonded with External Carbon Fiber Sheets. Materials. 10. Paper ID: 666, 1-18, 2017.

HAISLER, W. E.; STRICKLIN, J. A. Displacement incrementation in nonlinear structure analysis by the self-correcting method. International journal for numerical methods in engineering, v.11, p.3-10, 1977. 
HOLZAPFEL, G. A. Nonlinear solid mechanics a continuum approach for engineering. Chichester: John Wiley \& Sons Ltd., 2000.

JUVANDES, L.F.P.; MARQUES, A.T.; FIGUEIRAS, J.A. Materiais compósitos no reforço de estruturas de betão. Porto, Faculdade de Engenharia da Universidade do Porto. 112p. Relatório Técnico, 1996.

KACHANOV, L.M. On the Time to Failure under Creep Conditions, Izv. Akad. Nauk. SSR, Otd. Tekhn. n.8, 26-31, 1958.

KANG, J.Y.; PARL, Y.H.; PARK, J.S.; YOU, Y.J.; JUNG, W.T. Analytical Evaluation of RC Beams Strengthened with Near Surface Mounted CFRP Laminates. In: 7th international symposium - Fiber-reinforced polymer reinforcement for concrete structures (FRPRCS - 7), p.779-794, Kansas City, 2005. Proceedings.

KIRSCH, G. Die theorie der elastizität und die bedürfnisse der festigkeitslehre. Springer, 1898

LEAL, U. Curativo para concreto. Revista Téchne, São Paulo, n.45, p. 52-55, mar - abr, 2000.

LEMAITRE, J.; CHABOCHE, J.C. Mechanique des materiaux solides. Paris, Dunod-Bordas, 1985.

LEMOS DE FARIA, M.; RIBEIRO, C.F. Recuperação e reabilitação estrutural do viaduto Santo Amaro. Concreto \& Construções, IBRACON, n.82, p. 40-48, abr-jun. 2016.

LEONEL, E.D. Notas de aula para a disciplina Introdução à Mecânica da Fratura. 293 p. Notas de Aula. Escola de Engenharia de São Carlos, Universidade de São Paulo, São Carlos, 2018.

LI, S.; LIU, W.K. Meshfree and particle methods and their applications. Applied Mechanics Reviews- ASME DC, v. 55, n. 1, p. 1-34, 2002.

LUENBERG, D. Linear and nonlinear programming. Addison-Wesley Publishing Company, 1989.

MACHADO, A.P.; MACHADO, B.A. Reforços de estruturas de concreto armado: um resumo das alternativas disponíveis. Concreto \& Construções, IBRACON, n.82, p. 23-30, abr-jun. 2016.

MARQUES, G. Estudo e desenvolvimento de código computacional baseado no MEF para análise dinâmica não linear geométrica de sólidos bidimensionais. Dissertação (Mestrado). Escola de Engenharia de São Carlos, Universidade de São Paulo, São Carlos, 2006.

MATTIASSON, K. Numerical results from large deflection beam and frame problems analysed by means of elliptic integrals. International journal for numerical methods in engineering, v.17, p.145-153, 1981.

Manual de reabilitação de estruturas de concreto: reparo, reforço e proteção. Red Rehabilitar, editores. São Paulo, 2003. 
MAZARS, J. Application de la mechanique de l'endommagement au comportement non lineaire et à la rupture du béton de structure. Paris, Thèse de Doctorat d'État, Université Paris 6, 1984.

MESQUITA; A. D. Novas metodologias e formulações para o tratamento de problemas inelásticos com acoplamento MEC/MEF progressivo. São Carlos, SP. Tese (Doutorado). Departamento de Engenharia de Estruturas, Escola de Engenharia de São Carlos, Universidade de São Paulo: São Carlos. 2002

MONDKAR, D.P.; POWELL, G.H. Finite element analysis of non-linear static and dynamic response. International journal for numerical methods in engineering, v.11, p.499-520, 1977.

MOURA; C. A. Aplicação de formulação baseada no Método dos Elementos Finitos Posicional na análise bidimensional elástica de compósitos particulados. São Carlos, SP. Dissertação (Mestrado). Departamento de Engenharia de Estruturas, Escola de Engenharia de São Carlos, Universidade de São Paulo: São Carlos. 2015

PACCOLA, R. R.; CODA, H. B. AcadView. Escola de Engenharia de São Carlos, Universidade de São Paulo, São Carlos, 2005. (Disponível em: http://www.set.eesc.usp.br/portal/pt/softwares)

PASCON, J. P. Modelos constitutivos para materiais hiperelásticos: estudo e implementação computacional. Dissertação (Mestrado). Departamento de Engenharia de Estruturas, Escola de Engenharia de São Carlos, Universidade de São Paulo, São Carlos, 2008.

PEREIRA, D. P. Análise não linear geométrica de sólidos elásticos tridimensionais reforçados com fibras através do método dos elementos finitos. Dissertação (Mestrado). Escola de Engenharia de São Carlos, Universidade de São Paulo, São Carlos, 2015.

PIEDADE NETO, D. Sobre estratégias de resolução numérica de problemas de contato. Dissertação (Mestrado). Escola de Engenharia de São Carlos, Universidade de São Paulo, São Carlos, 2009.

PIEDADE NETO, D.; FAGÁ JÚNIOR, R.; PACCOLA, R. R. AcadMesh. Escola de Engenharia de São Carlos, Universidade de São Paulo, São Carlos, 2012. (Disponível em: http://www.set.eesc.usp.br/portal/pt/softwares)

PIEDADE NETO, D.; R, R. PACCOLA, R. R. Sparse Set. Escola de Engenharia de São Carlos, Universidade de São Paulo, São Carlos, 2010. (Disponível em: http://www.set.eesc.usp.br/portal/pt/softwares)

PITUBA, J. J. C.; LACERDA, M. M. S. Simplified damage models applied in the numerical analysis of reinforced concrete structures. Revista IBRACON de Estruturas e Materiais, v. 5, n. 1, p. 26-37, 2012.

REIS, A. P. A. Reforço de vigas de concreto armado submetidas a pré-carregamento e ações de longa duração com aplicação de concretos de alta resistência e concretos com fibras de aço. São Carlos, SP. Tese (Doutorado) - Universidade de São Paulo, 2003 
REIS, M. C. J.; CODA, H. B. Physical and geometrical non-linear analysis of plane frames considering elastoplastic semi-rigid connections by the positional FEM. Latin American Journal of Solids and Structures, v. 11, n. 7, p. 1163-1189, 2014.

RIGOBELLO, R. Desenvolvimento e aplicação de código computacional para análise de estruturas de aço aporticadas em situação de incêndio. (Tese de Doutorado). Escola de Engenharia de São Carlos, Universidade de São Paulo: São Carlos. 2011. p. 296.

RIKS, E. The application of Newton's methods to the problem of elastic stability. Journal of applied mechanics, v.39, p.1060-1066, 1972.

RIKS, E. Incremental approach to the solution of snapping and buckling problems. International journal of solids and structures, v.15, p.529-551, 1979.

SAMARTIN, A. Numerical methods in nonlinear analysis of shell structures. Journal of the International Association for Shell and Spatial Structures, 34, 81-102, 1993.

SAMPAIO, M.S.M. Análise não linear geométrica de cascas laminadas reforçadas com fibras. Tese (Doutorado em engenharia de Estruturas) - Escola de Engenharia de São Carlos, Universidade de São Paulo, São Carlos, 2014. P. 190.

SAMPAIO, M.S.M.; CODA, H.B.; PACCOLA, R.R. Análise não linear geométrica de sólidos elásticos bidimensionais reforçados com fibras via MEF. Cadernos de Engenharia de Estruturas, v. 13, n. 59, p. 59-62, 2011. Edição Especial ENDOSET 2011. ISSN: 1809-5860.

SAMPAIO, M. do S. M.; PACCOLA, R. R.; CODA, H. B. Fully adherent fiber-matrix FEM formulation for geometrically nonlinear $2 \mathrm{~d}$ solid analysis. Finite Elements in Analysis and Design, v. 66, n. 0, p. $12-25,2013$.

SANCHEZ, J. A. G. Uma formulação em elementos finitos para a análise dinâmica e estática não linear de risers incluindo o contato com o leito do mar. Tese (Doutorado). Departamento de Engenharia de Estruturas, Escola de Engenharia de São Carlos, Universidade de São Paulo, São Carlos, 2013.

SANCHES JUNIOR, F.; VENTURINI, W. S. Damage modelling of reinforced concrete beams. Advances in Engineering Software, v. 38, n. 8, p. 538-546, 2007.

SCHULZ, M.; FILIPPOU, F.C. Non-linear spatial Timoshenko beam element with curvature interpolation. International journal for numerical methods in engineering, v.50, p.761-785, 2001.

SORIANO, H.L. Método dos elementos finitos em análise de estruturas. São Paulo: EDUSP, 2003.

SOUZA NETO, E. A.; FENG, Y. T. On the determination of the path direction for arc-length methods in the presence of bifurcations and 'snap-backs'. Computer methods in applied mechanics and engineering. v.179, p.81-89, 1999.

SOUZA, V.; RIPPER, T. Patologia, Recuperação e Reforço de Estruturas de Concreto. - São Paulo: Pini, 1998. 
SURANA, K.S. Geometrically non-linear formulation for 2 dimensional curved beam elements. Computer \& structures, v.17, p.105-114, 1983.

TOULEMONDE, C.; MASSON, R.; GHARIB, J.E. Modeling the effective elastic behavior of composites: a mixed finite element and homogenisation approach. C. R. Mecanique, v. 336, p. 275-282, 2008.

TRESCA, H. Sur l'ecoulement des corps solides soumis à des fortes pressions. Compt. Rend., 59, 754, 1864.

TURNER, M. J.; DILLM E. H.; MARTIN, H. C.; MELOSH, R. J. Large deflection of structures subject to heating and external load. J. Aero. Sci., v. 27, p 97-106, 1960.

VANALLI, L. O MEC e o MEF aplicados à análise de problemas viscoplásticos em meios anisotrópicos e compostos. Tese (Doutorado) - Escola de Engenharia de São Carlos, Universidade de São Paulo. São Carlos. 2004.

VANALLI, L.; PACCOLA, R. R.; CODA, H. B. A simple way to introduce fibers into FEM models. Commun. Numer. Methods Eng., 24, 585-603, 2008.

WANG, Z.M.; KWAN, A.K.H.; CHAN, H.C. Mesoscopic study of concrete II: nonlinear finite element analysis. Computers \& Structures, v.70, n.5, p. 545-556, 1999.

WONG M.B.; TINLOI F. Geometrically nonlinear analysis of elastic framed structures. Computers \& structures, v.34, p.633-640, 1990.

YANG, Y. B.; McGUIRE, W. A work control method for geometrically nonlinear analysis. In NUMETA 85 - 1985 International conference on numerical methods in engineering: Theory and applications. Edited by J. Middleton \& G. N. Pande, University College Swansea, Wales, UK, p.913-921, 1985.

YANG, Y. B.; SHIEH, M. S. Solution Method for nonlinear problems with multiple critical points. AIAA Journal, v.28, p.2110-2116, 1990.

YASIN, M.; KAPURIA, S. An efficient layerwise finite element for shallow composite and sandwich shells. Composite Structures, 98, 202-214, 2013.

ZIENKIEWICZ, O.C.; KELLY, D.W.; BETTES, P. The coupling of the finite element method and boundary solution procedures. Int. J. Num. Meth. Engng. v.11, 355-375. 1977.

ZIENKIEWICZ, O.C.; TAYLOR, R.L.; ZHU, J.Z. The finite element method: its basis \& fundamentals. Ed. Butterworth-Heinemann, Massachusetts, 2013.

ZIENKIEWICZ, O. C.; VALLIAPPAN, S.; KING, I. P. Elasto-plastic solution of engineering problems; initial stress, finite element approach. Int. J. Num. Methods Engrg., v. 1, p. 75-100, 1969. 
112 | Referências 


\section{APÊNDICE A - PONTOS E PESOS DE HAMMER}

Para sete pontos de integração, a Tabela A mostra os adimensionais dos pontos de Hammer com os seus respectivos pesos.

Tabela A - Pontos e pesos de Hammer

\begin{tabular}{ccccc} 
ih & $\xi_{1}$ & $\xi_{2}$ & $\xi_{3}$ & wih \\
\hline \hline 1 & $1 / 3$ & $1 / 3$ & $1 / 3$ & 0.1125 \\
\hline 2 & 0.797426985 & 0.101286507 & 0.101286507 & $0.125939180544827 / 2$ \\
\hline 3 & 0.101286507 & 0.797426985 & 0.101286507 & $0.125939180544827 / 2$ \\
\hline 4 & 0.101286507 & 0.101286507 & 0.797426985 & $0.125939180544827 / 2$ \\
\hline 5 & 0.470142064 & 0.470142064 & 0.059715872 & $0.132394152788506 / 2$ \\
\hline 6 & 0.059715872 & 0.470142064 & 0.470142064 & $0.132394152788506 / 2$ \\
\hline 7 & 0.470142064 & 0.059715872 & 0.470142064 & $0.132394152788506 / 2$ \\
\hline
\end{tabular}

